\title{
Phylogenomics of monitor lizards and the role of competition in dictating body size disparity
}

5

Ian G. Brennan ${ }^{1}$, Alan R. Lemmon ${ }^{2}$, Emily Moriarty Lemmon ${ }^{2}$, Daniel M. Portik ${ }^{3}$, Valter Weijola ${ }^{4}$, Luke Welton ${ }^{5}$, Stephen C. Donnellan ${ }^{6,7}$, J.Scott Keogh ${ }^{1}$

10

${ }^{1}$ Division of Ecology $\&$ Evolution, Research School of Biology, Australian National University, Canberra, ACT 2601 Australia

${ }^{2}$ Department of Biological Science, Florida State University, Tallahassee, FL 32306, USA

15

${ }^{3}$ Department of Ecology and Evolution, University of Arizona, Biosciences West Rm 310, 1041 E. Lowell St, Tucson, AZ 85745 USA

${ }^{4}$ Zoological Museum, Biodiversity Unit, FI-20014 University of Turku, Finland

${ }^{5}$ Univeristy of Kansas Biodiversity Institute $\&$ Natural History Museum, 1345 Jayhawk Blvd, Lawrence, KS 66045 USA

${ }^{6}$ School of Biological Sciences, The University of Adelaide, Adelaide, SA 5005, Australia

${ }^{7}$ South Australian Museum, North Terrace, Adelaide SA 5000 Australia 


\section{Abstract}

Organismal interactions drive the accumulation of diversity by influencing species ranges, morphology, and behavior. Interactions vary from agonistic to cooperative and should result in predictable patterns in trait and range evolution. However, despite a conceptual understanding of these processes, they have been difficult to model, particularly on macroevolutionary timescales and across broad geographic spaces. Here we investigate the influence of biotic interactions on trait evolution and community assembly in monitor lizards (Varanus). Monitors are an iconic radiation with a cosmopolitan distribution and the greatest size disparity of any living terrestrial vertebrate genus. Between the colossal Komodo dragon Varanus komodoensis and the smallest Australian dwarf goannas, Varanus length and mass vary by multiple orders of magnitude. To test the hypothesis that size variation in this genus was driven by character displacement, we extended existing phylogenetic comparative methods which consider lineage interactions to account for dynamic biogeographic history and apply these methods to Australian monitors and marsupial predators. We use a phylogenomic approach to estimate the relationships among living and extinct varaniform lizards, incorporating both exon-capture molecular and morphological datasets. Our results suggest that communities of Australian Varanus show high functional diversity as a result of continent-wide interspecific competition among monitors but not with faunivorous marsupials. We demonstrate that patterns of trait evolution resulting from character displacement on continental scales are recoverable from comparative data and highlight that these macroevolutionary patterns may develop in parallel across widely distributed sympatric groups.

Keywords: comparative methods, phylogenetics, Varanus, trait evolution, character displacement. 


\section{${ }_{45}$ Introduction}

Organismal interactions provide an important selective force for evolution (Darwin 1859). On macroevolutionary time scales, interspecific interactions help drive the accumulation and distribution of diversity (Benton 1987). Common antagonistic interactions (e.g. competition) are suggested to facilitate the assembly of communities by encouraging ecological, behavioral, and morphological differentiation through character displacement (Brown and Wilson 1956; Sepkoski Jr 1996). This process has been repeatedly identified in insular adaptive radiations like Darwin's finches, Caribbean anoles, and Lake Victoria cichlids, where young clades have rapidly diverged into many available phenotypes, ecologies, and/or behavioral syndromes (Schluter et al. 1985; Losos 1990; Grant and Grant 2006). While insular systems are instructive, they account for only a fraction of earth's biodiversity, and it has been much more difficult to quantify the influence of competition at continental scales (Drury et al. 2018b). We therefore know little about how competition among organisms may influence the evolution of traits and distribution of most of life on earth.

The most obvious axis for differentiation between organisms is absolute size (Peters and Peters 1986). In animals, body size is often used as a proxy for guild, and because it dramatically affects life-history traits and ecology, it is the most commonly used measurement in macroevolutionary studies (Wilson 1975). Among terrestrial vertebrates, monitor lizards Varanus exhibit the greatest variation in body size within a single genus (Pianka 1995). Extant monitors include island giants like the Komodo dragon $V$. komodoensis (up to $3 \mathrm{~m}$ long and $100 \mathrm{~kg}$ ), and desert dwarves like the short-tailed goanna $V$. brevicauda $(0.2 \mathrm{~m}$ and $0.016 \mathrm{~kg})$, which vary by orders of magnitude. In fact, while size estimates vary, the recently extinct Australian monitor Varanus (Megalania) priscus may have dwarfed even the Komodo dragon, reaching lengths of over four meters (Wroe 2002; Conrad et al. 2012). Despite a conservative body plan, monitor lizards are ecologically diverse and can be found at home in trees, among rocks, in burrows, and swimming through watercourses and even the open ocean (Pianka 1995). Though there are roughly 80 described monitors, the greatest morphological diversity is concentrated in the 30 or so Australian species (Uetz and Hošek 2019). All Australian monitors are hypothesized to constitute a single radiation that likely dispersed from Sundaland into Sahul (Australopapua), though the timing and biogeographic history of this group remains uncertain (Vidal et al. 2012). Such incredible diversity in body size begs the question, what has driven it?

75 Over the years, researchers have suggested that this disparity is the result of habitat partitioning (Collar et al. 2011), or release from competition with carnivoran mammals (Pianka 1995; Sweet and Pianka 2007). However, no one has yet investigated whether variation in monitor body sizes is instead the result of character displacement through competition, either with other Varanus or other large carnivores with which they may vie for resources. This is likely due to the fact that probabilistic trait evolutionary models largely remain ignorant of such interactions even though they are ubiquitous (Harmon et al. 2019). Only recently have methods for modelling continuous traits attempted to take into account the influence of lineages on one another (Drury et al. 2016; Manceau et al. 2017; Adams and Nason 2018; Quintero and Landis 2019).

In Australia, monitor lizards are not the only radiation of terrestrial vertebrate predators. A similarly diverse co-distributed group are the carnivorous and omnivorous marsupial mammals. Dasyuromorphians and peramelemorphians cover a similar breadth in range and body size, inhabiting deserts and closed forests, ranging from the tiny Ningaui up to the recently extinct canine-convergent Thylacine. Outside of Australia, there is evidence to suggest varanid lizards may compete either directly (through predation) or indirectly (vying for resources) with small-to-moderate sized carnivorans, and this may explain the lack of small monitors west of Wallace's Line (Sweet and Pianka 2007). This presents the question of whether or not Australian monitors and their marsupial neighbors 
have influenced the size evolution of one another, and if this signature may be discernible from comparative data.

In order to address these macroevolutionary questions on the origins and diversity of varanid lizards, it is essential to first construct a reliable time-scaled phylogeny. Relationships among Varanus have been reconstructed historically through a number of morphological and molecular methods, but recovered subgeneric relationships have been notoriously inconsistent (Fuller et al. 1998; Ast 2001; Fitch et al. 2006; Conrad et al. 2012; Vidal et al. 2012; Lin and Wiens 2017). We generated a nuclear exon capture dataset and combined it with existing morphological data to build a comprehensive phylogenetic hypothesis for Varanus in a combined evidence framework, incorporating both fossil and extant taxa. Our phylogenetic estimates are well-resolved at multiple taxonomic levels and we use them to reconstruct the global biogeographic history of varaniform lizards, then focus on the evolution of body size among Australian taxa. To address the influence of competition on size evolution, we extend a series of novel comparative phylogenetic models. These include models which integrate continental biogeographic history (not just contemporary distribution), and the possibility of competition with another group of highly diverse Australian carnivores.

\section{Materials \& Methods}

Walkthroughs of the data, code, analyses, and results are available in the Supplementary Material, on GitHub at www.github.com/IanGBrennan/MonitorPhylogenomics, and from the Dryad Digital Repository: http://dx.doi.org/10.5061/dryad.tx95x69t8

\section{Molecular Data Collection}

We assembled an exon-capture dataset across 103 Varanus specimens representing 61 of 80 currently recognized species. This sampling covers all nine subgenera and major clades of Varanus, as well as recognized subspecies, and known divergent populations. We included four additional non-varanoid anguimorphs (Elgaria, Heloderma, Shinisaurus, Xenosaurus), a skink (Plestiodon), and tuatara (Sphenodon) as outgroups. Nuclear exons were targeted and sequenced using the Anchored Hybrid Enrichment approach (Lemmon et al. 2012), and resulted in 388 loci (average coverage 350 loci, $\min =112, \max =373)$ totalling $\sim 600 \mathrm{kbp}$ per sample (Fig.S7).

\section{Morphological Sampling}

In addition to novel phylogenomic sampling, we included morphological data collected by Conrad et al. (2011). We chose to exclude a number of characters added to this matrix in Conrad et al. (2012) because of extensive missing data and uncertain homology. We filtered the data matrix using an allowance of $50 \%$ missing data per character, excluding characters above this threshold, and removed taxa with greater than $70 \%$ missing data, as we found these samples to be disruptive in exploratory analyses. We removed invariant characters from the remaining data to conform to assumptions of the MKv model, resulting in a final morphological matrix comprising 303 characters. Disruptive samples - often called 'rogues' - are not limited to those with large amounts of missing data. To identify if rogue taxa are causing topological imbalances in our phylogenetic hypotheses, we applied RogueNaRok (Aberer et al. 2012) to initial combined evidence analyses, identified rogues, and removed them for downstream analyses. Morphological sampling includes 55 extant Varanus, as well as the extinct $V$. priscus. A number of extant and fossil outgroups are included to sample the closely related groups Helodermatidae (Heloderma suspectum), Lanthanotidae (Lanthanotus borneensis, 
Cherminotus longifrons), Paleovaranidae (formerly Necrosauridae) (Paleovaranus (Necrosaurus) cayluxi, P. giganteus, 'Saniwa' feisti) (Georgalis 2017), Shinisauridae (Shinisaurus crocodilurus), and uncertain varaniform lizards (Aiolosaurus oriens, Ovoo gurvel, Telmasaurus grangeri, Saniwides mongoliensis).

\section{Phylogenetic Analyses}

We reconstructed a partitioned concatenated species tree and individual genealogies for our exoncapture data $(\mathrm{n}=388)$ under maximum-likelihood in IQTREE (Schmidt et al. 2014), allowing the program to assign the best fitting model of molecular evolution using PartitionFinder, then perform 1,000 ultrafast bootstraps (Haeseler et al. 2013). We then estimated the species tree using the shortcut coalescent method ASTRAL III (Zhang et al. 2017), with IQTREE gene trees as input. Further, we also estimated species trees using the full multispecies coalescent (MSC) and fossilized birth-death MSC (FBD-MSC) models implemented in StarBEAST2 (Ogilvie et al. 2016). Computational limitations under the MSC required we reduce the input data size and so we summarized per-locus informativeness using AMAS (Borowiec 2016), then used custom scripts to sort the loci sequentially by $(i)$ missing taxa per alignment, $(i i)$ number of variable sites, and (iii) AT content. We then chose the first three sets of twenty loci $(1-20 ; 21-40 ; 41-60)$ as representatives of the most informative and complete loci, and used them to build our phylogeny (Fig.S8).

Phylogenetic reconstruction under the FBD-MSC allowed us to jointly infer a molecular and morphological species tree, and divergence times using structured node and tip date priors (Supplementary Material: "Node Priors and Varanus in the Fossil Record"; Table S8). Morphological data were modelled under the Mkv model, a special case of the Mk model (Lewis 2001) - the most commonly used model for discrete morphological data. We partitioned morphological characters by differing numbers of states following Gavryushkina et al. (2017). All StarBEAST2 analyses were run for four independent chains under uncorrelated relaxed lognormal (UCLN) and strict molecular clocks for 1 billion generations and sampled each $5 \times 10^{5}$ generations, to assess convergence among runs. To further inspect our prior assumptions we ran all analyses under the priors only and compared against empirical runs. We inspected the MCMC chains for stationarity (ESS > 200) using Tracer v1.7.0 (Rambaut et al. 2018), and discarded the first 10-40\% of each run as burn-in as necessary before combining runs. Combined evidence analyses may be biased by difficulties in accurately modelling morphological evolution (Puttick et al. 2017; Luo et al. 2018; Goloboff et al. 2018). In contrast to molecular sites or loci, morphological characters are likely more often correlated (Billet and Bardin 2018), nonhomologous (Baum and Donoghue 2002), or evolving under dramatically different mechanisms (Goloboff et al. 2018), and may disrupt our best efforts at reconstructing phylogeny, divergence times, and rates of evolution. To address this, we also estimated divergence dates using an "extant-only" approach, limiting the sampling to living taxa with molecular data, and used the multispecies coalescent model implemented in StarBEAST2, using the same clock and substitution models, and chain lengths as above.

Fossil taxa are almost always assumed to represent terminal tips that have since gone extinct. To test this assumption, we allowed fossil taxa to be identified as terminal or stem lineages using the Sampled Ancestors package implemented in StarBEAST2. Using our prior-only analyses we calculated Bayes factors (BF) for each fossil taxon to test competing hypotheses (ancestor or tip). We used a threshold of $\log (\mathrm{BF})>1$ to identify sampled ancestors, $\log (\mathrm{BF})<-1$ to recognize terminal taxa, and $-1<\log (\mathrm{BF})<1$ taxa were categorized as equivocal. 
bioRxiv preprint doi: https://doi.org/10.1101/2020.02.02.931188; this version posted February 3, 2020. The copyright holder for this preprint (which was not certified by peer review) is the author/funder, who has granted bioRxiv a license to display the preprint in perpetuity. It is made available under aCC-BY-NC-ND 4.0 International license.

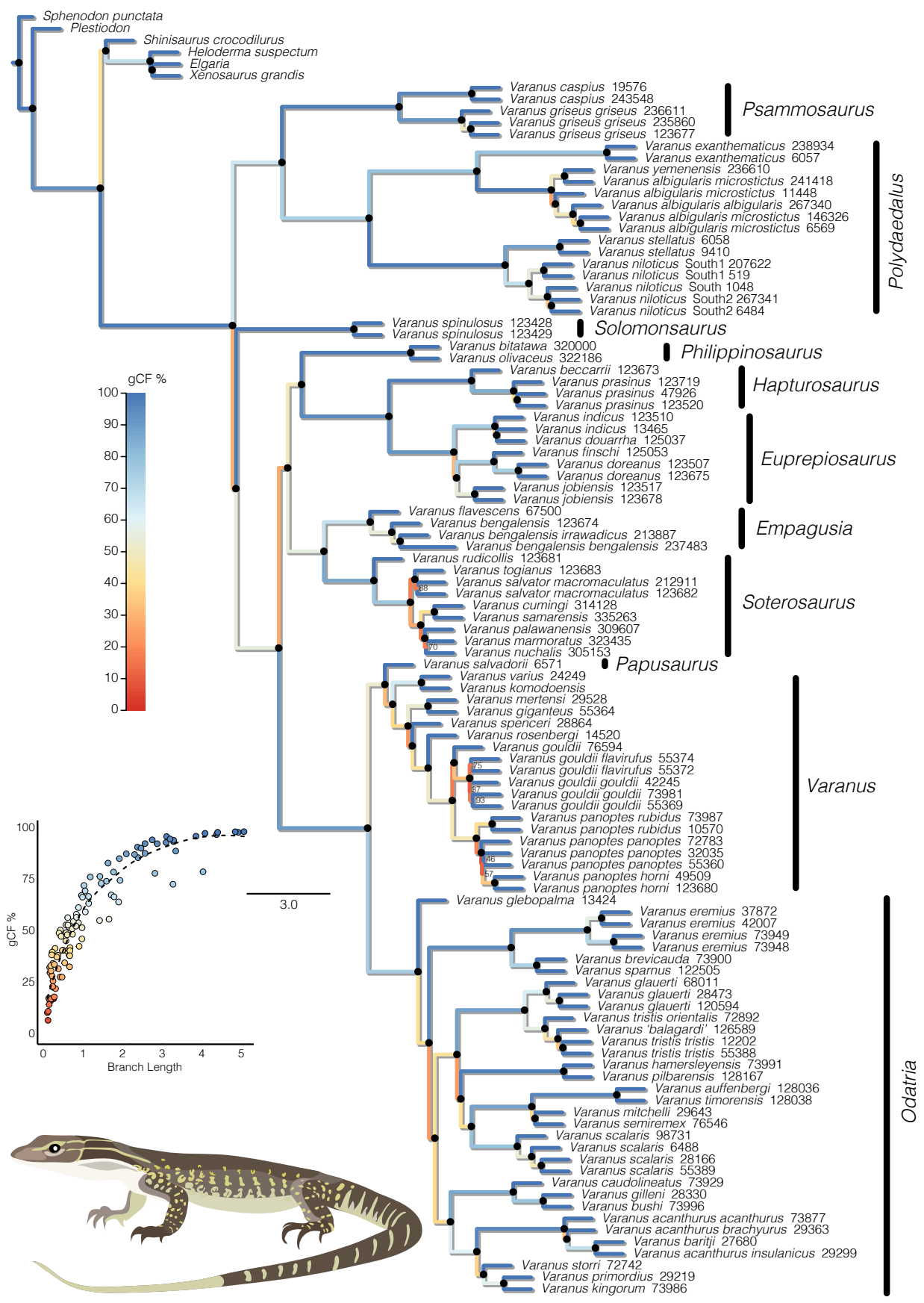

Figure 1: The fully sampled species tree estimated with ASTRAL is largely concordant with our total evidence species tree (Fig.S3). Nodes denoted by a $\bullet$ black circle are supported by local posterior probability values $>0.90$, all others $(<0.90)$ are considered equivocal and designated by lpp values. Branch colors correspond to gene concordance factors, and represent the percent of gene trees which decisively support the presented bifurcation. Inset plot shows that as expected, gCF values increase with increasing branch lengths, shown in coalescent units. Subgeneric names are listed to the right of each group. 


\section{Biogeographic History}

Varanus lizards have been variously hypothesized to have originated in Asia (Keast 1971; Estes 1983; Fuller et al. 1998; Jennings and Pianka 2004; Amer and Kumazawa 2008; Vidal et al. 2012; Conrad et al. 2012), Africa (Holmes et al. 2010), or Gondwana (Schulte et al. 2003) with conclusions largely based on which taxa were included, and the timing of varanid divergence events. We used BioGeoBEARS (Matzke 2014) to infer the biogeographic history of varanids and kin, dividing their range into seven major regions: North America, Europe, Sundaland/Wallacea, AustraloPapua, Africa/Arabia, West Asia (Indian subcontinent and surrounds), and East Asia (China, Mongolia, mainland Southeast Asia). As input we used the maximum clade credibility tree from our combined evidence analyses. Because of the deep evolutionary history of this group we took plate tectonic history into account by correcting dispersal probability as a function of distance between areas. We estimated distances between areas and continents through time at five million year intervals from 0-40 million years ago, then ten million year intervals from 40-100 million years, using latitude and longitude positions from GPlates (Boyden et al. 2011), and calculated pairwise distance matrices using the $\mathrm{R}$ package geosphere (Hijmans 2016). Additionally, we limited the model-space by providing information about area adjacency. For each time period, we removed unrealistic combinations of ranges (e.g. North America + AustraloPapua), with the aim of recovering more realistic biogeographic scenarios.

To understand the spatial evolution of Varanus in Australia, we used a Bayesian method rase (Quintero et al. 2015) which assumes a Brownian motion diffusion process to infer ancestral ranges as point data. We downloaded occurrence records for all continental Australian Varanus species from the Atlas of Living Australia (ala.org), curating the data for erroneous records, then trimmed our input tree down to just Australian taxa. We ran rase for 10,000 generations, sampling each 10th generation, then discarded the first 10\% (100 samples) as burn-in, leaving 900 samples. We inspected the traces of the MCMC chains for stationarity using coda (Plummer et al. 2006).

\section{Signature of Character Displacement}

Ecological communities are generally thought to assemble under opposing processes of habitat filtering and interlineage competition. Filtering is suggested to select for species with similar phenotypes, resulting in conservatism or convergence, whereas competition is expected to result in greater phenotypic disparity. These expectations can be tested by investigating the functional diversity of communities across the landscape. We divided the Australian continent into half-degree cells, and created a site by species matrix using the ALA distribution data for (i) monitor lizards and again for (ii) monitors and dasyuromorph/peramelemorph marsupials together. We estimated the functional diversity for the two data sets using the package $F D$ (Laliberté et al. 2014) and Rao's Quadratic, using body size as the trait of interest. We then estimated functional diversity for each inhabited cell 100 times using a dispersal null metric model which sampled from nearby cells assuming a probability proportional to the inverse of the distance from the focal cell. To compare observed and simulated functional diversities, we calculated standardized effect sizes (SES) for each cell, and a mean SES across the continent with $95 \%$ confidence intervals.

\section{Modelling Body Size Evolution with Competition}

Only within the past few years have phylogenetic comparative methods (PCMs) begun to account for the interaction of lineages on trait evolution. Conceptual work by Nuismer and Harmon (2015) led to the development of the Matching Competition (MC) model by Drury et al. (2016), which infers an interaction parameter $(S)$ dictating attraction towards or repulsion from the mean trait 
value of interacting lineages. This was extended by Drury et al. (2018b) to incorporate interactions matrices which limited interactions to only codistributed species. We build upon this framework by expanding the biogeographic information to include temporally and spatially dynamic ranges for ancestral taxa (inferred from rase, example in Fig.S6). In natural ecosystems, many different organisms compete for the same resources, so accounting for competition only within a single group is perhaps unrealistic. To address this issue, we consider the influence of another broadly distributed group of like-sized carnivores and omnivores, dasyuromorphian and peramelemorphian marsupials, on the size evolution of Australian monitor lizards. To test this hypothesis we begin by trimming the marsupial phylogeny of Brennan and Keogh (2018) down to just the faunivorous clades, from which we also dropped Myrmecobius because of its unusual ecology. We collected body size (mm) information for marsupials from Pantheria (Jones et al. 2009), and monitors from the literature (Wilson and Swan 2013). Manceau et al. (2017) introduced a framework for estimating the effect of one clade on the trait evolution of another, incorporating two phylogenetic trees, referred to as the Generalist Matching Mutualism (GMM) model. This is essentially a two-clade extension of the $M C$ model, which makes the assumption that the evolution of trait values in clade A are the result of interactions only with lineages in clade B, and vice versa. The GMM model however makes two very basic assumptions that we expect do not fit our data: (1) interactions between phenotypes are limited to interclade (between trees) matching or competition, meaning there is no influence of intraclade (within tree) interactions, and (2) that all contemporaneous lineages are interacting, regardless of geographic distribution. To address these assumptions, we developed and fit a series of models that expand on the interaction parameter $S$ and incorporate biogeography to provide more realistic models of trait evolution. We present summaries and graphical descriptions of these models in Fig.4 and the Supplementary Material (Fig.S1). Further, we test if size evolution is instead dictated by non-ecological processes, by employing standard models of trait evolution, Brownian Motion BM and Ornstein Uhlenbeck OU. Using these traditional null models, we can again ask if monitor and dasyuromorphian size has evolved under similar or independent rates using ratebytree in phytools, though we also provide implementations of shared BM and OU models in the RPANDA framework-CoBM and CoOU. To compare against an alternative hypothesis of varanid size evolution (Collar et al. 2011) where variation is dictated by habitat use, we also fit a multi-optima (OUM) model in OUwie (Beaulieu et al. 2012).

To incorporate historical and contemporary biogeography, we extended our rase analyses to marsupials with data collected from the ALA. We designed a number of custom scripts and functions to process the spatial data and model objects including extensions of the 'CreateGeoObject' of RPANDA. Our functions 'CreateGeoObject_SP' and 'CreateCoEvoGeoObject_SP' produce $R P A N D A$ GeoObjects that take as input a tree, spatial distribution data in latitude/longitude format, and a post-processed rase object. Internally, these functions use the packages $s p$ and rgeos to translate spatial data into spatial polygons representative of species distributions. Then, at each cladogenetic event, we determine the pairwise overlap of all contemporaneous lineages to construct our GeoObject (see Fig.S6). The 'CreateCoEvoGeoObject_SP' function has adapted this process for two trees, to be applied to GMM-type models.

\section{Model Behavior and Identifiability}

The ability to identify competition and estimate associated parameters using process-based models has been tested extensively previously (Drury et al. 2016, 2018a, 2018b). From this we know that the ability to recover competitive models and estimate the interaction parameter $S$-when it is the generating process - is strongly linked to the absolute value of $S$, and to a lesser degree the size of the phylogeny. Parameter estimate and recovery of $S$ can also be highly influenced by the 
incorporation of stabilizing selection $(\psi$ or $\alpha$ ), with the two parameters working agonistically in instances of competition $(-S)$, and synergistically in mutualistic circumstances $(+S)$. To ensure that we can accurately identify our models and estimate parameter values, we undertook a focused simulation exercise. Following the advice of Manceau et al. (2017), we simulated data directly onto our Australian monitor and marsupial trees under the same models we fit to our empirical data: $\mathrm{BM}_{\text {shared }}$, $\mathrm{OU}_{\text {shared }}$, CoEvo, $\mathrm{CoEvo}_{\text {all }}$, $\mathrm{CoEvo}_{\text {split }}$, JointPMgeo, and $\mathrm{CoPM}_{\text {geo }}$. We used the RPANDA function 'simulateTipData' to simulate body size data under all specified models, keeping the empirical biogeography constant. Specifics of the generating parameter values are noted in the Table S3. We then iteratively fit the models to our simulated data, and compared fit using AICc and plotted AICc weights. To determine the ability to accurately recover parameter values, we then compared estimated to simulated values under each model.

\section{Results}

\section{Phylogenetics of Monitor Lizards and Kin}

Topologies estimated across maximum-likelihood (IQTREE Schmidt et al. (2014)), shortcutcoalescent (ASTRAL Zhang et al. (2017)), and Bayesian multispecies coalescent (StarBEAST2 Ogilvie et al. (2016)) methods are highly concordant and generally strongly supported (Fig.S3,1). Contentious nodes are limited to some subspecific (Varanus gouldii, V. panoptes) and interspecific relationships ( $V$. salvator complex) which occur across a number of extremely short branches with low gene concordance factors, indicating both low information content and confidence. All analyses support the monophyly of Varanus and anguimorphs, and unite the Shinisauridae with the Helodermatidae, Anguidae, and Xenosauridae along a short internal branch. The Varanidae is sister to this group.

Interestingly, much of our trees are consistent with the first molecular phylogenies of Varanus proposed by Fuller et al. Fuller et al. (1998) and Ast et al. Ast (2001) two decades ago. Our results verify the monophyly of African and Arabian monitor lizards, and contrary to other recent studies (Lin and Wiens 2017), support the monophyly of both Psammosaurus and Polydaedalus subgenera. Our data support a geographically widespread clade comprising Philippines (Philippinosaurus) and tree (Hapturosaurus) and mangrove monitors (Euprepiosaurus), with water monitors (Soterosaurus) and species from the Indian subcontinent (Empagusia). We return a well resolved clade of IndoAustralopapuan monitors comprising the crocodile monitor (Papuasaurus), and the subgenera Varanus and Odatria (the dwarf monitors). Further, we record the first phylogenetic placement of the engimatic monitor V. spinulosus (Solomonsaurus) as sister to the Asian and Pacific clade, and confidently place $V$. gleboplama as sister to the rest of Odatria.

Dating estimates from our combined evidence and node-calibrated molecular analyses in StarBEAST2 agree on the timing of Varanus divergences. They suggest an origin of varanids (split between Varanidae and Lanthanotidae) in the mid-to-late Cretaceous (80-100 ma), and an earlyto-mid Oligocene (28-35 ma) origin for the crown divergence of extant Varanus. These dates are comparable with recent estimates from the literature (Lin and Wiens 2017; Pyron 2017), and younger than previous estimates (Vidal et al. 2012; Portik and Papenfuss 2012) which used stem varanids to calibrate the crown (Fig.S4). Ten fossil taxa form relatively poorly resolved higherorder relationships, with the Palaeovaranidae (formerly Necrosauridae) forming a clade with the Lanthanotidae (Lanthanotus, Cherminotus), together as sister to the Varanidae (Varanus, Saniwa). Varanus priscus, which is generally considered an extinct relative of the Indo-Australopapuan clade of giant monitors including $V$. varius, V. komodoensis, and V. salvadorii, is consistently placed in the Australian radiation. Given the existing morphological data, the majority of fossil taxa are 
recovered as tips in our analyses (Fig.S10).

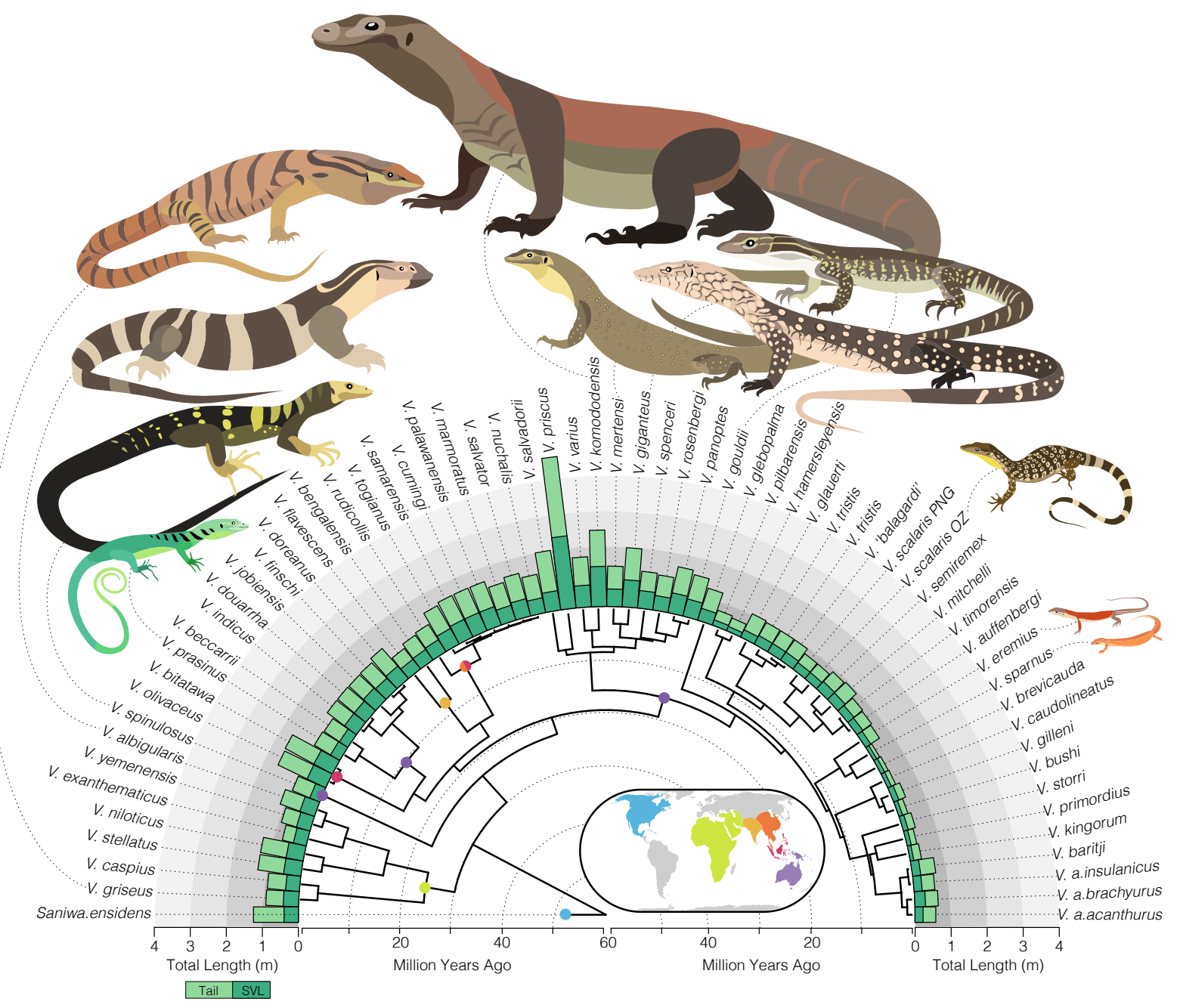

Figure 2: Body size among Varanus species varies across multiple orders of magnitude. Bar plots at tips of the tree show total length of sampled monitor lizards broken down into snout-vent length (SVL) and tail length. The smallest monitor species Varanus sparnus reaches just over $200 \mathrm{~mm}$ long from snout to tail tip and may weigh only $20 \mathrm{~g}$, while the largest living species Varanus komodoensis can reach well over 2 meters long $(2000+\mathrm{mm})$ and top the scales at $100 \mathrm{~kg}(100,000 \mathrm{~g})$. By all accounts, the recently extinct Varanus priscus was even larger than the Komodo dragon and may have reached over $4 \mathrm{~m}$ long (Wroe 2002; Conrad et al. 2012). Inset map shows a rough global distribution of monitor lizards and the extinct relative Saniwa ensidens. Colored circles at nodes indicate primary distribution of the major clades of Varanus and correspond to distributions on the map (blue-North America; green-Africa and the Middle East; light orange-Indian Subcontinent; dark orange-Indochina and China; red-Sundaland and Wallacea; purple-AustraloPapua).

\section{Biogeography and Community Assembly}

Global biogeographic analysis of Varanus and allies suggests an origin of varaniform lizards in East

Asia, with dispersals west across Laurasia into Europe, and east into North America. The origin of the genus Varanus is equivocal (Fig.S11), but likely followed a similar pattern, with independent clades dispersing west through the Middle East and into Africa and Europe, and south and east through Southeast Asia, Sundaland, and into Indo-Australia. After reaching the western and eastern 
extents of their range, both the African and Australopapuan clades appear to have begun dispersals back towards their origins. This has resulted in $V$. yemenensis extending across the Red Sea into the Arabian Peninsula, and V. komodoensis and members of the V. scalaris complex reaching back into Wallacea. A DEC model incorporating dispersal probability as a function of distance is strongly preferred $(\mathrm{AIC}=170.66, x=-0.682)$ over the traditional $\mathrm{DEC}$ model $(\mathrm{AIC}=186.04, \Delta \mathrm{AIC}=$ 15.38).

Biogeographic reconstruction of Australian Varanus reveals an origin spread across much of northern and central Australia (Fig.3). Considering northern Australia was the most likely colonization point for monitors, it makes sense that our analyses of community structure highlight this area as the center of greatest species richness for Varanus, with up to eleven species recorded in some half-degree grid cells. Taken together with dasyuromorph and peramelemorph marsupials, we again see high richness in the Top End, but also note species richness hotspots in the Central Deserts and the Pilbara regions. These regions are functionally diverse for monitors as well, but much less so for communities of marsupials and monitors analyzed jointly. Overall, we find support for overdispersion in trait values in the monitor-only dataset. Across Australia functional diversity of most communities is greater than expected under our null model (mean SES across all cells for monitors $=0.07 \pm 0.05$; . Functional diversity is greatest in monitor communities of moderate-tohigh (3-7 spp.) richness (mean SES $=0.45 \pm 0.13$ ), and lower than we would expect under our null model in communities of only two species (mean SES $=-0.16 \pm 0.08$ ) (Table S9). In contrast, communities of monitors and marsupials together have estimates of functional diversity consistently lower than expected under the null model (mean SES across all cells $=1.2 \pm 0.26$ ) (Table S10).
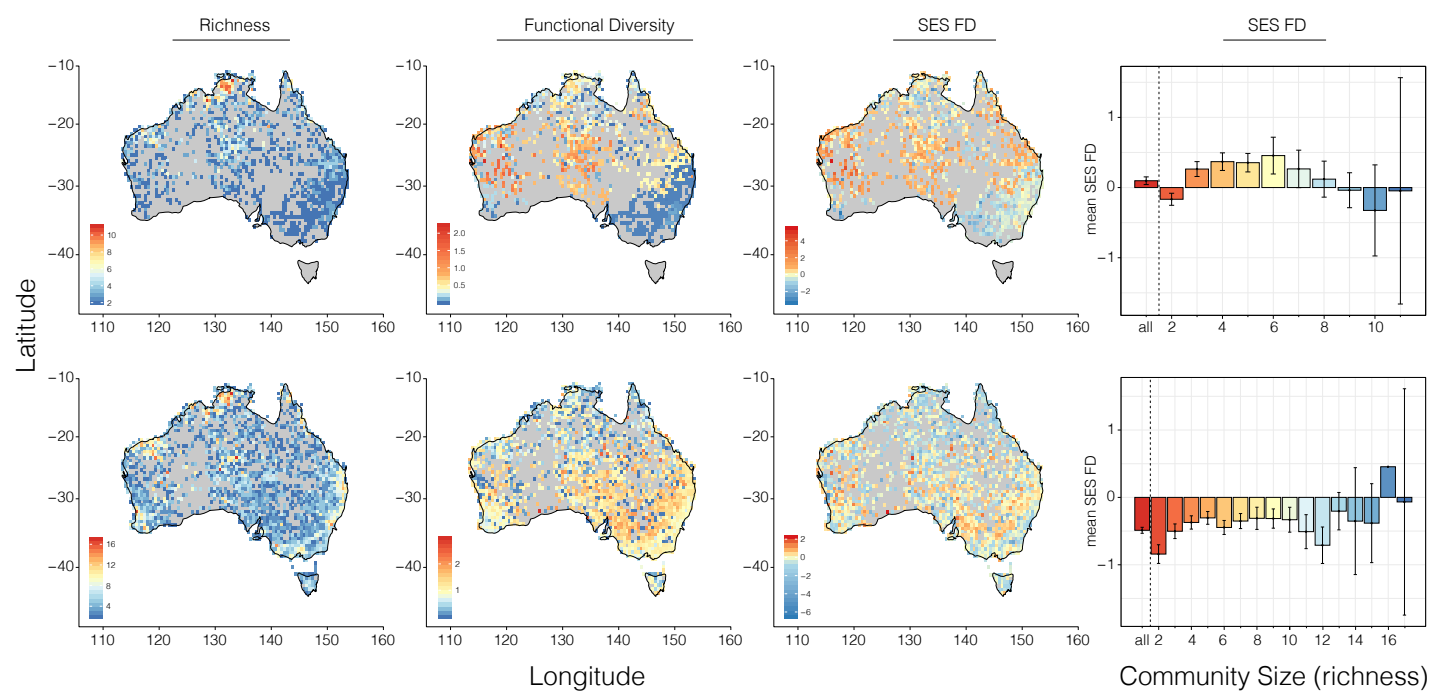

Figure 3: Maps of Australia showing patterns of richness (number of species) and functional diversity for monitor lizards (top row) and for monitor lizards and faunivorous marsupials together (bottomr row). Values were calculated and plotted for half-degree squares, with warmer colors indicating greater values - but note different scales for each plot. The left plots display species richness across the landscape and center-left plots show absolute values for functional diversity (FD - Rao's Q). Center-right plots show the standardized effect size (SES) of functional diversity when compared to the dispersal-corrected null model, and right plots show how the mean standardized effect sizes vary across communities of varying richness. In communities of moderate richness (3-7 spp), functional diversity is overdispersed in monitor lizards, suggesting character displacement. Functional diversity is almost always underdispersed when considering monitors and marsupials in communities together. 


\section{Modelling Body Size Evolution}

We extend a coevolutionary comparative method framework (Manceau et al. 2017) to incorporate historical biogeography and estimate the influence of lineage interactions on trait evolution. Comparison of traditional models of trait evolution (Brownian Motion, Ornstein Uhlenbeck) with those that incorporate interactions among lineages decisively favors interactive models (AICc weight 94\%) (Figs.4, S12). These models can be broadly divided into those which estimate the interaction parameter $S$ from occurrences $(\mathbf{1})$ within clades $\left(S_{\text {intra }}\right),(\mathbf{2})$ between clades $\left(S_{\text {inter }}\right)$, or $(\mathbf{3})$ both. We find greatest support for models that estimate interactions only within clades (Fig.4). Support for the best-fitting model $C o P M_{g e o}$ - which fits only a single $S_{\text {intra }}$ parameter for both trees - suggests that the strength of intraclade interactions can not be differentiated between the two groups. Across fitted models that estimate $S_{\text {intra }}$, we inferred negative values of $S$, supporting competitive interactions in both monitors and marsupials, $S_{\text {intra }}=-0.043 \pm 0.005$.

Support for the CoPM geo model also comes indirectly from parameter estimates of the CoEvo split $_{\text {. }}$

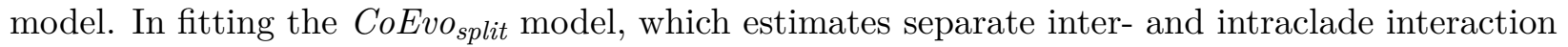
parameters $\left(S_{\text {inter }}, S_{\text {intra }}\right)$, we estimate a weak positive $S_{\text {inter }}$ parameter of 0.0043 . This parameter estimate is small enough to likely be biologically meaningless, and with $S_{\text {inter }} \approx 0$ the CoEvo split model collapses to CoPMgeo (see Supplementary Material-Nested Models). This suggests that interclade interactions between marsupials and varanids are indistinguishable from these data.

Results of our model identifiability exercise indicate that all proposed models can be recovered under realistic circumstances (Fig.S13). Because a number of these are nested forms of one variety or another, when simulated values of $S$ (as $S_{1}$ or $S_{2}$ ) approach 0, some models may be incorrectly conflated. Consistent with previous assessment (Drury et al. 2016), we also find that the accuracy of estimated $S$ is directly related to the absolute value of $S$, with greater values of $S$ being more precisely recovered (Fig.S14).

\section{Discussion}

Competitive interactions are expected to impact diversity by influencing species ranges, and influence phenotypic and behavioral evolution through character displacement (Brown and Wilson 1956; Benton 1987). Varanus represent a diverse group of lizards with exceptional variation in body size and ecologies (Fig.2). To investigate the role of competition in size evolution in monitors, we started by building a phylogenomic hypothesis of living and extinct varanids and their allies. By using a total evidence dating approach we were able to take advantage of both molecular and morphological data to incorporate fossil taxa, and reconstruct the global biogeography of varaniform lizards. Focusing on the Australian continent, we used a temporally dynamic Brownian Motion dispersal process to infer ancestral ranges for monitor lizards and co-occurring marsupial predators. We then quantified the functional diversity of monitor communities, and monitor-marsupial communities to address how these assemblages are structured. Finally, we developed and implemented a number of comparative models to account for interspecific interactions and estimate competition among monitors and with dasyuromorphian marsupials. Results of our comparative modelling provide a compelling case for considering competition in phylogenetic comparative methods (PCMs) of trait evolution. 

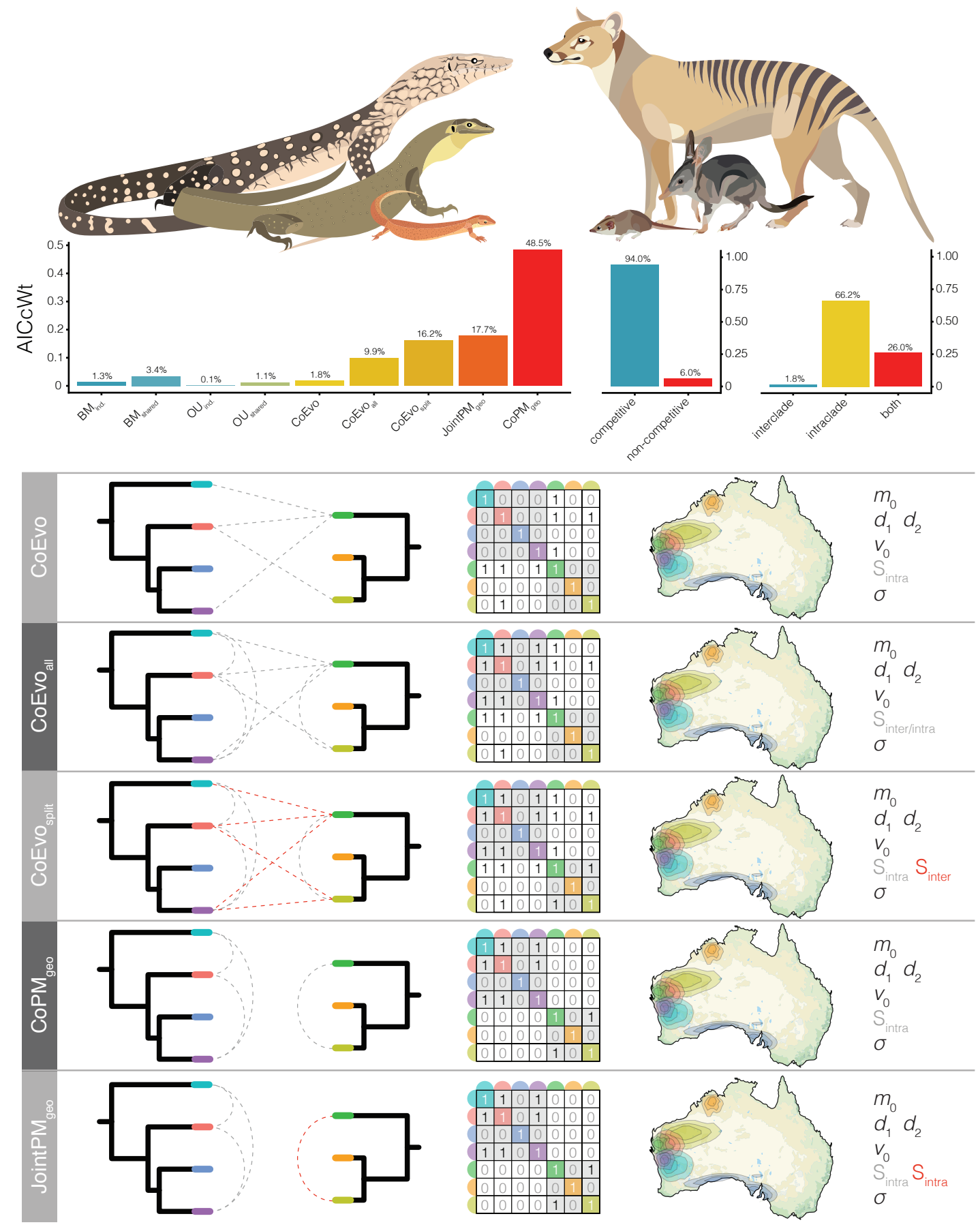

Figure 4: Comparative model fitting highlights the importance of incorporating interactions when modelling body size evolution of monitor lizards and faunivorous marsupials. Top, examples of Australian monitor lizards (Varanus giganteus, V. mertensi, V. sparnus) and marsupials (Thylacinus cynocephalus, Macrotis lagotis, Pseudantechinus bilarni), drawn roughly to scale. Middle, modelling competition vastly improves model fit, but size evolution appears largely driven by intraclade evolution and not competition between monitors and mammals. Bottom, hypothetical schematic components of biogeographically-informed lineage-interaction comparative models for two clades. Each model is named at left, followed by a diagram of the the two trees with interlineage interactions allowed under the given model designated by dashed lines. If more than one interaction parameter $S$ is estimated, it is denoted by red dashed lines. The contemporary summary of these interactions are presented in the interaction matrix $P$, and the estimated parameters are listed at far right. Maps show the distribution of the taxa used in these examples, and inform the interaction matrices. 


\section{Phylogenetic Relationships and Origins}

Relationships between anguimorph lizard groups have been contentious, particularly with regard to the placement of fossil taxa (Conrad 2008; Conrad et al. 2011; Pyron 2017). Different datasets have supported strongly competing hypotheses including a monophyletic Varanoidea (Varanidae, Shinisauridae, Monstersauria) (Gauthier et al. 2012), paraphyly of Varanoidea with regards to Anguidae, and even sister relationships between Varanidae and Mosasauria (Conrad 2008) or Varanidae and Serpentes (Hejnol et al. 2018). Existing hypotheses about relationships among these groups appear highly sensitive to the data used, with conflicting molecular and morphological signals (Pyron 2017; Hejnol et al. 2018), and even incongruences between different morphological datasets (Conrad 2008; Conrad et al. 2011; Gauthier et al. 2012; Pyron 2017). Much of this likely has to do with the fragmentary nature of many fossil taxa, morphological models of character evolution, and previous reliance on mitochondrial DNA of extant taxa. Our reanalysis of these morphological data in concert with novel phylogenomic data are largely consistent with previous assessments, however we provide new insights into the phylogenetics of living members of Varanus.

One of the most intriguing results from our data is the the phylogenetic placement of $V$. spinulosus. Although it is not wholly unexpected (Ziegler et al. 2007b, 2007a; Bucklitsch et al. 2016), it is not affiliated with the subgenus Varanus (Sweet and Pianka 2007) or with Euprepiosaurus (Harvey and Barker 1998). Instead, we place V. spinulosus alone on a long branch between the African and Asian monitors, and corroborate the previous erection of a unique subgenus Solomonsaurus (Bucklitsch et al. 2016). The phylogenetic position of $V$. spinulosus is remarkable given that it is a Solomon Islands endemic, meaning it likely made a considerable over-water dispersal or island hopped to the Solomons only shortly after their formation $\sim 30$ Ma (Hall 2002). This corroborates the intriguing observation that relatively young Melanesian islands have long been sources for ancient endemic diversity (Pulvers and Colgan 2007; Heads 2010; Oliver et al. 2017, 2018). It also suggests at least three independent dispersals of Varanus across Wallace's line, and a convoluted history of movement throughout the Indo-Australian region.

Our phylogeny of Varanus also highlights the adaptive capacity of these amazing lizards (Fig.2, S5). For example, the perentie $V$. giganteus is the largest extant Australian lizard, reaching well over two meters long, while remaining extremely thin. Its sister species $V$. mertensi in contrast, is a heavy bodied semiaquatic lizard built for the watercourses of northern Australia. Together, these species are sister to a group of sturdy terrestrial wanderers - the sand goannas-V. gouldii, $V$. panoptes, $V$. rosenbergi, and $V$. spenceri. In roughly five million years, these monitors diverged broadly both ecologically and morphologically, and spread across Australia's landscape. In the process of diversifying, monitor lizards have also converged repeatedly on ecological niches and body plans. There are at least four different origins of amphibious monitors ( V. salvator, V. mertensi, V. mitchelli, V. niloticus groups), and four or more origins of arboreal species (V. prasinus, $V$. gilleni, V. salvadorii, V. olivaceous, V. dumerilii groups), emphasizing the ability of monitors to fill available niches.

A number of phylogenetic questions evade our sampling, and largely concern the population genetics of known species complexes. These include the $V$. acanthurus, V. doreanus, V. griseus,

${ }_{420} V$. indicus, V. jobiensis, V. prasinus, V. salvator, V. scalaris, and V. tristis groups, of which most have recognized subspecies, very closely related species, or are paraphyletic in our data (Fig.1). Some of these taxa have experienced dramatic taxonomic growth in recent years as a result of more extensive sampling, and are sure to present exciting phylogeographic and systematic stories when the right data and sampling are paired together.

425 Overall, we suggest a younger timeline for the diversification of modern varanid lizards when compared to other phylogenetic studies, with a crown age in the early-to-mid Oligocene. This timing 
suggests Varanus potentially dispersed into the Indo-Australian region shortly after the collision of the Australian and Asian plates. If this is true, the connection of Sahul to Sundaland likely facilitated the dispersal of monitor lizards across an Indonesian island bridge, and extensive overwater dispersals seem less probable. Similarly, this proximity has also allowed small Australopapuan Varanus like the $V$. scalaris complex, as well as the largest extant monitor $V$. komodoensis to disperse back into the Indonesian archipelago (at least Wallacea). This pattern is consistent with the adaptive radiation of Australopapuan elapid snakes (Keogh 1998) and pythons (Reynolds et al. 2014; Esquerre et al. 2019), from Asian origins, and may underlie a more common diversification trend.

\section{Competition, Character Displacement \& Size Evolution}

Despite a relatively conservative body form, Varanus lizards have diverged into a number of ecologies and an astonishing array of body sizes. These include highly crytpozoic pygmy monitors like $V$. primordius, slender canopy dwellers like $V$. prasinus, the stout-bodied semiaquatic $V$. mertensi and $V$. salvator complex, and monstrous apex predators like the Komodo dragon $V$. komodoensis and extinct $V$. priscus. Across their range, monitors have also converged ecomorphologically with a number of mammalian predators, potentially putting them in direct competition for resources (Sweet and Pianka 2007). Competition is expected to influence interacting lineages by driving similar organisms apart in geographic space (exclusion), or in phenotypic or behavioral traits (character displacement) (Brown and Wilson 1956). In Australia, the diversity of varanids is matched by that of carnivorous marsupials, which vary from tenacious shrew-sized ningauis (Ningaui) up to the recently extinct wolf-like Thylacine.

By modelling the evolution of body size of Australian monitors and dasyuromorph and peramelemorph marsupials using lineage interaction-informed PCMs, we find strong support for the accumulation of size disparity as a result of character displacement independently and in parallel in these two groups. This is corroborated by greater than expected functional diversity of monitor assemblages (over dispersion). However, we do not find evidence of competition between marsupials and monitors and instead size evolution appears to have been dictated instead by within-clade character displacement. This may seem counterintuitive, considering carnivorous marsupials and monitors largely overlap in diet and size, with small animals - monitors and marsupials alike eating large invertebrates and small lizards, and larger animals taking larger vertebrate prey (James et al. 1992). But, marsupial predators and monitors differ in one very basic way, which is their activity period. Both are active foragers, covering wide tracks of land in search of food, but while monitors are almost exclusively diurnal, often roaming during the hottest part of the day, nearly all faunivorous marsupials are nocturnal. This temporal separation may explain the lack of competition in our analyses, and their continued coexistence. Data from other continents lend some support to this hypothesis. Across Africa, the Indian subcontinent, and throughout Southeast Asia, monitor lizards compete with other diurnal carnivorans, such as herpestids (mongooses), viverrids (civets), canids (dogs), mustelids (weasels), and felids (cats). Throughout these regions, Varanus have not diversified to the same extent as in Australia. The possibility of competitive release upon reaching the Australian continent provides a plausible explanation for the diversification of dwarf monitor species (Sweet and Pianka 2007).

While monitor lizards and marsupial predators appear to have diversified without outwardly influencing each others' trait evolution, both groups appear to have diverged according to character displacement occurring within their respective radiations. This suggests that community assembly processes may result in the same observable macroevolutionary patterns across different sympatric groups. Character displacement has long been associated with trait divergence, and was principally 
described on shallow scales from observable interactions among extant lineages (Vaurie 1951; Brown and Wilson 1956). The practice of extrapolating this idea to fit evolution on geological timescales fits the concept of a micro-to-macro evolutionary spectrum that is dictated by the same processes. The concept of competition as an impetus for evolution however, has been difficult to show explicitly from the fossil or phylogenetic record, and has been criticized for an unnecessarily "progressive" view of the process of evolution (Benton 1987). With the recent development of more appropriate process-generating models, we are now capable of better testing the influence of lineage interactions on evolutionary outcomes (Drury et al. 2016, 2018b; Manceau et al. 2017; Quintero and Landis 2019). In the case of monitor lizards, the exaggerated disparity in body sizes of Australian species is best described by an evolutionary model which accounts for competition among taxa in both space and time. This finding is further supported by evidence of overdispersion in body size variation within monitor communities, suggesting niche partitioning by body size is prevalent across the continent.

\section{Conclusion}

Monitors are an exceptional radiation of lizards capable of traversing sandy deserts and open ocean, living in the canopy and below ground. Here we present a comprehensive phylogenomic hypothesis of the genus, and place them among related varaniform and anguimorph lizards. In agreement with previous study, we find that varanids likely originated in Eurasia in the late Cretaceous or early Paleocene, but have long been spread across Europe, North America, and Africa, with their greatest richness in Indo-Australia. We also present a set of interaction-informed geographically explicit comparative models that help us propose an explanation for the extreme size disparity of living Varanus. We suggest that the diversity of sizes of Australian monitors may be the result of a combination of competitive release from carnivorans, and character displacement among other monitor species. Because organisms evolve in natural communities - and not in ecology-free vaccuums - we stress the importance of incorporating macroecological processes into macroevolutionary models. Our methodology involves a stepwise process of estimating ancestral ranges in continuous space (Quintero et al. 2015), then using this to inform interaction matrices in comparative models of trait evolution (Drury et al. 2018b). This framework also provides the opportunity to test the influence of taxa from more than one phylogeny on the evolution of a trait of interest (Manceau et al. 2017), with the goal of better understanding how communities develop and evolve. While our stepwise framework is limited by the unidirectionality of influence (species distributions may dictate trait evolution, but not vice versa), already methods are being developed to jointly infer these processes (Quintero and Landis 2019), as the evolutionary community works to provide a more holistic view of speciation, biogeography, and trait evolution. 


\section{Supplementary Material}

\section{Supplementary Methods}

\section{Phylogenetic Analyses}

To generate a molecular species tree, we started by reconstructing individual genealogies for each of the 388 recovered loci under maximum-likelihood in IQ-TREE (Schmidt et al. 2014). We allowed the program to automatically pick the best fitting model of molecular evolution using PartitionFinder (Lanfear et al. 2012), then perform 1,000 ultrafast bootstraps (Haeseler et al. 2013). As a preliminary step, we also used IQ-TREE to infer the phylogeny from a concatenated alignment, with individual partitions assigned by PartitionFinder. To estimate a species tree, coalescent methods have been shown more accurate than concatenation (Kubatko and Degnan 2007), and so we used the shortcut coalescent method ASTRAL III (Zhang et al. 2017), with all our IQ-TREE gene trees as input. We estimated local posterior probabilities in ASTRAL and gene concordance factors (gCF) to address node support.

As a complementary strategy to estimating Varanus relationships using ASTRAL, we also estimated a species tree using the full multispecies coalescent (MSC) model implemented in Computational requirements limit the number of loci we can realistically use under the MSC, and so we summarized per-locus informativeness using AMAS (Borowiec 2016). We then used custom scripts to sort the loci sequentially by $(i)$ missing taxa per alignment, $(i i)$ number of variable sites, and (iii) AT content. Given this order, we then chose the first three sets of twenty loci $(1-20 ; 21-40$; 41-60) as representatives of the most informative and complete loci, and used them to build our phylogeny (Fig.S8).

Advances in phylogenetic reconstruction methods have sought to better integrate molecular sequence data with fossil ages and morphological data (Lee et al. 2009; Pyron 2011; Ronquist et al. 2012; Beck and Lee 2014; Heath et al. 2014; Gavryushkina et al. 2017). Incorporating these lines of information in a combined evidence approach has provided more accurate phylogenetic estimation, and timing of divergence events. We reconstructed the phylogeny of living and extinct varaniforme lizards using the Fossilized Birth-Death Multi-Species Coalescent implemented in starBEAST2 (Ogilvie et al. 2018). In divergence dating analyses fossil information may be included using node priors (generally hard minimum bounds with diffuse upper bounds) or as tip dates (an estimate of the fossil sampling time) (Ho and Phillips 2009). Where data is available, combining node- and tip-dating may provide an advantage over using either method independently (Beck and Lee 2014; O'Reilly and Donoghue 2016). This provides the opportunity to co-estimate the phylogeny and divergence times, while providing structured priors on nodes which may otherwise be driven to unrealistic deep or shallow values. In most implementations of tip-dating fossil ages are fixed to a single value - most often this is the median value between upper and lower bounds. To avoid unintentional bias in choosing exact fossil ages, we instead incorporate uncertainty by sampling from informed uniform priors allowing the fossil ages to be jointly estimated (Barido-Sottani et al. 2019). Morphological data were modelled under the Mkv model, a special case of the Mk model (Lewis 2001) - the most commonly used model for discrete morphological data. The Mk model operates under the assumption that each character may exhibit $k$ states, and can transition among states at equal frequencies/rates. Because different characters may exhibit differing numbers of states, we applied the partitioning strategy of Gavryushkina et al. (2017), which partitions the morphological data based on the number of observed states of each character. Traditionally, invariant characters are either not coded, or stripped from discrete morphological alignments, resulting in an ascertainment bias for variable characters. The Mkv model (Lewis 2001) was proposed to account for this. All analyses were run for four independent chains under uncorrelated relaxed lognormal 
(UCLN) and strict molecular clocks for 1 billion generations and sampled each $5 \times 10^{5}$ generations, to assess convergence among runs. We inspected the MCMC chains for stationarity (ESS > 200) using Tracer v1.7.0 (Rambaut et al. 2018), and discarded the first 10-40\% of each run as burn-in as necessary before combining runs.

Morphological and molecular phylogenies of living and extinct monitor lizards have previously provided conflicting results regarding the relationships between the major clades and subgenera of Varanus. Inconsistencies among these data types may partially be due to difficulties in accurately modelling morphological evolution (Goloboff et al. 2018). While our knowledge of the homology, rate, and process of molecular evolution is considerable, it has been much more difficult to adequately model morphological data. In contrast to molecular sites or loci, morphological characters are likely more often correlated (Billet and Bardin 2018), nonhomologous (Baum and Donoghue 2002), or evolving under dramatically different mechanisms (Goloboff et al. 2018), and may disrupt our best efforts at reconstructing phylogeny, divergence times, and rates of evolution. This difficulty is exaggerated on deep time scales and highlights important caveats to consider in the application of combined- or total-evidence methods (Puttick et al. 2017; Luo et al. 2018). To address this, we also estimated divergence dates using an "extant-only" approach, limiting the sampling to living taxa with molecular data, and used the multispecies coalescent model implemented in StarBEAST2. We again used subsets of 20 loci, and applied several node calibrations described in Table S8, and discussed in the Supplemental Material ("Node Priors and Varanus in the Fossil Record"). We ran four independent chains under uncorrelated relaxed lognormal (UCLN) clocks with the GTR substitution model applied to all partitions for 1 billion generations and sampled each $5 \times 10^{5}$ generations, to assess convergence among runs. Again, we inspected the MCMC chains for stationarity (ESS > 200) using Tracer v1.7.0 (Rambaut et al. 2018), and discarded the first 10-20\% of each run as burn-in as necessary before combining runs.

\section{Fossil Taxa as Sampled Ancestors}

Fossil taxa are almost always assumed to represent terminal tips that have since gone extinct. To test this assumption, we allowed fossil taxa to be identified as terminal or stem lineages using the Sampled Ancestors package implemented in StarBEAST2. After running our full analyses, we also ran prior-only analyses for each dataset and used these to calculate Bayes factors (BF) for each fossil taxon to test competing hypotheses. Given that we place a prior on the age of each taxon $(\tau)$ and are jointly estimating their position among the phylogeny, including a model $(M)$ of the molecular and morphological evolution, we can sample exclusively from both the prior and posterior of our starBEAST2 analyses (Supplementary Material). We used a threshold of $\log (\mathrm{BF})>1$ to identify sampled ancestors, $\log (\mathrm{BF})<-1$ to recognize terminal taxa, and $-1<\log (\mathrm{BF})<1$ taxa were categorized as equivocal.

\section{Biogeographic History}

Varanus lizards have been variously hypothesized to have originated in Asia (Keast 1971; Estes 1983; Fuller et al. 1998; Jennings and Pianka 2004; Amer and Kumazawa 2008; Vidal et al. 2012; Conrad et al. 2012), Africa (Holmes et al. 2010), or Gondwana (Schulte et al. 2003) with conclusions largely based on which taxa were included, and the timing of varanid divergence events. To infer the biogeographic history of varanids and their allies, we used BioGeoBEARS (Matzke 2014). Because of the broad distribution of living and extinct monitors, we divided their range into seven major regions relevant to this group: North America, Europe, Sundaland/Wallacea, Australo-Papua, Africa/Arabia, West Asia (Indian subcontinent and surrounds), and East Asia (China, Mongolia, 
mainland Southeast Asia). We used as input our maximum clade credibility tree from the total evidence dating analysis in order to incorporate the geographic history of fossil taxa. Because of the deep evolutionary history of this group we took plate tectonic history into account by correcting dispersal probability as a function of distance between areas. We estimated distances between areas and continents through time at five million year intervals from 0-40 million years ago, then ten million year intervals from 40-100 million years, using latitude and longitude positions from GPlates (Boyden et al. 2011), and calculated pairwise distance matrices using the $\mathrm{R}$ package geosphere (Hijmans 2016). Additionally, we limited the model-space by providing information about area adjacency. For each time period, we removed unrealistic combinations of ranges (e.g. North America + AustraloPapua), with the aim of recovering more realistic biogeographic scenarios. We undertake the exercise of reconstructing the biogeographic history of this group fully recognizing that the observation of current (or fossilized) ranges of terminal taxa provide little information about the processes that got them there (Ree and Sanmartín 2018). Recognizing this, we implement only the dispersal-extinction-cladogenesis model (DEC) and the jump extension of this model (DEC $+\mathrm{j})$, and compare models with and without dispersal-distance-penalties. Further, we acknowledge the DEC model's proclivities for inflating the importance of cladogenetic dispersal, and consider its conclusions cautiously.

To further understand the spatial evolution of Varanus, we used a Bayesian method to model the dispersal of monitors across the Australian landscape. The $\mathrm{R}$ package rase (Quintero et al. 2015) assumes a Brownian motion diffusion process, using point data instead of discrete areas to infer geographic ranges which may be irregular or discontinuous. We started by downloading occurrence records for all continental Australian Varanus species from the Atlas of Living Australia (ala.org), curating the data for erroneous records, then trimmed our input tree down to just Australian taxa. We ran rase for 10,000 generations, sampling each 10th generation, then discarded the first $10 \%$ (100 samples) as burn-in, leaving 900 samples. We inspected the traces of the MCMC chains for stationarity using coda (Plummer et al. 2006).

\section{Signature of Character Displacement}

Ecological communities are generally thought to assemble under opposing processes of habitat filtering and interlineage competition. Filtering is suggested to select for species with similar phenotypes, resulting in conservatism or convergence, whereas competition is expected to result in greater phenotypic disparity. These expectations can be tested by investigating the functional diversity of communities across the landscape. We divided the Australian continent into half-degree cells, and created a site by species matrix using the ALA distribution data for (i) monitor lizards and again for (ii) monitors and dasyuromorphian marsupials together. We estimated the functional diversity for the two data sets using the package $F D$ (Laliberté et al. 2014) and Rao's Quadratic, using body size as the trait of interest. We then estimated functional diversity for each inhabited cell 100 times using a dispersal null metric model which sampled from nearby cells assuming a probability proportional to the inverse of the distance from the focal cell. To compare observed and simulated functional diversities, we calculated standardized effect sizes (SES) for each cell, and a mean SES across the continent with $95 \%$ confidence intervals.

\section{Modelling Body Size Evolution with Competition}

Only within the past few years have phylogenetic comparative methods (PCMs) begun to account for the interaction of lineages on trait evolution. Building off conceptual work by Nuismer \& Harmon

(Nuismer and Harmon 2015), Drury et al. (Drury et al. 2016) and Manceau et al. (Manceau et al. 
2017) integrated a system of ordinary differential equations in RPANDA (Morlon et al. 2016) for estimating the effect of competition on trait evolution in a maximum likelihood framework. This methodology allows us to estimate a parameter $S$ which describes the strength of the interaction, as well as the polarity: negative values of $S$ indicate repulsion, positive values indicate attraction towards common values. In its most simplistic form (the Phenotypic Matching PM, or Matching Competition MC model), the $S$ parameter interacts with the mean trait values of all other lineages (vector $X_{\mathrm{t}}$ ), to reflect their relationship (Supplementary Material Equation 1). To take into account changes through evolutionary time, the $S$ parameter further interacts with the evolutionary rate $(\sigma)$, and drift $(d)$, to dictate the trajectory of trait evolution. This model however, assumes that all lineages in a tree are sympatric and interact with one another. To address this, Drury et al. (Drury et al. 2018b) extended the model by incorporating interaction matrices $(P)$ that dictate which taxa interact with one another to more realistically estimate $S$ (equation 1 ).

In natural ecosystems, many different organisms compete for the same resources, so accounting for competition only within a single group is perhaps unrealistic. To address this issue, we consider the influence of another broadly distributed group of like-sized carnivores and omnivores, dasyuromorphian and peramelemorphian marsupials, on the size evolution of Australian monitor lizards. To test this hypothesis we begin by trimming the marsupial phylogeny of Brennan \& Keogh (Brennan and Keogh 2018) down to just the faunivorous clade, from which we also dropped Myrmecobius because of its unusual ecology. We collected body size ( $\mathrm{mm}$ ) information for marsupials from Pantheria (Jones et al. 2009), and monitors from the literature (Wilson and Swan 2013). Manceau et al. (Manceau et al. 2017) introduced a framework for estimating the effect of one clade on the trait evolution of another, incorporating two phylogenetic trees, referred to as the Generalist Matching Mutualism GMM model. This is essentially a two-clade extension of the PM model, which makes the assumption that the evolution of trait values in clade $\mathrm{A}$ are the result of interactions only with lineages in clade B, and vice versa. We present a graphical description of this and additional models below (Fig.S1). The GMM model however makes two very basic assumptions that we expect do not fit our data: (1) interactions between phenotypes are limited to interclade (between trees) matching or competition, meaning there is no influence of intraclade (within tree) interactions, and (2) that all contemporaneous lineages are interacting, regardless of on the interaction parameter $S$, and incorporate biogeography with the hopes of providing more realistic models of trait evolution. We briefly summarize and illustrate those models here, but discuss their behavior more extensively in the Supplementary Material.

Existing and new models described here allow us to test a number of hypotheses regarding the evolution of varanid body size. We focus on those that incorporate dasyuromorphian marsupials as well, because this provides a more holistic view of the macroevolution of two iconic groups of Australian vertebrates. Using these models we first test the idea that the evolution of varanid and dasyuromorphian body size has been dictated by competition with congeners, between clades, or both. We then test whether the strength of intraclade competition is equivalent in the two groups, and if the inclusion of geography via coexistence matrices improves model fit. Finally, we can ask if size evolution is instead dictated by non-ecological processes, by implementing standard models of trait evolution, Brownian Motion BM and Ornstein Uhlenbeck OU. Using these traditional null models, we can again ask if monitor and dasyuromorphian size has evolved under similar or independent rates using ratebytree in phytools, though we also provide implementations of shared BM and OU models in the RPANDA framework-CoBM and CoOU.

To incorporate historical and contemporary biogeography, we started by extending our rase analyses to marsupials with data collected from the ALA. We designed a number of custom scripts and functions to process the spatial data and model objects including extensions of the 'CreateGeoObject' 
of RPANDA. Our functions 'CreateGeoObject_SP' and 'CreateCoEvoGeoObject_SP' produce $R P A N D A$ GeoObjects that take as input a tree, spatial distribution data in latitude/longitude format, and a post-processed rase object. Internally, these functions use the packages $s p$ and rgeos to translate spatial data into spatial polygons representative of species distributions. Then, at each cladogenetic event, we determine the pairwise overlap of all contemporaneous lineages to construct our GeoObject (see Fig.S6). The 'CreateCoEvoGeoObject_SP' function has adapted this process for two trees, to be applied to GMM-type models.

\section{Interaction Model Summaries}

The following comparative models are summarized visually in Fig.S1.

The Phenotypic Matching (PM) (Nuismer and Harmon 2015) or Matching Competition (MC) (Drury et al. 2016) model is the basis for many PCMs incorporating interactions between lineages. $S$ is estimated from the interaction of all contemporaneous lineages.

The Phenotypic Matching Geography $\left(P M_{g e o}\right.$ or $M C_{g e o}$ ) (Drury et al. 2016) model was built as a geographic extension to the PM/MC model. Originally designed to account for sympatric island lineage interactions (determined in $P$ matrices), only codistributed species influence the estimation of $S$.

The Generalist Matching Mutualism (GMM) model. Assumes equal interaction (S) between all inter-clade lineages, but no interaction (0) among lineages within a tree (intra-clade). We embrace a broad description of the GMM mdoel, where $S$ can be positive indicating attraction towards the mean trait value of interacting lineages, or negative indicating repulsion away from the mean trait value of interacting lineages. Because interactions are estimated only between clades, $p_{k, l}=1$ if lineages $k$ and $l$ are from different clades (trees), and $p_{k, l}=0$ for any two lineages $k$ and $l$ from the same clade (tree).

The Generalist Matching Mutualism All $\left(G M M_{\text {all }}\right)$ model. Assumes equal interaction (S) between all taxa in both trees (inter- and intra-clade). $S$ can be positive indicating attraction towards the mean trait value of interacting lineages, or negative indicating repulsion away from the mean trait value of interacting lineages, but $p_{k, l}=1$ always.

The CoEvo model. An extension of the GMM model, accounting for interactions only between geographic co-occurring lineages. As with the GMM model, it only estimates interaction (S) between taxa across trees (inter-clade, not intra-clade). This model also properly accounts for the number of co-occuring lineages by dividing $\mathrm{S}$ (Pk/l) using rowsums (see Manceau et al. pg.559, equation 7).

The CoEvo all model. This is a CoEvo extension of the $\mathrm{GMM}_{\text {all }}$ model, estimating interaction $(S)$ between all co-occurring taxa (inter-clade and intra-clade). $p_{k, l}=1$ always. In calculating the interaction matrices, this model accounts for the number of co-occuring lineages by dividing $S / p_{k, l}$, assuming an equal strength of interaction with each cohabiting lineage.

The CoEvosplit model. Again, an extension of the GMM model, accounting for interactions only between geographic co-occurring lineages. It accounts for interactions between all taxa like the $\mathrm{CoEvo}_{\text {all }}$ model, but estimates a different interaction parameter for intra-clade (S2) and inter-clade (S1) interactions. In calculating the interaction matrices, this model accounts for the number of co-occuring lineages by dividing $S / p_{k, l}$, assuming an equal strength of interaction with each cohabiting lineage. This model is identical to the models: CoPM geo if $S_{1}=0$, CoEvo if $S_{2}=0$, and CoEvoall if $S_{1}=S_{2}$.

The CoPM model. This is a joint estimation of the PM model for two trees. It estimates single interaction $(S)$ and rate $(\sigma)$ values for both trees, but $S$ is estimated solely from intra-clade interactions (no interaction between trees). All lineages in a tree are assumed to interact with all other lineages in that tree 
The $C o P M_{\text {geo }}$ model. This is an extension of the CoPM model, which is a joint estimation of the PM model for two trees. It estimates single interaction $(S)$ and rate $(\sigma)$ values for both trees, but $S$ is estimated solely from intra-clade interactions (no interaction between trees). It correctly accounts for interaction only among geographic overlapping lineages, and corrects the interaction estimate for the number of overlapping lineages.

The JointPM model. This is a joint estimation of the PM model for two trees. It differs from the CoPM model by estimating separate interaction values for each clade $\left(\operatorname{tree}_{1}=S_{1}\right.$; tree $_{2}=S_{2}$ ). All lineages in a tree are assumed to interact with all other lineages in that tree.

The Joint $P M_{\text {geo }}$ model. This is a joint estimation of the PM model for two trees. It differs from the $\mathrm{CoPM}_{\text {geo }}$ model by estimating separate interaction values for each clade $\left(\right.$ tree $_{1}=S_{1}$; tree $_{2}=$ $S_{2}$ ). Like the CoPM geo (unlike JointPM) it correctly estimates the interaction parameters $\left(S_{1}, S_{2}\right)$ for only geographic overlapping taxa (it also corrects for the number of taxa overlapping). This model is identical to the CoPM geo model if $S_{1}=S_{2}$. 


\section{Model Behavior and Identifiability}

The ability to identify competition and estimate associated parameters using process-based models has been tested extensively previously (Drury et al. 2016, 2018a, 2018b). From this we know that the ability to recover competitive models and estimate the interaction parameter $S$ - when it is the generating process - is strongly linked to the absolute value of $S$, and to a lesser degree the size of the phylogeny. Parameter estimate and recovery of $S$ can also be highly influenced by the incorporation of stabilizing selection $(\psi$ or $\alpha$ ), with the two parameters working agonistically in instances of competition $(-S)$, and synergistically in mutualistic circumstances $(+S)$.

To ensure that we can accurately identify our models and estimate parameter values, we undertook a focused simulation exercise. Following the advice of Manceau et al. (Manceau et al. 2017), we simulated data directly onto our Australian monitor and marsupial trees under the same models we fit to our empirical data: $\mathrm{BM}_{\text {shared }}$, $\mathrm{OU}_{\text {shared }}$, CoEvo, $\mathrm{CoEvo}_{\text {all }}, \mathrm{CoEvo}_{\text {split }}$, JointPM $\mathrm{PMo}_{\text {geo }}$ and $\mathrm{CoPM}_{\text {geo. }}$ We used the RPANDA function 'simulateTipData' to simulate body size data under all specified models, keeping the empirical biogeography constant. Specifics of the generating parameter values are noted in the Table S3. We then iteratively fit the models to our simulated data, and compared fit using AICc and plotted AICc weights. To determine the ability to accurately recover parameter values, we then compared estimated to simulated values under each model.

\section{Historical Models of Monitor Size Evolution}

To test our hypothesis of character displacement as a driving force of Varanus size disparity, we also fit standard stochastic (Brownian Motion) and stabilizing (Ornstein-Uhlenbeck-OU) models of trait evolution, and a multi-optima (OUM) model following Collar et al. (2011). This multi-OU (OUM) model explains size evolution as a result of differing selective optima correlated with habitat use. These models were implemented and fit using geiger (Pennell et al. 2014) and OUwie (Beaulieu et al. 2012). 
Equation 1. Following Manceau et al. (2017), we can estimate if lineage $k$ is repelled from (-S) or attracted to $(+S)$ the average trait value of the lineages it interacts with. $S$ represents the the strength of the interaction on trait evolution. $d_{1}$ and $d_{2}$ represent the shift values for lineages from clade 1 and 2 respectively, with the expectation that $d_{1}+d_{2}=0 . \delta_{k}$ equals one if lineage $k$ belongs to clade 1 , and zero it if belongs to clade 2 , and $p_{k, l}$ equals one if lineages $k$ and $l$ interact (in our case it is assumed if they are sympatric) and zero otherwise. $n_{k}=\sum_{l} p_{k, l}$ is the number of lineages interacting with lineage $k$, and $n$ is the total number of lineages.

$$
d X_{t}^{(k)}=S\left(\delta_{k} d+\left(1-\delta_{k}\right) d_{2}+\frac{1}{n} \sum_{k}^{n} p_{l=1} X_{t}^{(l)}-X_{t}^{(k)}\right) d t+\sigma d W_{t}^{(k)}
$$


Table S1. Taxon sampling for this project. The $\dagger$ symbol denotes extinct taxa included in the combined evidence analyses. Lanthanotus borneensis is the only extant taxon lacking molecular data.

\begin{tabular}{|c|c|c|c|}
\hline Taxon & Tree ID & Accession Number & Locality \\
\hline Aiolosaurus oriens $^{\dagger}$ & - & IGM 3/171 & Ukhaa Tolgod, Mongolia \\
\hline Cherminotus longifrons ${ }^{\dagger}$ & - & ZPAL MgR-III/59/67 & Khermeen Tsav, Mongolia \\
\hline Elgaria & 76547 & ABTC 76547 & Oregon, USA \\
\hline Heloderma suspectum & - & SAMAR 55982 & - \\
\hline Lanthanotus borneensis & - & FMNH 130981/134711 & Borneo \\
\hline Ovoo gurvel ${ }^{\dagger}$ & - & IGM $3 / 767$ & Ukhaa Tolgod, Mongolia \\
\hline Palaeovaranus (Necrosaurus) giganteus ${ }^{\dagger}$ & - & GM 4021 & Geiseltal, Germany \\
\hline Palaeovaranus (Necrosaurus) cayluxi ${ }^{\dagger}$ & - & BMNH PR 3486 & Quercy, France \\
\hline Plestiodon & 81170 & ABTC81170 & - \\
\hline Saniwa ensidens ${ }^{\dagger}$ & - & USNM 2185 & Wyoming, USA \\
\hline 'Saniwa' feisti ${ }^{\dagger}$ & - & SMF ME-A 160 & Darmstadt, Germany \\
\hline Saniwides mongoliensis ${ }^{\dagger}$ & - & ZPal MgR-I/72 & Khulsan, Mongolia \\
\hline Shinisaurus crocodilurus & - & - & - \\
\hline Sphenodon punctata & - & - & - \\
\hline Telmasaurus grangeri ${ }^{\dagger}$ & - & AMNH FR6643 & Bain Dzak, Mongolia \\
\hline Varanus acanthurus acanthurus & 73877 & WAMR 117242 & Yilbrinna Pool, Australia \\
\hline Varanus acanthurus brachyurus & 29363 & NTMR 20528 & Cape Crawford, Australia \\
\hline Varanus acanthurus insulanicus & 29299 & NTMR 19073 & Guluwuru Island, Australia \\
\hline Varanus albigularis albigularis & 276340 & MVZ 267340 & Limpopo, South Africa \\
\hline Varanus albigularis microstictus & 6569 & - & - \\
\hline Varanus albigularis microstictus & 146326 & MVZ 146326 & Gorongosa NP, Mozambique \\
\hline Varanus albigularis microstictus & 241148 & UMFS 11448 & Dodoma, Tanzania \\
\hline Varanus albigularis microstictus & 11448 & UMFS 11448 & Dodoma, Tanzania \\
\hline Varanus auffenbergi & 128036 & WAMR 105802 & Rote Ndau, Indonesia \\
\hline Varanus 'balagardi' & 12689 & NTMR 36799 & Arnhemland, Australia \\
\hline Varanus baritji & 27680 & NTMR 13150 & Donydji, Australia \\
\hline Varanus beccarrii & 123673 & UMMZ 225561 & Aru Islands, Indonesia \\
\hline Varanus bengalensis & 123674 & ABTC 123674 & Captive (Baltimore Zoo) \\
\hline Varanus bengalensis bengalensis & 237483 & MVZ 237483 & Laghman Province, Afghanistan \\
\hline Varanus bengalensis irrawadicus & 213887 & CAS 213887 & Magwe Division, Myanmar \\
\hline Varanus bitatawa & 320000 & KU 320000 & Barangay Casapsipan, Philippines \\
\hline Varanus brevicauda & 73900 & WAMR 90898 & Woodstock Station, Australia \\
\hline Varanus bushi & 73996 & WAMR 108999 & Marandoo, Australia \\
\hline Varanus caudolineatus & 73929 & WAMR 122576 & Australia \\
\hline Varanus cumingi & 314128 & KU 314128 & Barangay San Marcos, Philippines \\
\hline Varanus doreanus & 123507 & BPBM 19509 & Mount Obree, Papua New Guinea \\
\hline Varanus doreanus & 123675 & UMMZ 227117 & Merauke, Indonesia \\
\hline Varanus douarrha & 125037 & ABTC 125037 & New Ireland, Papua New Guinea \\
\hline Varanus eremius & 37872 & SAMAR 49961 & Purni Bore, Australia \\
\hline Varanus eremius & 42007 & SAMAR 48779 & Mt. Lindsay, Australia \\
\hline Varanus eremius & 73948 & WAMR 121347 & Australia \\
\hline Varanus eremius & 73949 & WAMR 121348 & Australia \\
\hline Varanus exanthematicus & 238934 & MVZ 238934 & Gbele Resource Reserve, Ghana \\
\hline Varanus exanthematicus & 6057 & UWBM 6057 & Duidan Iddar, Nigeria \\
\hline Varanus finschi & 125053 & ABTC 125053 & Kokopo, Papua New Guinea \\
\hline Varanus flavescens & 67500 & UF 67500 & Sindh Province, Pakistan \\
\hline Varanus giganteus & 55364 & SAMAR 20988 & Oodnadatta, Australia \\
\hline Varanus gilleni & 28330 & NTMR 13778 & Australia \\
\hline Varanus glauerti & 28473 & ABTC 28473 & Bungle Bungles, Australia \\
\hline Varanus glauerti & 68011 & NTMR 24867 & Bradshaw Station, Australia \\
\hline Varanus glauerti & 120594 & ABTC 120594 & Mt. Elizabeth Station, Australia \\
\hline Varanus glebopalma & 13424 & ABTC 13424 & Adelaide River, Australia \\
\hline Varanus gouldii & 76594 & ABTC 76594 & Katherine, Australia \\
\hline
\end{tabular}


bioRxiv preprint doi: https://doi.org/10.1101/2020.02.02.931188; this version posted February 3, 2020. The copyright holder for this preprint (which was not certified by peer review) is the author/funder, who has granted bioRxiv a license to display the preprint in perpetuity. It is made available under aCC-BY-NC-ND 4.0 International license.

\begin{tabular}{|c|c|c|c|}
\hline Taxon & Tree ID & Accession Number & Locality \\
\hline Varanus gouldii flavirufus & 55372 & SAMAR 24554 & Etadunna Station, Australia \\
\hline Varanus gouldii flavirufus & 55374 & SAMAR 24717 & Australia \\
\hline Varanus gouldii gouldii & 42245 & SAMAR 50146 & Sentinel Hill, Australia \\
\hline Varanus gouldii gouldii & 55369 & SAMAR 22941 & Perth, Australia \\
\hline Varanus gouldii gouldii & 73981 & WAMR 117288 & Doole Island, Australia \\
\hline Varanus griseus caspius & 19576 & ZISP 19576 & Chardjou Region, Turkmenistan \\
\hline Varanus griseus caspius & 243548 & MVZ 243548 & Sistan and Baluchistan Province, Iran \\
\hline Varanus griseus griseus & 123677 & UMMZ 238881 & - \\
\hline Varanus griseus griseus & 235860 & MVZ 235860 & Nouakchott, Mauritania \\
\hline Varanus griseus griseus & 236611 & MVZ 236611 & Al Hudaydah, Yemen \\
\hline Varanus hamersleyensis & 73991 & WAMR 125100 & Newman, Australia \\
\hline Varanus indicus & 13465 & ABTC 13465 & Maningrida, Australia \\
\hline Varanus indicus & 123510 & BPBM 20841 & Rossel Island, Papua New Guinea \\
\hline Varanus jobiensis & 123517 & BPBM 19510 & Dorobisoro, Papua New Guinea \\
\hline Varanus jobiensis & 123678 & ABTC 123678 & Papua, Indonesia \\
\hline Varanus kingorum & 73986 & WAMR 136382 & Turkey Creek, Australia \\
\hline Varanus komodoensis & 75731 & - & Captive (Taronga Zoo) \\
\hline Varanus komodoensis & genome & - & - \\
\hline Varanus marmoratus & 323435 & KU 323435 & Barangay Villa Aurora, Philippines \\
\hline Varanus mertensi & 29528 & NTMR 21389 & Musselbrook Reservoir, Australia \\
\hline Varanus mitchelli & 29643 & NTMR 21745 & Litchfield NP, Australia \\
\hline Varanus niloticus South & 6484 & ABTC 6484 & - \\
\hline Varanus niloticus South & 1048 & ELI 1048 & Rumonge, Burundi \\
\hline Varanus niloticus South & 267341 & MVZ 267341 & Limpopo, South Africa \\
\hline Varanus niloticus South & 519 & DMP 519 & Edea, Cameroon \\
\hline Varanus niloticus South & 207622 & CAS 207622 & Bioko Id, Equatorial Guinea \\
\hline Varanus nuchalis & 305153 & KU 305153 & Barangay Camalanda-an, Philippines \\
\hline Varanus olivaceus & 322186 & ABTC 126105 & Philippines \\
\hline Varanus palawanensis & 309607 & KU 309607 & Palawan, Philippines \\
\hline Varanus panoptes horni & 49509 & AMSR 121162 & Wipim, Papua New Guinea \\
\hline Varanus panoptes horni & 123680 & UMMZ 227307 & Merauke, Indonesia \\
\hline Varanus panoptes panoptes & 32035 & ABTC 32035 & Rosebank Station, Australia \\
\hline Varanus panoptes panoptes & 55360 & NTMR 10690 & Alligator Head, Australia \\
\hline Varanus panoptes panoptes & 72783 & - & Smithburne River, Australia \\
\hline Varanus panoptes rubidus & 10570 & ABTC 10570 & Yuinmery Station, Australia \\
\hline Varanus panoptes rubidus & 73987 & WAMR 102099 & Mt. Cotton, Australia \\
\hline Varanus pilbarensis & 128167 & WAMR 163916 & Goldsworthy, Australia \\
\hline Varanus prasinus & 47926 & ABTC 47926 & Wau, Papua New Guinea \\
\hline Varanus prasinus & 123520 & BPBM 18696 & Apele, Papua New Guinea \\
\hline Varanus prasinus & 123719 & BPBM 18695 & Dorobisoro, Papua New Guinea \\
\hline Varanus primordius & 29219 & NTMR 17884 & Elizabeth Downs Station, Australia \\
\hline Varanus (Megalania) priscus $^{\dagger}$ & - & AMNH FR 1968,6302-4 & Australia \\
\hline Varanus rosenbergi & 14520 & AMSR 123331 & Kulnura, Australia \\
\hline Varanus rudicollis & 123681 & R OM24456 & Kalimantan, Indonesia \\
\hline Varanus salvadorii & 6571 & ABTC 6571 & Papua New Guinea \\
\hline Varanus salvator macromaculatus & 123682 & UMMZ 225562 & Rantra Prapat, Indonesia \\
\hline Varanus salvator macromaculatus & 212911 & CAS 212911 & Ayeyarwade Division, Myanmar \\
\hline Varanus samarensis & 335263 & KU 335263 & Barangay Danicop, Philippines \\
\hline Varanus scalaris & 6488 & WAMR 77223 & Mitchell Plateau, Australia \\
\hline Varanus scalaris & 28166 & ABTC 28166 & Katherine Gorge, Australia \\
\hline Varanus scalaris & 98731 & ABTC 98731 & Wegamu, Papua New Guinea \\
\hline Varanus scalaris & 55389 & ABTC 55389 & Scotts Creek, Australia \\
\hline Varanus semiremex & 76546 & ANWCR 6121 & Cooktown, Australia \\
\hline Varanus sparnus & 122505 & WAMR 168475 & Coulomb Point, Australia \\
\hline Varanus spenceri & 28864 & ABTC 28864 & Tablelands Highway, Australia \\
\hline Varanus spinulosus & 123428 & ABTC 123428 & Isabel, Solomon Islands \\
\hline Varanus spinulosus & 123429 & ABTC 123429 & Isabel, Solomon Islands \\
\hline
\end{tabular}


bioRxiv preprint doi: https://doi.org/10.1101/2020.02.02 931188; this version posted February 3, 2020. The copyright holder for this preprint (which was not certified by peer review) is the author/funder, who has granted bioRxiv a license to display the preprint in perpetuity. It is made available under aCC-BY-NC-ND 4.0 International license.

\begin{tabular}{llll}
\hline Taxon & Tree ID & Accession Number & Locality \\
\hline Varanus stellatus & 19410 & PEM R 19410 & Sierra Leone \\
Varanus stellatus & 6058 & UWBM 6058 & Bvi NP, Ghana \\
Varanus storri & 72742 & SAMAR 54351 & Mount Isa, Australia \\
Varanus timorensis & 128038 & WAMR 105914 & Semau, Indonesia \\
Varanus togianus & 123683 & ABTC 123683 & Sulawesi, Indonesia \\
Varanus tristis tristis & 12202 & SAMAR 38779 & Tennant Creek, Australia \\
Varanus tristis tristis & 55388 & SAMAR 32491 & Coongie, Australia \\
Varanus tristis orientalis & 72892 & SAMAR 54476 & Torrens Creek, Australia \\
Varanus varius & 24249 & ABTC 24249 & Kroombit Tops, Australia \\
Varanus yemenensis & 236610 & MVZ 236610 & Al Hudaydah, Yemen \\
Xenosaurus grandis & 137786 & - & - \\
\hline
\end{tabular}


Table S2. Per locus best fitting models of molecular evolution, determined by IQ-TREE and the Bayesian Information Criterion (BIC). Independent gene trees were estimated using the preferred model, and 1,000 ultrafast bootstraps.

\begin{tabular}{|c|c|c|c|c|c|}
\hline Locus & Site Model & Locus & Site Model & Locus & Site Model \\
\hline L1 & $\mathrm{K} 3 \mathrm{Pu}+\mathrm{F}+\mathrm{R} 3$ & L131 & $\mathrm{HKY}+\mathrm{F}+\mathrm{G} 4$ & L260 & TIM2e+R3 \\
\hline L2 & $\mathrm{K} 3 \mathrm{Pu}+\mathrm{F}+\mathrm{R} 3$ & L132 & $\mathrm{K} 3 \mathrm{Pu}+\mathrm{F}+\mathrm{R} 3$ & L261 & $\mathrm{K} 2 \mathrm{P}+\mathrm{R} 3$ \\
\hline L3 & $\mathrm{TIM}+\mathrm{F}+\mathrm{R} 3$ & L133 & $\mathrm{HKY}+\mathrm{F}+\mathrm{G} 4$ & L262 & $\mathrm{GTR}+\mathrm{F}+\mathrm{R} 3$ \\
\hline L4 & $\mathrm{TN}+\mathrm{F}+\mathrm{R} 2$ & L134 & $\mathrm{K} 3 \mathrm{Pu}+\mathrm{F}+\mathrm{R} 3$ & L263 & $\mathrm{HKY}+\mathrm{F}+\mathrm{G} 4$ \\
\hline L5 & $\mathrm{TVM}+\mathrm{F}+\mathrm{R} 3$ & L135 & $\mathrm{HKY}+\mathrm{F}+\mathrm{R} 3$ & L264 & $\mathrm{TIM}+\mathrm{F}+\mathrm{R} 3$ \\
\hline L6 & TIMe+G4 & L136 & $\mathrm{TPM} 3 \mathrm{u}+\mathrm{F}+\mathrm{G} 4$ & L265 & $\mathrm{HKY}+\mathrm{F}+\mathrm{R} 3$ \\
\hline L7 & $\mathrm{TIM}+\mathrm{F}+\mathrm{R} 3$ & L137 & TIM3e+G4 & L266 & $\mathrm{K} 3 \mathrm{P}+\mathrm{R} 3$ \\
\hline L8 & $\mathrm{HKY}+\mathrm{F}+\mathrm{R} 3$ & L138 & $\mathrm{HKY}+\mathrm{F}+\mathrm{G} 4$ & L267 & $\mathrm{TVM}+\mathrm{F}+\mathrm{I}+\mathrm{G} 4$ \\
\hline L9 & $\mathrm{K} 2 \mathrm{P}+\mathrm{R} 2$ & L139 & $\mathrm{K} 2 \mathrm{P}+\mathrm{G} 4$ & L268 & $\mathrm{HKY}+\mathrm{F}+\mathrm{R} 2$ \\
\hline L10 & $\mathrm{K} 3 \mathrm{Pu}+\mathrm{F}+\mathrm{G} 4$ & L140 & $\mathrm{K} 2 \mathrm{P}+\mathrm{R} 3$ & L269 & $\mathrm{TIM}+\mathrm{F}+\mathrm{R} 3$ \\
\hline L11 & $\mathrm{HKY}+\mathrm{F}+\mathrm{G} 4$ & L141 & $\mathrm{K} 2 \mathrm{P}+\mathrm{R} 2$ & L270 & $\mathrm{K} 3 \mathrm{P}+\mathrm{R} 3$ \\
\hline L12 & $\mathrm{HKY}+\mathrm{F}+\mathrm{G} 4$ & L142 & TIM2e+R3 & L271 & $\mathrm{TPM} 2 \mathrm{u}+\mathrm{F}+\mathrm{I}+\mathrm{G} 4$ \\
\hline L13 & $\mathrm{TIM}+\mathrm{F}+\mathrm{R} 3$ & L143 & $\mathrm{TN}+\mathrm{F}+\mathrm{R} 3$ & $\mathrm{~L} 272$ & $\mathrm{TNe}+\mathrm{G} 4$ \\
\hline L14 & $\mathrm{K} 2 \mathrm{P}+\mathrm{G} 4$ & L144 & $\mathrm{HKY}+\mathrm{F}+\mathrm{G} 4$ & L273 & $\mathrm{TIM}+\mathrm{F}+\mathrm{R} 3$ \\
\hline L15 & $\mathrm{K} 2 \mathrm{P}+\mathrm{G} 4$ & L145 & $\mathrm{HKY}+\mathrm{F}+\mathrm{G} 4$ & $\mathrm{~L} 274$ & $\mathrm{TPM} 2 \mathrm{u}+\mathrm{F}+\mathrm{R} 3$ \\
\hline L16 & $\mathrm{HKY}+\mathrm{F}+\mathrm{R} 2$ & L146 & $\mathrm{K} 2 \mathrm{P}+\mathrm{R} 3$ & $\mathrm{~L} 275$ & $\mathrm{TPM} 2 \mathrm{u}+\mathrm{F}+\mathrm{R} 3$ \\
\hline L17 & $\mathrm{TNe}+\mathrm{R} 2$ & L147 & $\mathrm{TIM}+\mathrm{F}+\mathrm{R} 3$ & L276 & $\mathrm{TIM} 3+\mathrm{F}+\mathrm{R} 2$ \\
\hline L18 & $\mathrm{TNe}+\mathrm{I}$ & L148 & $\mathrm{TN}+\mathrm{F}+\mathrm{R} 2$ & $\mathrm{~L} 277$ & $\mathrm{TN}+\mathrm{F}+\mathrm{G} 4$ \\
\hline L19 & $\mathrm{HKY}+\mathrm{F}+\mathrm{I}+\mathrm{G} 4$ & L149 & $\mathrm{HKY}+\mathrm{F}+\mathrm{R} 3$ & $\mathrm{~L} 278$ & $\mathrm{~K} 3 \mathrm{P}+\mathrm{I}+\mathrm{G} 4$ \\
\hline L20 & $\mathrm{HKY}+\mathrm{F}+\mathrm{G} 4$ & L150 & $\mathrm{HKY}+\mathrm{F}+\mathrm{G} 4$ & L279 & $\mathrm{HKY}+\mathrm{F}+\mathrm{G} 4$ \\
\hline L21 & $\mathrm{TNe}+\mathrm{R} 2$ & L151 & $\mathrm{HKY}+\mathrm{F}+\mathrm{G} 4$ & L281 & $\mathrm{K} 2 \mathrm{P}+\mathrm{G} 4$ \\
\hline L22 & TIM2e+R3 & L152 & $\mathrm{K} 2 \mathrm{P}+\mathrm{R} 2$ & L282 & $\mathrm{TVMe}+\mathrm{I}+\mathrm{G} 4$ \\
\hline L23 & $\mathrm{K} 2 \mathrm{P}+\mathrm{R} 3$ & L153 & $\mathrm{TN}+\mathrm{F}+\mathrm{R} 2$ & $\mathrm{~L} 283$ & TIM2e+R2 \\
\hline L24 & $\mathrm{TIM}+\mathrm{F}+\mathrm{R} 3$ & L154 & $\mathrm{K} 2 \mathrm{P}+\mathrm{G} 4$ & $\mathrm{~L} 284$ & $\mathrm{TN}+\mathrm{F}+\mathrm{R} 2$ \\
\hline L25 & $\mathrm{K} 3 \mathrm{Pu}+\mathrm{F}+\mathrm{R} 3$ & L155 & $\mathrm{TN}+\mathrm{F}+\mathrm{G} 4$ & L285 & $\mathrm{HKY}+\mathrm{F}+\mathrm{G} 4$ \\
\hline L27 & $\mathrm{HKY}+\mathrm{F}+\mathrm{G} 4$ & L156 & $\mathrm{K} 3 \mathrm{Pu}+\mathrm{F}+\mathrm{G} 4$ & L286 & $\mathrm{TPM} 2 \mathrm{u}+\mathrm{F}+\mathrm{R} 3$ \\
\hline L28 & $\mathrm{HKY}+\mathrm{F}+\mathrm{G} 4$ & L157 & $\mathrm{HKY}+\mathrm{F}+\mathrm{G} 4$ & $\mathrm{~L} 287$ & $\mathrm{HKY}+\mathrm{F}+\mathrm{G} 4$ \\
\hline L29 & $\mathrm{K} 3 \mathrm{Pu}+\mathrm{F}+\mathrm{R} 2$ & L158 & $\mathrm{TIM} 2+\mathrm{F}+\mathrm{I}+\mathrm{G} 4$ & L288 & $\mathrm{TN}+\mathrm{F}+\mathrm{R} 3$ \\
\hline L30 & $\mathrm{K} 3 \mathrm{Pu}+\mathrm{F}+\mathrm{G} 4$ & L159 & $\mathrm{HKY}+\mathrm{F}+\mathrm{R} 3$ & L289 & $\mathrm{K} 2 \mathrm{P}+\mathrm{R} 3$ \\
\hline L31 & $\mathrm{K} 3 \mathrm{Pu}+\mathrm{F}+\mathrm{I}+\mathrm{G} 4$ & L160 & $\mathrm{TIM} 2+\mathrm{F}+\mathrm{G} 4$ & L290 & $\mathrm{GTR}+\mathrm{F}+\mathrm{R} 2$ \\
\hline L32 & $\mathrm{TN}+\mathrm{F}+\mathrm{R} 3$ & L161 & $\mathrm{TPM} 3 \mathrm{u}+\mathrm{F}+\mathrm{R} 3$ & L291 & $\mathrm{TIM} 2+\mathrm{F}+\mathrm{I}+\mathrm{G} 4$ \\
\hline L33 & $\mathrm{HKY}+\mathrm{F}+\mathrm{G} 4$ & L162 & $\mathrm{K} 2 \mathrm{P}+\mathrm{G} 4$ & L292 & $\mathrm{TN}+\mathrm{F}+\mathrm{G} 4$ \\
\hline L34 & $\mathrm{HKY}+\mathrm{F}+\mathrm{G} 4$ & L163 & $\mathrm{HKY}+\mathrm{F}+\mathrm{G} 4$ & L293 & $\mathrm{HKY}+\mathrm{F}+\mathrm{R} 3$ \\
\hline L35 & $\mathrm{TPM} 3 \mathrm{u}+\mathrm{F}+\mathrm{R} 3$ & L164 & $\mathrm{K} 3 \mathrm{Pu}+\mathrm{F}+\mathrm{R} 2$ & L294 & $\mathrm{TPM} 2+\mathrm{F}+\mathrm{G} 4$ \\
\hline L36 & $\mathrm{TIM} 2+\mathrm{F}+\mathrm{G} 4$ & L165 & $\mathrm{K} 3 \mathrm{P}+\mathrm{G} 4$ & L295 & $\mathrm{HKY}+\mathrm{F}+\mathrm{I}$ \\
\hline L37 & TIM3e+R2 & L166 & $\mathrm{HKY}+\mathrm{F}+\mathrm{G} 4$ & L296 & $\mathrm{TNe}+\mathrm{R} 2$ \\
\hline L38 & $\mathrm{TIM} 3+\mathrm{F}+\mathrm{R} 3$ & L167 & $\mathrm{HKY}+\mathrm{F}+\mathrm{R} 2$ & L297 & $\mathrm{TVMe}+\mathrm{I}+\mathrm{G} 4$ \\
\hline L39 & $\mathrm{K} 3 \mathrm{P}+\mathrm{R} 3$ & L168 & $\mathrm{HKY}+\mathrm{F}+\mathrm{I}$ & L298 & $\mathrm{K} 3 \mathrm{P}+\mathrm{I}+\mathrm{G} 4$ \\
\hline L40 & $\mathrm{HKY}+\mathrm{F}+\mathrm{R} 3$ & L169 & $\mathrm{HKY}+\mathrm{F}+\mathrm{G} 4$ & L299 & $\mathrm{HKY}+\mathrm{F}+\mathrm{R} 2$ \\
\hline L41 & $\mathrm{TPM} 2 \mathrm{u}+\mathrm{F}+\mathrm{I}+\mathrm{G} 4$ & L170 & $\mathrm{K} 3 \mathrm{P}+\mathrm{R} 3$ & L300 & $\mathrm{HKY}+\mathrm{F}+\mathrm{R} 3$ \\
\hline L42 & $\mathrm{TIM}+\mathrm{F}+\mathrm{R} 3$ & L171 & $\mathrm{K} 3 \mathrm{Pu}+\mathrm{F}+\mathrm{R} 3$ & L301 & $\mathrm{TPM} 2+\mathrm{F}+\mathrm{G} 4$ \\
\hline L43 & $\mathrm{TIM}+\mathrm{F}+\mathrm{R} 2$ & L172 & $\mathrm{TIM} 3+\mathrm{F}+\mathrm{G} 4$ & L302 & $\mathrm{TN}+\mathrm{F}+\mathrm{R} 3$ \\
\hline L44 & $\mathrm{TPM} 3+\mathrm{F}+\mathrm{G} 4$ & L173 & $\mathrm{HKY}+\mathrm{F}+\mathrm{R} 3$ & L303 & $\mathrm{K} 3 \mathrm{P}+\mathrm{R} 3$ \\
\hline L45 & $\mathrm{HKY}+\mathrm{F}+\mathrm{G} 4$ & L174 & $\mathrm{HKY}+\mathrm{F}+\mathrm{G} 4$ & L304 & $\mathrm{HKY}+\mathrm{F}+\mathrm{G} 4$ \\
\hline L46 & $\mathrm{HKY}+\mathrm{F}+\mathrm{G} 4$ & L175 & $\mathrm{TIM}+\mathrm{F}+\mathrm{G} 4$ & L305 & $\mathrm{JC}$ \\
\hline $\mathrm{L} 47$ & $\mathrm{HKY}+\mathrm{F}+\mathrm{R} 3$ & L176 & $\mathrm{K} 3 \mathrm{Pu}+\mathrm{F}+\mathrm{I}$ & L306 & $\mathrm{TIM} 3+\mathrm{F}+\mathrm{G} 4$ \\
\hline $\mathrm{L} 48$ & $\mathrm{HKY}+\mathrm{F}+\mathrm{R} 3$ & L177 & $\mathrm{TVM}+\mathrm{F}+\mathrm{R} 4$ & L307 & $\mathrm{SYM}+\mathrm{R} 3$ \\
\hline L49 & $\mathrm{TIM}+\mathrm{F}+\mathrm{R} 3$ & L178 & $\mathrm{TN}+\mathrm{F}+\mathrm{R} 2$ & L308 & $\mathrm{K} 2 \mathrm{P}+\mathrm{G} 4$ \\
\hline L50 & $\mathrm{K} 2 \mathrm{P}+\mathrm{R} 2$ & L179 & $\mathrm{TIM} 3+\mathrm{F}+\mathrm{R} 3$ & L309 & $\mathrm{TNe}+\mathrm{R} 3$ \\
\hline L51 & $\mathrm{TN}+\mathrm{F}+\mathrm{R} 3$ & L180 & $\mathrm{K} 2 \mathrm{P}+\mathrm{G} 4$ & L310 & $\mathrm{K} 3 \mathrm{P}+\mathrm{G} 4$ \\
\hline L52 & $\mathrm{K} 3 \mathrm{Pu}+\mathrm{F}+\mathrm{R} 3$ & L181 & $\mathrm{HKY}+\mathrm{F}+\mathrm{G} 4$ & L311 & $\mathrm{HKY}+\mathrm{F}+\mathrm{R} 3$ \\
\hline L53 & TIM2e+R2 & L182 & $\mathrm{HKY}+\mathrm{F}+\mathrm{G} 4$ & L312 & $\mathrm{HKY}+\mathrm{F}+\mathrm{G} 4$ \\
\hline L54 & $\mathrm{TPM} 2+\mathrm{F}+\mathrm{G} 4$ & L183 & $\mathrm{HKY}+\mathrm{F}+\mathrm{R} 2$ & L313 & $\mathrm{TIM}+\mathrm{F}+\mathrm{R} 3$ \\
\hline
\end{tabular}




\begin{tabular}{|c|c|c|c|c|c|}
\hline Locus & Site Model & Locus & Site Model & Locus & Site Model \\
\hline L55 & $\mathrm{HKY}+\mathrm{F}+\mathrm{G} 4$ & L184 & $\mathrm{TPM} 3 \mathrm{u}+\mathrm{F}+\mathrm{G} 4$ & L314 & $\mathrm{K} 3 \mathrm{Pu}+\mathrm{F}+\mathrm{R} 2$ \\
\hline L56 & $\mathrm{HKY}+\mathrm{F}+\mathrm{G} 4$ & L185 & $\mathrm{K} 3 \mathrm{Pu}+\mathrm{F}+\mathrm{G} 4$ & L315 & $\mathrm{TIMe}+\mathrm{R} 3$ \\
\hline L57 & $\mathrm{HKY}+\mathrm{F}+\mathrm{R} 2$ & L186 & $\mathrm{TIMe}+\mathrm{R} 3$ & L316 & $\mathrm{TVMe}+\mathrm{R} 3$ \\
\hline L58 & $\mathrm{K} 3 \mathrm{Pu}+\mathrm{F}+\mathrm{R} 2$ & L187 & $\mathrm{F} 81+\mathrm{F}+\mathrm{G} 4$ & L317 & $\mathrm{K} 3 \mathrm{Pu}+\mathrm{F}+\mathrm{G} 4$ \\
\hline L59 & $\mathrm{TIM}+\mathrm{F}+\mathrm{R} 3$ & L188 & $\mathrm{TIM} 3+\mathrm{F}+\mathrm{R} 2$ & L318 & $\mathrm{TN}+\mathrm{F}+\mathrm{I}+\mathrm{G} 4$ \\
\hline L60 & $\mathrm{TN}+\mathrm{F}+\mathrm{R} 3$ & L189 & $\mathrm{HKY}+\mathrm{F}+\mathrm{R} 3$ & L319 & $\mathrm{TN}+\mathrm{F}+\mathrm{G} 4$ \\
\hline L61 & TIM3+F+R3 & L190 & $\mathrm{HKY}+\mathrm{F}+\mathrm{G} 4$ & L320 & $\mathrm{HKY}+\mathrm{F}+\mathrm{I}+\mathrm{G} 4$ \\
\hline L62 & TIM3+F+R3 & L191 & $\mathrm{TPM} 3 \mathrm{u}+\mathrm{F}+\mathrm{R} 3$ & L321 & $\mathrm{TNe}+\mathrm{R} 2$ \\
\hline L63 & $\mathrm{TN}+\mathrm{F}+\mathrm{R} 3$ & L192 & $\mathrm{HKY}+\mathrm{F}+\mathrm{G} 4$ & L322 & $\mathrm{TVM}+\mathrm{F}+\mathrm{R} 3$ \\
\hline L64 & $\mathrm{HKY}+\mathrm{F}+\mathrm{G} 4$ & L193 & $\mathrm{TN}+\mathrm{F}+\mathrm{G} 4$ & L323 & $\mathrm{K} 3 \mathrm{P}+\mathrm{R} 3$ \\
\hline L65 & $\mathrm{HKY}+\mathrm{F}+\mathrm{G} 4$ & L194 & $\mathrm{HKY}+\mathrm{F}+\mathrm{R} 2$ & L324 & $\mathrm{HKY}+\mathrm{F}+\mathrm{R} 2$ \\
\hline L66 & $\mathrm{TIM} 2+\mathrm{F}+\mathrm{R} 3$ & L195 & $\mathrm{HKY}+\mathrm{F}+\mathrm{G} 4$ & L325 & $\mathrm{TIM}+\mathrm{F}+\mathrm{R} 3$ \\
\hline L67 & $\mathrm{HKY}+\mathrm{F}+\mathrm{G} 4$ & L196 & $\mathrm{HKY}+\mathrm{F}+\mathrm{R} 2$ & L326 & $\mathrm{TIMe}+\mathrm{R} 3$ \\
\hline L68 & $\mathrm{HKY}+\mathrm{F}+\mathrm{G} 4$ & L197 & $\mathrm{TNe}+\mathrm{R} 2$ & L327 & $\mathrm{TN}+\mathrm{F}+\mathrm{G} 4$ \\
\hline L69 & $\mathrm{TPM} 3 \mathrm{u}+\mathrm{F}+\mathrm{R} 3$ & L198 & $\mathrm{TPM} 2 \mathrm{u}+\mathrm{F}+\mathrm{G} 4$ & L328 & $\mathrm{TN}+\mathrm{F}+\mathrm{I}$ \\
\hline L70 & $\mathrm{TN}+\mathrm{F}+\mathrm{R} 2$ & L199 & $\mathrm{HKY}+\mathrm{F}+\mathrm{G} 4$ & L329 & $\mathrm{K} 3 \mathrm{Pu}+\mathrm{F}+\mathrm{I}+\mathrm{G} 4$ \\
\hline L71 & $\mathrm{GTR}+\mathrm{F}+\mathrm{I}+\mathrm{G} 4$ & L200 & $\mathrm{TIM} 2+\mathrm{F}+\mathrm{R} 3$ & L330 & $\mathrm{GTR}+\mathrm{F}+\mathrm{R} 3$ \\
\hline L72 & $\mathrm{HKY}+\mathrm{F}+\mathrm{R} 3$ & L201 & $\mathrm{K} 3 \mathrm{Pu}+\mathrm{F}+\mathrm{R} 3$ & L331 & $\mathrm{GTR}+\mathrm{F}+\mathrm{R} 3$ \\
\hline L73 & $\mathrm{TPM} 2 \mathrm{u}+\mathrm{F}+\mathrm{I}+\mathrm{G} 4$ & L202 & $\mathrm{TIM}+\mathrm{F}+\mathrm{R} 3$ & L332 & $\mathrm{HKY}+\mathrm{F}+\mathrm{G} 4$ \\
\hline L74 & $\mathrm{HKY}+\mathrm{F}+\mathrm{G} 4$ & L203 & $\mathrm{K} 2 \mathrm{P}+\mathrm{G} 4$ & L333 & $\mathrm{TVMe}+\mathrm{R} 3$ \\
\hline L75 & $\mathrm{TN}+\mathrm{F}+\mathrm{G} 4$ & L204 & $\mathrm{TPM} 3 \mathrm{u}+\mathrm{F}+\mathrm{R} 2$ & L334 & $\mathrm{K} 2 \mathrm{P}+\mathrm{R} 2$ \\
\hline $\mathrm{L} 76$ & $\mathrm{HKY}+\mathrm{F}+\mathrm{I}+\mathrm{G} 4$ & L205 & $\mathrm{TN}+\mathrm{F}+\mathrm{R} 3$ & L335 & $\mathrm{K} 3 \mathrm{P}+\mathrm{G} 4$ \\
\hline L77 & $\mathrm{HKY}+\mathrm{F}+\mathrm{G} 4$ & L206 & $\mathrm{HKY}+\mathrm{F}+\mathrm{G} 4$ & L336 & $\mathrm{HKY}+\mathrm{F}+\mathrm{G} 4$ \\
\hline L78 & $\mathrm{TPM} 3 \mathrm{u}+\mathrm{F}+\mathrm{R} 3$ & L207 & $\mathrm{HKY}+\mathrm{F}+\mathrm{R} 3$ & L337 & $\mathrm{K} 2 \mathrm{P}+\mathrm{G} 4$ \\
\hline L79 & $\mathrm{TN}+\mathrm{F}+\mathrm{G} 4$ & L208 & $\mathrm{TN}+\mathrm{F}+\mathrm{G} 4$ & L338 & $\mathrm{HKY}+\mathrm{F}+\mathrm{R} 2$ \\
\hline L80 & $\mathrm{TIM}+\mathrm{F}+\mathrm{R} 3$ & L209 & $\mathrm{K} 2 \mathrm{P}+\mathrm{R} 2$ & L339 & $\mathrm{HKY}+\mathrm{F}+\mathrm{R} 2$ \\
\hline L81 & $\mathrm{K} 2 \mathrm{P}+\mathrm{G} 4$ & L210 & $\mathrm{K} 3 \mathrm{P}+\mathrm{G} 4$ & L340 & $\mathrm{TIM}+\mathrm{F}+\mathrm{R} 3$ \\
\hline L82 & $\mathrm{TIM} 2+\mathrm{F}+\mathrm{G} 4$ & L211 & $\mathrm{HKY}+\mathrm{F}+\mathrm{G} 4$ & L341 & $\mathrm{K} 2 \mathrm{P}+\mathrm{G} 4$ \\
\hline L83 & $\mathrm{K} 3 \mathrm{Pu}+\mathrm{F}+\mathrm{R} 3$ & L212 & $\mathrm{K} 3 \mathrm{Pu}+\mathrm{F}+\mathrm{G} 4$ & L342 & $\mathrm{K} 2 \mathrm{P}+\mathrm{R} 3$ \\
\hline L84 & TIM3e+I+G4 & L213 & $\mathrm{K} 3 \mathrm{Pu}+\mathrm{F}+\mathrm{G} 4$ & L343 & $\mathrm{TIM}+\mathrm{F}+\mathrm{R} 3$ \\
\hline L85 & $\mathrm{TPM} 2 \mathrm{u}+\mathrm{F}+\mathrm{G} 4$ & L214 & $\mathrm{K} 3 \mathrm{Pu}+\mathrm{F}+\mathrm{G} 4$ & L344 & $\mathrm{HKY}+\mathrm{F}+\mathrm{G} 4$ \\
\hline L86 & $\mathrm{HKY}+\mathrm{F}+\mathrm{R} 3$ & L215 & $\mathrm{TPM} 2+\mathrm{F}+\mathrm{I}$ & L345 & $\mathrm{TIM} 2+\mathrm{F}+\mathrm{G} 4$ \\
\hline L87 & $\mathrm{K} 3 \mathrm{Pu}+\mathrm{F}+\mathrm{R} 3$ & L216 & $\mathrm{TIMe}+\mathrm{R} 2$ & L346 & $\mathrm{K} 3 \mathrm{P}+\mathrm{R} 2$ \\
\hline L88 & $\mathrm{K} 2 \mathrm{P}+\mathrm{R} 2$ & $\mathrm{~L} 217$ & $\mathrm{HKY}+\mathrm{F}+\mathrm{I}+\mathrm{G} 4$ & L347 & $\mathrm{TIM} 3+\mathrm{F}+\mathrm{G} 4$ \\
\hline L89 & $\mathrm{K} 2 \mathrm{P}+\mathrm{I}$ & L218 & $\mathrm{TPM} 3 \mathrm{u}+\mathrm{F}+\mathrm{R} 3$ & L348 & $\mathrm{TPM} 3 \mathrm{u}+\mathrm{F}+\mathrm{R} 2$ \\
\hline L90 & $\mathrm{TN}+\mathrm{F}+\mathrm{R} 2$ & L219 & $\mathrm{GTR}+\mathrm{F}+\mathrm{I}+\mathrm{G} 4$ & L349 & $\mathrm{K} 3 \mathrm{Pu}+\mathrm{F}+\mathrm{R} 2$ \\
\hline L91 & $\mathrm{TIM} 2+\mathrm{F}+\mathrm{R} 3$ & L220 & $\mathrm{TVM}+\mathrm{F}+\mathrm{R} 2$ & L350 & $\mathrm{TIM}+\mathrm{F}+\mathrm{R} 3$ \\
\hline L92 & $\mathrm{TN}+\mathrm{F}+\mathrm{R} 2$ & $\mathrm{~L} 221$ & $\mathrm{TIMe}+\mathrm{I}+\mathrm{G} 4$ & L351 & $\mathrm{K} 2 \mathrm{P}+\mathrm{G} 4$ \\
\hline L93 & $\mathrm{TN}+\mathrm{F}+\mathrm{R} 3$ & L222 & $\mathrm{GTR}+\mathrm{F}+\mathrm{G} 4$ & L352 & $\mathrm{TPM} 2+\mathrm{F}+\mathrm{G} 4$ \\
\hline L94 & $\mathrm{TN}+\mathrm{F}+\mathrm{G} 4$ & L223 & $\mathrm{K} 3 \mathrm{P}+\mathrm{R} 3$ & L353 & $\mathrm{K} 3 \mathrm{Pu}+\mathrm{F}+\mathrm{R} 3$ \\
\hline L95 & $\mathrm{HKY}+\mathrm{F}+\mathrm{R} 2$ & $\mathrm{~L} 224$ & $\mathrm{~K} 2 \mathrm{P}+\mathrm{R} 3$ & L354 & $\mathrm{TPM} 2 \mathrm{u}+\mathrm{F}+\mathrm{R} 3$ \\
\hline L96 & $\mathrm{K} 2 \mathrm{P}+\mathrm{G} 4$ & $\mathrm{~L} 225$ & $\mathrm{TNe}+\mathrm{G} 4$ & L355 & $\mathrm{HKY}+\mathrm{F}+\mathrm{R} 3$ \\
\hline L97 & $\mathrm{HKY}+\mathrm{F}+\mathrm{R} 2$ & L226 & $\mathrm{K} 2 \mathrm{P}+\mathrm{R} 3$ & L356 & $\mathrm{TIM}+\mathrm{F}+\mathrm{R} 2$ \\
\hline L98 & $\mathrm{K} 2 \mathrm{P}+\mathrm{G} 4$ & $\mathrm{~L} 227$ & $\mathrm{~K} 3 \mathrm{P}+\mathrm{R} 3$ & L357 & $\mathrm{HKY}+\mathrm{F}+\mathrm{G} 4$ \\
\hline L99 & $\mathrm{TIM}+\mathrm{F}+\mathrm{G} 4$ & L228 & $\mathrm{TIM}+\mathrm{F}+\mathrm{G} 4$ & L358 & $\mathrm{HKY}+\mathrm{F}+\mathrm{G} 4$ \\
\hline L100 & $\mathrm{TN}+\mathrm{F}+\mathrm{R} 2$ & L229 & $\mathrm{TPM} 3 \mathrm{u}+\mathrm{F}+\mathrm{R} 3$ & L359 & $\mathrm{K} 3 \mathrm{P}+\mathrm{R} 3$ \\
\hline L101 & $\mathrm{HKY}+\mathrm{F}+\mathrm{R} 3$ & L230 & $\mathrm{TIM}+\mathrm{F}+\mathrm{R} 3$ & L360 & $\mathrm{TIM}+\mathrm{F}+\mathrm{R} 3$ \\
\hline L102 & $\mathrm{K} 2 \mathrm{P}+\mathrm{I}+\mathrm{G} 4$ & L231 & $\mathrm{K} 3 \mathrm{Pu}+\mathrm{F}+\mathrm{R} 3$ & L361 & $\mathrm{HKY}+\mathrm{F}+\mathrm{G} 4$ \\
\hline L103 & $\mathrm{K} 3 \mathrm{P}+\mathrm{R} 2$ & L232 & $\mathrm{TIM}+\mathrm{F}+\mathrm{G} 4$ & L362 & $\mathrm{TPM} 3 \mathrm{u}+\mathrm{F}+\mathrm{R} 2$ \\
\hline L104 & $\mathrm{TPM} 2 \mathrm{u}+\mathrm{F}+\mathrm{R} 3$ & L233 & $\mathrm{HKY}+\mathrm{F}+\mathrm{I}$ & L363 & $\mathrm{TIM}+\mathrm{F}+\mathrm{R} 3$ \\
\hline L105 & $\mathrm{HKY}+\mathrm{F}+\mathrm{R} 3$ & $\mathrm{~L} 234$ & $\mathrm{~K} 2 \mathrm{P}+\mathrm{G} 4$ & L364 & $\mathrm{K} 3 \mathrm{P}+\mathrm{G} 4$ \\
\hline L106 & $\mathrm{HKY}+\mathrm{F}+\mathrm{R} 3$ & L235 & $\mathrm{K} 2 \mathrm{P}+\mathrm{I}$ & L365 & $\mathrm{HKY}+\mathrm{F}+\mathrm{R} 2$ \\
\hline L107 & $\mathrm{HKY}+\mathrm{F}+\mathrm{G} 4$ & L236 & $\mathrm{TN}+\mathrm{F}+\mathrm{G} 4$ & L366 & $\mathrm{TPM} 3+\mathrm{F}+\mathrm{G} 4$ \\
\hline L108 & $\mathrm{K} 2 \mathrm{P}+\mathrm{I}+\mathrm{G} 4$ & $\mathrm{~L} 237$ & $\mathrm{TPM} 3+\mathrm{F}+\mathrm{R} 3$ & L367 & $\mathrm{TN}+\mathrm{F}+\mathrm{R} 4$ \\
\hline L109 & $\mathrm{K} 2 \mathrm{P}+\mathrm{G} 4$ & L238 & $\mathrm{K} 3 \mathrm{P}+\mathrm{G} 4$ & L368 & $\mathrm{TN}+\mathrm{F}+\mathrm{G} 4$ \\
\hline L110 & $\mathrm{TIM}+\mathrm{F}+\mathrm{I}+\mathrm{G} 4$ & L239 & $\mathrm{K} 2 \mathrm{P}+\mathrm{G} 4$ & L369 & $\mathrm{HKY}+\mathrm{F}+\mathrm{R} 2$ \\
\hline L111 & $\mathrm{TN}+\mathrm{F}+\mathrm{R} 3$ & L240 & $\mathrm{TN}+\mathrm{F}+\mathrm{R} 3$ & L370 & $\mathrm{K} 3 \mathrm{Pu}+\mathrm{F}+\mathrm{R} 2$ \\
\hline
\end{tabular}


bioRxiv preprint doi: https://doi.org/10.1101/2020.02.02.931188; this version posted February 3, 2020. The copyright holder for this preprint (which was not certified by peer review) is the author/funder, who has granted bioRxiv a license to display the preprint in perpetuity. It is made available under aCC-BY-NC-ND 4.0 International license.

\begin{tabular}{lclclr}
\hline Locus & Site Model & Locus & Site Model & Locus & Site Model \\
\hline L112 & TN+F+R3 & L241 & HKY+F+G4 & L371 & K3P+R3 \\
L113 & K3Pu+F+G4 & L242 & HKY+F+G4 & L372 & K3Pu+F+G4 \\
L114 & HKY+F+G4 & L243 & TPM2u+F+R2 & L373 & K2P+G4 \\
L115 & HKY+F+G4 & L244 & HKY+F+G4 & L374 & HKY+F+G4 \\
L116 & K3Pu+F+G4 & L245 & K3Pu+F+G4 & L375 & HKY+F+R2 \\
L117 & HKY+F+R3 & L246 & HKY+F+G4 & L376 & HKY+F+R3 \\
L118 & HKY+F+R3 & L247 & HKY+F+G4 & L377 & K3Pu+F+G4 \\
L119 & TN+F+R3 & L248 & TPM3+F+G4 & L378 & HKY+F+G4 \\
L120 & TN+F+R3 & L249 & TN+F+R3 & L379 & HKY+F+G4 \\
L121 & HKY+F+G4 & L250 & TNe+R2 & L380 & HKY+F+R3 \\
L122 & HKY+F+G4 & L251 & K2P+G4 & L381 & K2P+R3 \\
L123 & K3Pu+F+G4 & L252 & K3P+G4 & L382 & TNe+R3 \\
L124 & HKY+F+R2 & L253 & TIMe+G4 & L383 & HKY+F+R3 \\
L125 & K3Pu+F+R3 & L254 & K2P+G4 & L384 & TPM2u+F+R3 \\
L126 & TVM+F+G4 & L255 & HKY+F+G4 & L385 & TN+F+G4 \\
L127 & TVMe+R2 & L256 & HKY+F+R2 & L386 & K3Pu+F+I \\
L128 & K2P+G4 & L257 & TVMe+R3 & L387 & HKY+F+R2 \\
L129 & TPM2u+F+R3 & L258 & SYM+R3 & L388 & TIM+F+R3 \\
L130 & HKY+F+G4 & L259 & TNe+R3 & L389 & TN+F+R2 \\
& & & & L390 & HKY+F+I+G4 \\
\hline
\end{tabular}




\section{Disruptive Morphological Samples}

We removed several morphological samples because of disruptive RogueNaRok scores in our preliminary analyses. Those taxa and their respective improvement values are listed below. Additional fossil taxa (V. mytilini, V. marathonensis, V. hooijeri, V. cf. bengalensis) were removed from the alignments before running combined evidence analyses becasue of their highly fragmentary and unstable phylogenetic nature.

Table S3. RogueNaRok scores for disruptive samples, which were ultimately pruned from final dating analyses.

\begin{tabular}{lrc}
\hline taxon & rawImprovement & RBIC \\
\hline Paravaranus angustifrons & 0.441300 & 0.852011 \\
Palaeosaniwa & 0.505000 & 0.811362 \\
Varanus rusingensis & 0.512000 & 0.836463 \\
Varanus dumerilii & 0.672919 & 0.895830 \\
\hline
\end{tabular}




\section{Simulation Exercise}

Table S4. We simulated traits onto our empirical trees under the parameters below.

\begin{tabular}{lll}
\hline Model & $\sigma$ & $\alpha$ \\
\hline Brownian Motion & $0.003,0.03,0.3$ & 0 \\
Ornstein-Uhlenbeck & 0.3 & $0.03,0.06,0.12$ \\
\hline
\end{tabular}

\begin{tabular}{llllllll}
\hline Model & $m_{0}$ & $v_{0}$ & $d_{1}$ & $d_{2}$ & $\sigma$ & $S_{1}$ & $S_{2}$ \\
\hline CoEvo & 0 & 0 & -0.01 & 0.01 & 0.3 & $-0.001,-0.01,-0.1,-1$ & - \\
CoEvoall & 0 & 0 & -0.01 & 0.01 & 0.3 & $-0.001,-0.01,-0.1,-1$ & - \\
CoPM $_{\text {geo }}$ & 0 & 0 & -0.01 & 0.01 & 0.3 & $-0.001,-0.01,-0.1,-1$ & - \\
JointPM $_{\text {geo }}$ & 0 & 0 & -0.01 & 0.01 & 0.3 & $-0.001,-0.01,-0.1,-1$ & $-0.005,-0.05,-0.5,-5$ \\
CoEvo $_{\text {split }}$ & 0 & 0 & -0.01 & 0.01 & 0.3 & $-0.001,-0.01,-0.1,-1$ & $-0.005,-0.05,-0.5,-5$ \\
\hline
\end{tabular}


bioRxiv preprint doi: https://doi.org/10.1101/2020.02.02.931188; this version posted February $3,2020$. The copyright holder for this preprint

(which was not certified by peer review) is the author/funder, who has granted bioRxiv a license to display the preprint in perpetuity. It is made available under aCC-BY-NC-ND 4.0 International license.

\section{Empirical Model Fitting}

Table S5. Model fitting results to accompany Figure 4.

\begin{tabular}{lclcccr}
\hline Model & logLik & Param. & AIC & AICc & deltaAICc & AICcWt \\
\hline CoPM $_{\text {geo }}$ & -23.90383 & 6 & 59.80767 & 60.78441 & 0.000000 & 0.484718461 \\
JointPM $_{\text {geo }}$ & -23.73944 & 7 & 61.47888 & 62.79653 & 2.012117 & 0.177240890 \\
CoEvo $_{\text {Split }}$ & -23.83223 & 7 & 61.66447 & 62.98212 & 2.197701 & 0.161534338 \\
CoEvoall & -25.49440 & 6 & 62.98880 & 63.96554 & 3.181127 & 0.098790805 \\
BM $_{\text {shared }}$ & -29.90901 & 3 & 65.81802 & 66.08768 & 5.303269 & 0.034190017 \\
CoEvo $_{\text {BM }_{\text {ind }}}^{-27.22316}$ & 6 & 66.44632 & 67.42307 & 6.638654 & 0.017535744 \\
OU $_{\text {shared }}$ & -29.77132 & 4 & 67.54264 & 67.99719 & 7.212771 & 0.013160008 \\
OU $_{\text {ind }}$ & -29.90844 & 4 & 67.81688 & 68.27142 & 7.487007 & 0.011473783 \\
\hline
\end{tabular}

Table S6. Model fitting results to accompany Figure S12.

\begin{tabular}{lclcccr}
\hline Model & logLik & Param. & AIC & AICc & deltaAICc & AICcWt \\
\hline CoPM $_{\text {geo }}$ & -23.90383 & 6 & 59.80767 & 60.78441 & 0.0000000 & 0.2750436948 \\
CoPM & -24.00661 & 6 & 60.01322 & 60.98997 & 0.2055527 & 0.2481798347 \\
JointPM $_{\text {geo }}$ & -23.73944 & 7 & 61.47888 & 62.79653 & 2.0121169 & 0.1005717613 \\
JointPM $_{\text {CoEvosplit }}$ & -23.81588 & 7 & 61.63177 & 62.94942 & 2.1650026 & 0.0931702707 \\
GMM $_{\text {all }}$ & -23.83223 & 7 & 61.66447 & 62.98212 & 2.1977010 & 0.0916593953 \\
CoEvoall $_{\text {GMM }}$ & -25.49440 & 6 & 62.98880 & 63.96554 & 3.1811274 & 0.0560568457 \\
BM $_{\text {shared }}$ & -26.43762 & 6 & 64.87524 & 65.85199 & 5.0675740 & 0.0218268965 \\
CoEvo & -29.90901 & 3 & 65.81802 & 66.08768 & 5.3032690 & 0.0194004344 \\
BM $_{\text {ind }}$ & -27.22316 & 6 & 66.44632 & 67.42307 & 6.6386539 & 0.0099503035 \\
OU $_{\text {shared }}$ & -29.77132 & 4 & 67.54264 & 67.99719 & 7.2127713 & 0.0074673808 \\
OU $_{\text {ind }}$ & -29.78290 & 6 & 71.56580 & 72.54254 & 11.758126 & 0.0007694085 \\
\hline
\end{tabular}

Table S7. Model fitting results for Varanus only analyses. The PMOU geo model is identical to the $\mathrm{PM}_{\text {geo }}$ model, but without the alpha/psi parameter of the OU process, meaning traits are not constrained to evolve around a single optimum value.

\begin{tabular}{lclcllr}
\hline Model & logLik & Param. & AIC & AICc & deltaAICc & AICcWt \\
\hline PMOU $_{\text {geo }}$ & -6.503810 & 4 & 21.00762 & 22.54608 & 0.000000 & 0.67565891 \\
BM & -7.963686 & 4 & 23.92737 & 25.46583 & 2.919753 & 0.15693186 \\
OU & -7.367979 & 5 & 24.73596 & 27.13596 & 4.589877 & 0.06808452 \\
PM $_{\text {geo }}$ & -5.955623 & 6 & 23.91125 & 27.41125 & 4.865166 & 0.05932944 \\
OUM $^{-6.349967}$ & 6 & 24.69993 & 28.19993 & 5.653854 & 0.03999527 \\
\hline
\end{tabular}


Table S8. Node and tip prior information. Bolded clades indicate priors which were constrained to be monophyletic. In our taxon sampling: Lepidosauria represents the root (all taxa-Rhynchocephalians + Squamata); Anguimorpha comprises all taxa to the exclusion of Sphenodon and Plestiodon; Neoanguimorpha comprises Heloderma, Xenosaurus, and Elgaria; Saniwa ensidens represents the split between Lanthanotus and Varanus; and Varanus rusingensis is the oldest discernible crown Varanus. An alternative node calibration for the crown of extant monitor lizards, the "Jebel Qatrani" Varanus (Holmes et al. 2010), is included here, but used only to illustrate the influence of such a calibration (Fig.S4).

\begin{tabular}{|c|c|c|c|c|}
\hline Fossil Taxon & Min.Age & Max.Age & Clade & Calibration \\
\hline Vellberg Jaw & 238 & - & Lepidosauria & Exp.; $M=10$, Off $=238$ \\
\hline Dalinghosaurus & 113 & - & Anguimorpha & $\log ; M=2, S=1$, Off $=113$ \\
\hline Primaderma & 98 & - & Neoanguimorph & Exp.; $\mathrm{M}=4, \mathrm{Off}=98$ \\
\hline Saniwa ensidens & 48 & - & Lanthanotus + Varanus & Gamma; $\mathrm{A}=2, \mathrm{~B}=8, \mathrm{Off}=45$ \\
\hline Varanus rusingensis & 16 & - & Crown Varanus & Gamma; $\mathrm{A}=2, \mathrm{~B}=8, \mathrm{Off}=16$ \\
\hline Varanus komodoensis & 3.6 & - & $V$. komodoensis $+V$. varius & Exp.; $M=1$, Off $=3.6$ \\
\hline Jebel Qatrani Varanus & 30 & - & Crown Varanus & Gamma; $\mathrm{A}=2, \mathrm{~B}=8, \mathrm{Off}=30$ \\
\hline$\cdots$ & $\cdots$ & $\cdots$ & $\cdots$ & $\ldots$ \\
\hline Aiolosaurus oriens & 70.6 & 84.9 & tip & Uniform; $\min -\max$ \\
\hline Cherminotus longifrons & 70.6 & 84.9 & tip & Uniform; $\min -\max$ \\
\hline Ovoo gurvel & 70.6 & 84.9 & tip & Uniform; min-max \\
\hline Palaeovaranus cayluxi & 33.9 & 37.2 & tip & Uniform; $\min -\max$ \\
\hline Palaeovaranus giganteus & 33.9 & 48.6 & tip & Uniform; $\min -\max$ \\
\hline Saniwa ensidens & 50.3 & 48.8 & tip & Uniform; $\min -\max$ \\
\hline 'Saniwa' feisti & 40.4 & 48.6 & tip & Uniform; min-max \\
\hline Saniwides mongoliensis & 70.6 & 84.9 & tip & Uniform; min-max \\
\hline Telmasaurus grangeri & 70.6 & 84.9 & tip & Uniform; min-max \\
\hline Varanus priscus & 0.012 & 0.126 & tip & Uniform; $\min -\max$ \\
\hline
\end{tabular}




\section{Node Priors and Varanus in the Fossil Record}

Monitor lizards and their relatives are not rare in the fossil record, however the phylogenetic affinities of fossil taxa have been difficult to resolve. This is perhaps best captured by Ralph Molnar in his chapter titled The Long and Honorable History of Monitors and their Kin (Molnar 2004):

"Although some of the Cretaceous monitors, particularly those from Mongolia, are known from nice skulls, words like 'fragmentary' and 'frustrating' involuntarily spring to mind when considering the fossil record of varanids, particularly of Varanus itself."

There is a relatively large resource of fossil Varanus material. Many of these fossils have been identified in the literature, however comparatively few have been assigned to living or extinct species, and even fewer have been scored and included in phylogenetic analyses. This makes the inclusion of this fossil information difficult. We quickly discuss how some known and other rumored fossils could potentially be used to date the diversification of monitor lizards, but admit this is nowhere near a complete library of fossil varanids and defer to Molnar's Molnar (2004) publication for a more thorough discussion of fossil Varanus.

To calibrate our phylogeny, we used a combination of node and tip priors to incorporate fossil taxa that were directly sampled (tips) in morphological data or indirectly sampled (nodes) using estimated fossil ages. Previous studies of monitor lizards have used varied calibration schemes to estimate divergence times. The most influential of these has been the application of a hard minimum prior on the crown age of Varanus (Vidal et al. 2012; Portik and Papenfuss 2012). This minimum bound is either attributed to the age of the 'Jebel Qatrani Varanus' (Holmes et al. 2010), or the 'Yale Quarry Varanus' (Smith et al. 2008). However, based on preliminary assessment (Smith et al. 2008), and more extensive morphological analyses of monitors and their kin (Conrad et al. 2012; Ivanov et al. 2017), these fragmentary fossils are not recovered within the crown of Varanus and are more likely stem varanids, suggesting that they should not be used to constrain the minimum age of extant Varanus.

In Australia, Stirton (1961) mentioned varanid material from the Etadunna formation, however this material was misattributed, and appears to actually have been a snake (Estes 1984). Estes (1984) further went on to briefly discuss the existence of Varanus fossil material from the Mid Miocene Lake Ngapakaldi area, though these vertebrae have not since been described. The same goes for Oligo-Miocene material mentioned by Scanlon (2014), which comes from the Hiatus and White Hunter sites of Riversleigh World Heritage Area (Scanlon 2014). Interestingly, the Riversleigh material contains "the occasional isolated tooth, jaw element, or limb or girdle bone" in addition to the more common vertebrae. Hiatus and White Hunter sites have been dated via biocorrelation (15-25 ma), but could not be radiometrically dated (Woodhead et al. 2016). Also mentioned by Scanlon (2014) are Miocene fossils from Bullock Creek and Alcoota, which are roughly 11-16 ma and 5-12 ma respectively (Murray \& Megirian, 1992), but have not been described, evaluated, or scored. Many of these fossils would be particularly valuable for dating the Australian radiation of Varanus, but again cannot be placed within the crown of Australian Varanus (Odatria + Varanus), and so should probably only be used to provide a minimum age on the divergence between the Australian radiation and the Asian clade (Soterosaurus, Empagusia, Euprepriosuarus, Hapturosaurus, et al.).

Other more recent and perhaps applicable fossils were described by Hocknull (2009) and include a number of cranial and postcranial elements from both Varanus komodoensis and an extinct taxon from Timor. The oldest material ascribable to $V$. komodoensis are from Early Pliocene sites at Bluff Downs in northeastern Queensland, Australia. These sites have been dated using whole rock $\mathrm{K} / \mathrm{Ar}$ (potassium-argon) methods of the overlaying basalt layer to 3.6 million years old. Using this informationw we can set a minimum prior on the divergence between $V$. komodoensis and its closest 
bioRxiv preprint doi: https://doi.org/10.1101/2020.02.02.931188; this version posted February 3, 2020. The copyright holder for this preprint (which was not certified by peer review) is the author/funder, who has granted bioRxiv a license to display the preprint in perpetuity. It is made available under aCC-BY-NC-ND 4.0 International license.

855 living relative $V$. varius of 3.6 ma. We outline the remaining node calibrations we applied in our analyses in Table S8. 
Table S9. Standard effect sizes across Australian Varanus communities of varying richness.

\begin{tabular}{lllllll}
\hline CI Lower & CI Upper & Error & Mean & SD & N & Richness \\
\hline 0.01765771 & 0.12753556 & 0.05493893 & 0.07259663 & 0.9740691 & 1210 & $2-11$ (all) \\
-0.25265258 & -0.08109514 & 0.08577872 & -0.1668738 & 1.0689687 & 599 & 2 \\
0.15781727 & 0.36964206 & 0.10591239 & 0.26372966 & 0.8588049 & 255 & 3 \\
0.24372979 & 0.49436858 & 0.12531940 & 0.36904918 & 0.8026238 & 160 & 4 \\
0.22269865 & 0.48620457 & 0.13175296 & 0.35445161 & 0.5996291 & 82 & 5 \\
0.19333878 & 0.71750885 & 0.26208504 & 0.45542381 & 0.9877488 & 57 & 6 \\
-0.00146655 & 0.53272406 & 0.26709530 & 0.26562875 & 0.6612764 & 26 & 7 \\
-0.13678194 & 0.37627128 & 0.25652661 & 0.11974467 & 0.4442921 & 14 & 8 \\
-0.28734231 & 0.21086400 & 0.24910315 & -0.0382391 & 0.3482222 & 10 & 9 \\
-0.97490634 & 0.32296756 & 0.64893695 & -0.3259693 & 0.5226349 & 5 & 10 \\
-1.65996651 & 1.56567795 & 1.61282223 & -0.0471442 & 0.1795088 & 2 & 11 \\
& & & & & & \\
\hline
\end{tabular}

Table S10.

\begin{tabular}{lllllll}
\hline CI Lower & CI Upper & Error & Mean & SD & N & Richness \\
\hline-0.5327245 & -0.44379796 & 0.04446327 & -0.4882612 & 30.9785372 & 1863 & $2-17$ (all) \\
-0.9799777 & -0.70273700 & 0.13862037 & -0.8413573 & 71.3797493 & 383 & 2 \\
-0.6111262 & -0.39385028 & 0.10863795 & -0.5024882 & 21.0244188 & 344 & 3 \\
-0.4704297 & -0.27335183 & 0.09853892 & -0.3718907 & 40.8643596 & 298 & 4 \\
-0.3990601 & -0.20963823 & 0.09471094 & -0.3043491 & 70.7557160 & 247 & 5 \\
-0.5503313 & -0.34245597 & 0.10393767 & -0.4463936 & 40.7145822 & 184 & 6 \\
-0.4627334 & -0.23970379 & 0.11151482 & -0.3512186 & 00.6324771 & 126 & 7 \\
-0.4751302 & -0.14600575 & 0.16456224 & -0.3105680 & 00.7250327 & 77 & 8 \\
-0.4569476 & -0.17121931 & 0.14286415 & -0.3140834 & 60.5625626 & 62 & 9 \\
-0.5162656 & -0.14677388 & 0.18474588 & -0.3315197 & 60.6568637 & 51 & 10 \\
-0.7607036 & -0.25664101 & 0.25203131 & -0.5086723 & 20.7107791 & 33 & 11 \\
-0.9809260 & -0.43973639 & 0.27059482 & -0.7103312 & 00.6408206 & 24 & 12 \\
-0.4821964 & 0.07296914 & 0.27758279 & -0.2046136 & 50.5398841 & 17 & 13 \\
-1.1456556 & 0.44100276 & 0.79332918 & -0.3523264 & 20.7559579 & 6 & 14 \\
-0.9684752 & 0.20328734 & 0.58588127 & -0.3825939 & 20.6334908 & 7 & 15 \\
NA & NA & NA & 0.45452696 & NA & 1 & 16 \\
-1.7472785 & 1.61220378 & 1.67974112 & -0.0675373 & 50.6761868 & 3 & 17 \\
\hline
\end{tabular}




\section{Nested Models}

We can show that some of the proposed models are nested. We start by simulating data under the simplest intraclade interaction model $\mathrm{CoPM}_{\text {geo }}$.

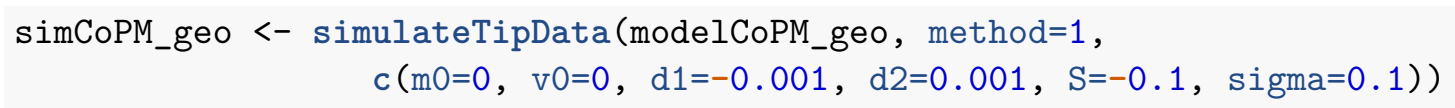

We can then fit the $\mathrm{JointPM}_{\text {geo }}$, CoPM $\mathrm{Meo}_{\text {g }}$ and $\mathrm{CoEvo}_{\text {split }}$ models, using the getDataLikelihood function, keeping all other parameters the same.

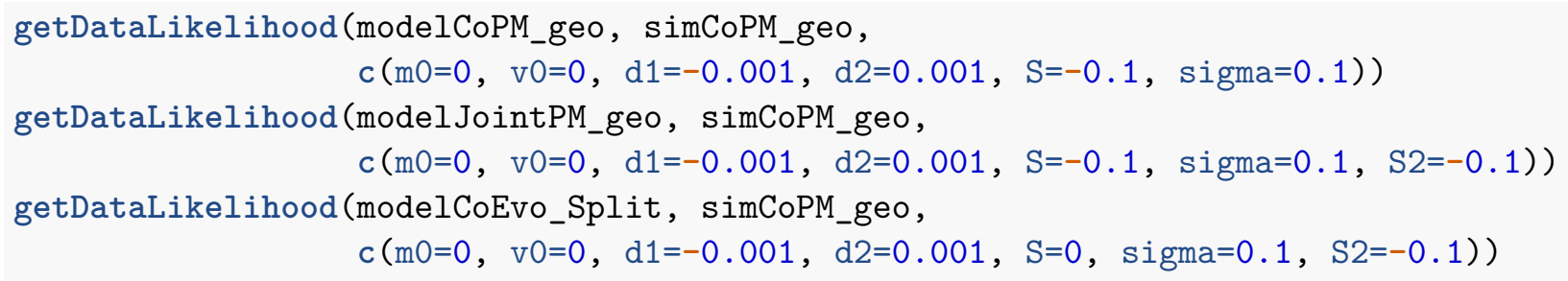

These result in near identical log-likelihood values, showing that the JointPMgeo and $\mathrm{CoEvo}_{\text {split }}$ models collapse into the CoPM geo model when $S_{1}=S_{2}$, and when $S_{1}=0$, respectively.

We can further show that the CoEvo and $\mathrm{CoEvo}_{\text {all }}$ models are special cases of the $\mathrm{CoEvo}_{\text {split }}$ model.

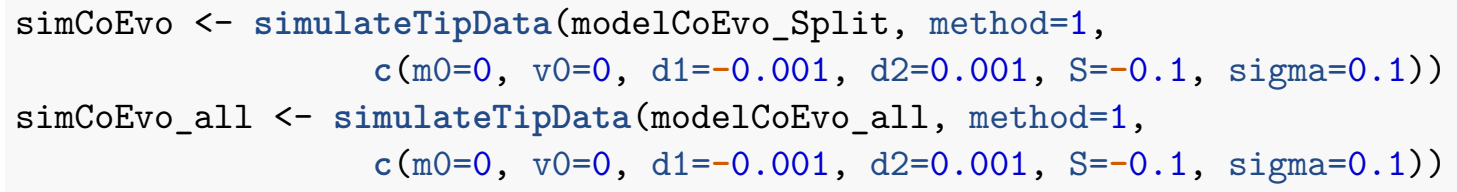

We then estimate the likelihood for CoEvo and $\mathrm{CoEvo}_{\text {split }}$ models to the first dataset, and CoEvoall and $\mathrm{CoEvo}_{\text {split }}$ models to the second dataset.

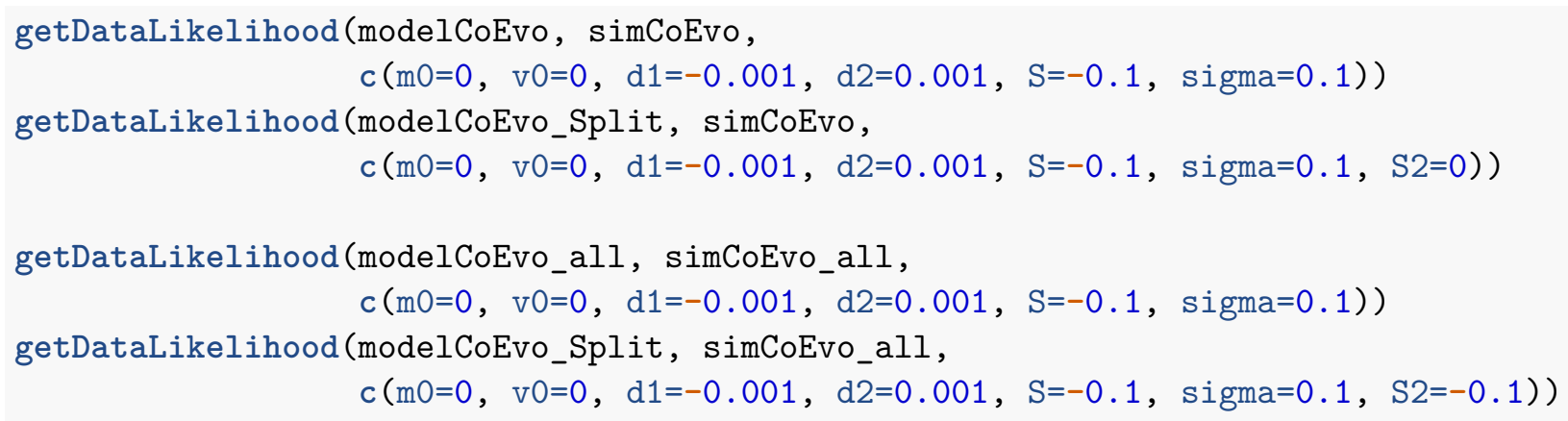


bioRxiv preprint doi: https://doi.org/10.1101/2020.02.02.931188; this version posted February 3, 2020. The copyright holder for this preprint (which was not certified by peer review) is the author/funder, who has granted bioRxiv a license to display the preprint in perpetuity. It is made available under aCC-BY-NC-ND 4.0 International license.

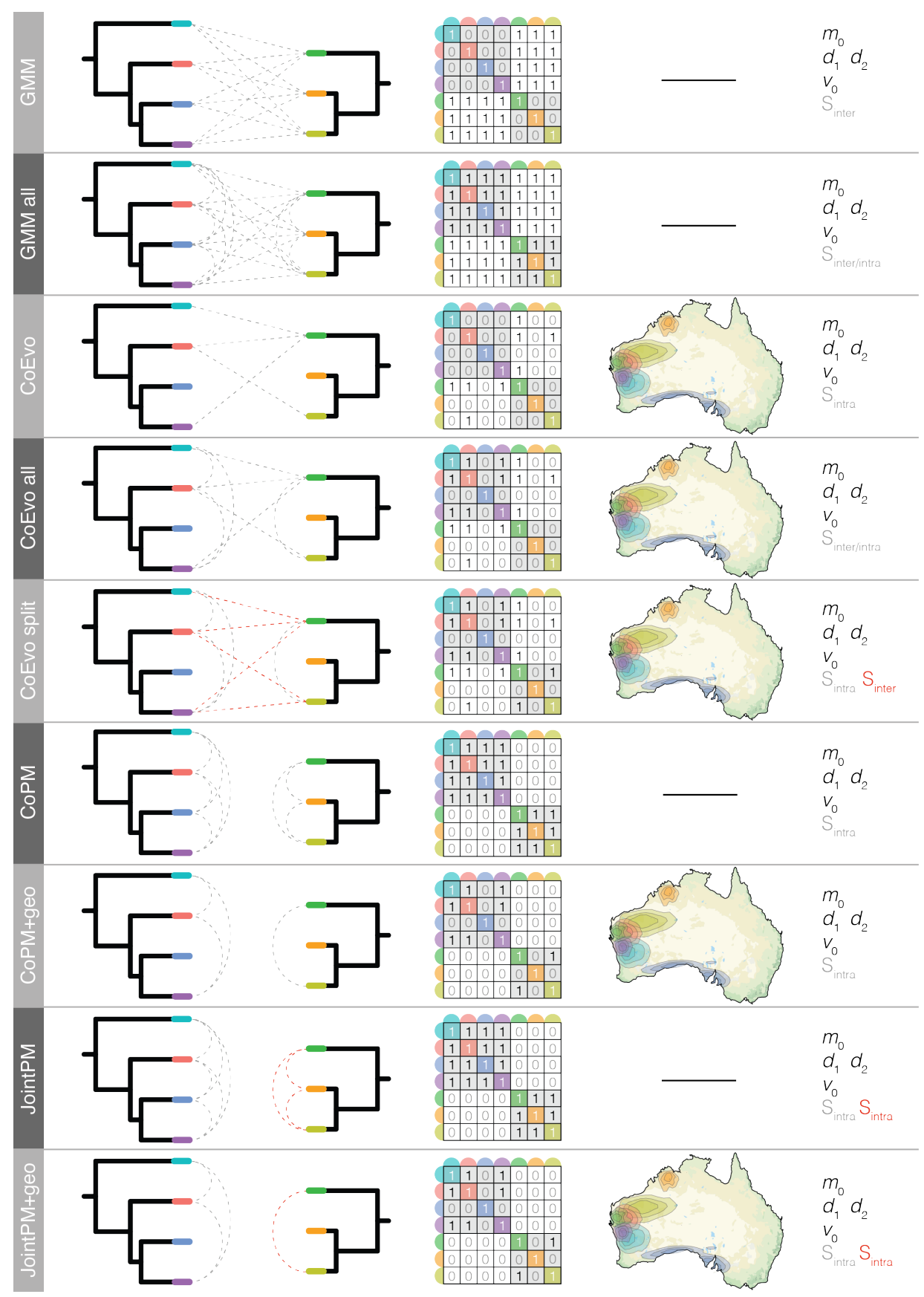

Figure S1: Schematic components of various GMM-type models of evolution including two clades. Each model name is listed at left, followed by a diagram of the two trees with interlineage interactions allowed under the given model designated by dashed grey lines. If more than one interaction parameter $S$ is estimated, it is denoted by red dashed lines. The contemporary summary of these interactions are presented in the interaction matrix $P$, and the estimated parameters are listed at the far right. If the interaction matrix is geographically informed, a map showing species ranges is shown to the right of the interaction matrix. 
bioRxiv preprint doi: https://doi.org/10.1101/2020.02.02 931188; this version posted February 3, 2020. The copyright holder for this preprint (which was not certified by peer review) is the author/funder, who has granted bioRxiv a license to display the preprint in perpetuity. It is made available under aCC-BY-NC-ND 4.0 International license.
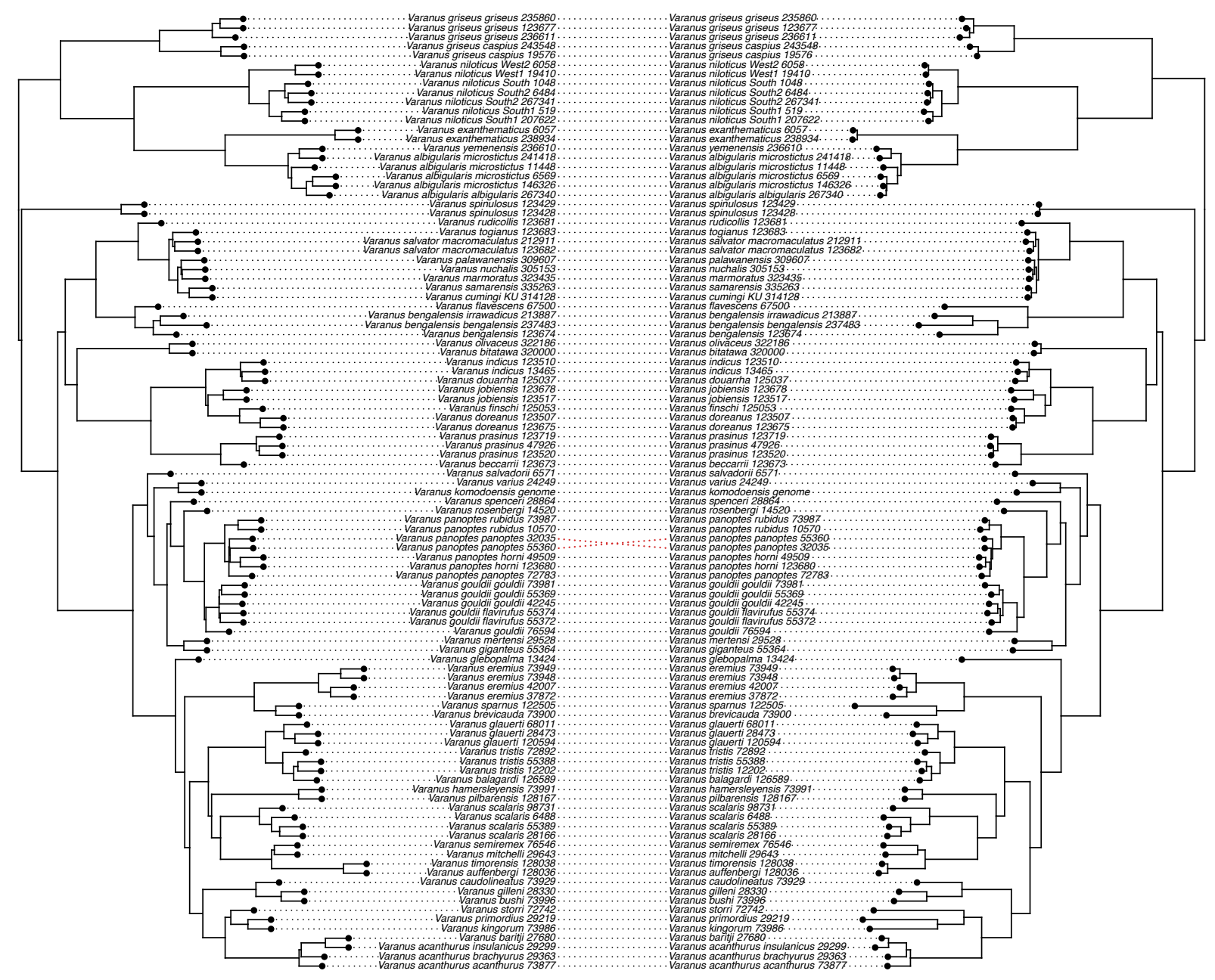

Figure S2: Phylogenetic estimates from shortcut coalescent (ASTRAL—left) Zhang et al. (2017) and partitioned maximum likelihood (IQTREE-right) Schmidt et al. (2014) analyses return nearly identical topologies. 


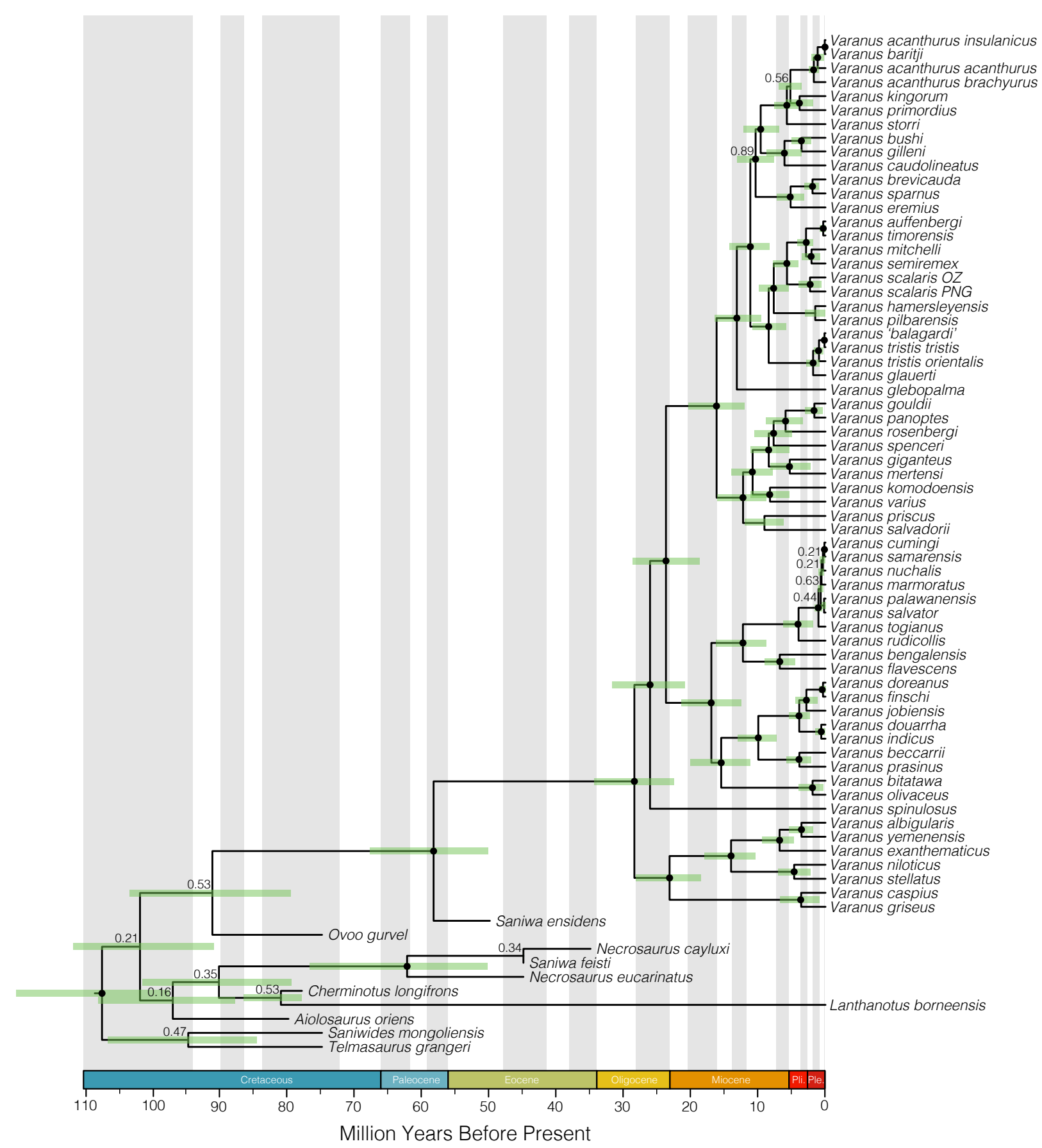

Figure S3: Relationships among living and extinct varaniform lizards and relatives, as a result of combined evidence dating (molecular and morphological data). The resolution of fossil taxa are volatile and appear highly sensitive to the fragmentary remains of many of these taxa. Varanids emerge in the late Paleocene or early Eocene, and extant Varanus appear in the Oligocene. Support values for relationships among Varanus subgenera as well as interspecific relationships are consistently high, though extinct Varanus are again difficult to place in our phylogeny. Nodes denoted by $\bullet$ are supported by posterior probabilities $>0.90$, all others are considered equivocal and labeled with posterior probabilites. 


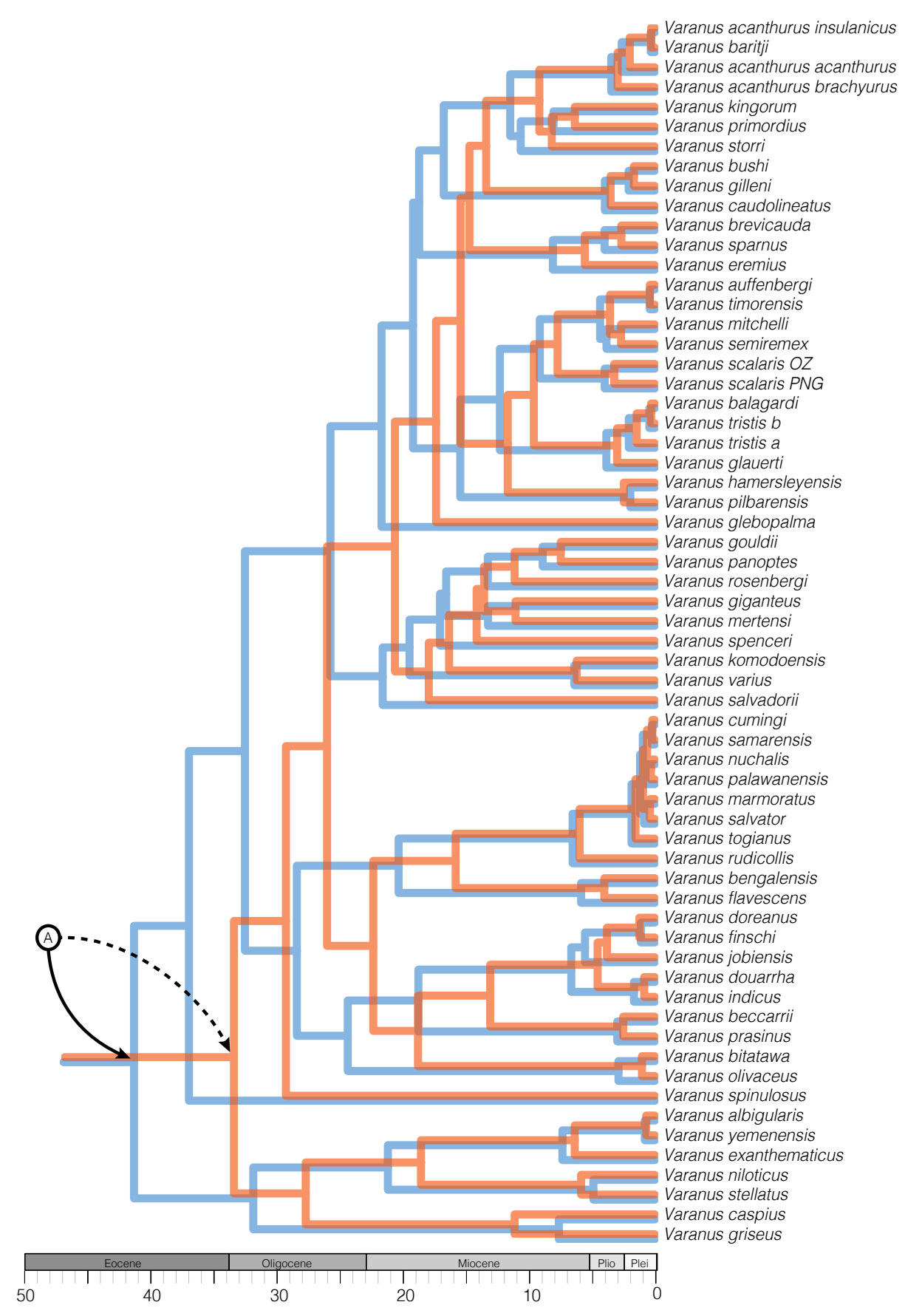

Figure S4: Varanus divergence estimates are strongly influenced by the inclusion of the 'Jebel Qatrani Varanus' (Holmes et al. 2010) as a minimum age node prior on crown Varanus. Morphological analyses have suggested that this taxon likely represents a stem varanid and incorporating this taxon as a node calibration prior inflates divergence times across the tree. The two presented trees are the result of calibrated multispecies coalescent analyses in StarBEAST2 using only extant taxa and molecular data. (A) denotes the position of the Varanus crown, the blue tree shows divergence times estimated using the 'Jebel Qatrani' fossil calibration, and the orange tree shows without. See further discussion of fossil taxa in Node Priors and Varanus in the Fossil Record in the Supplementary Material, and Table S8. 
bioRxiv preprint doi: https://doi org/10.1101/2020.02.02 931188; this version posted February 3, 2020. The copyright holder for this preprint (which was not certified by peer review) is the author/funder, who has granted bioRxiv a license to display the preprint in perpetuity. It is made available under aCC-BY-NC-ND 4.0 International license.

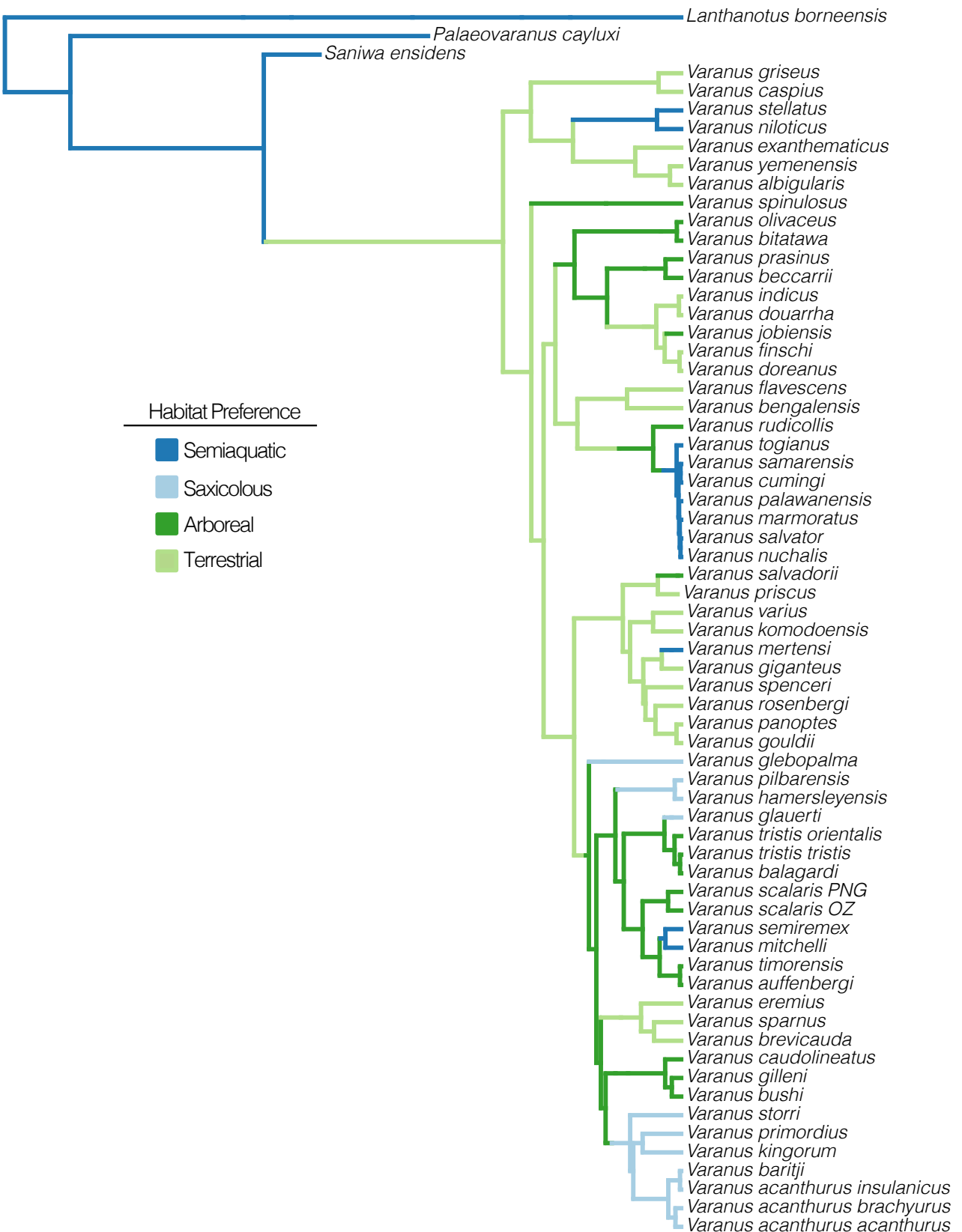

Figure S5: A single SIMMAP representation of the distribution of ecologies across Varanus lizards. 


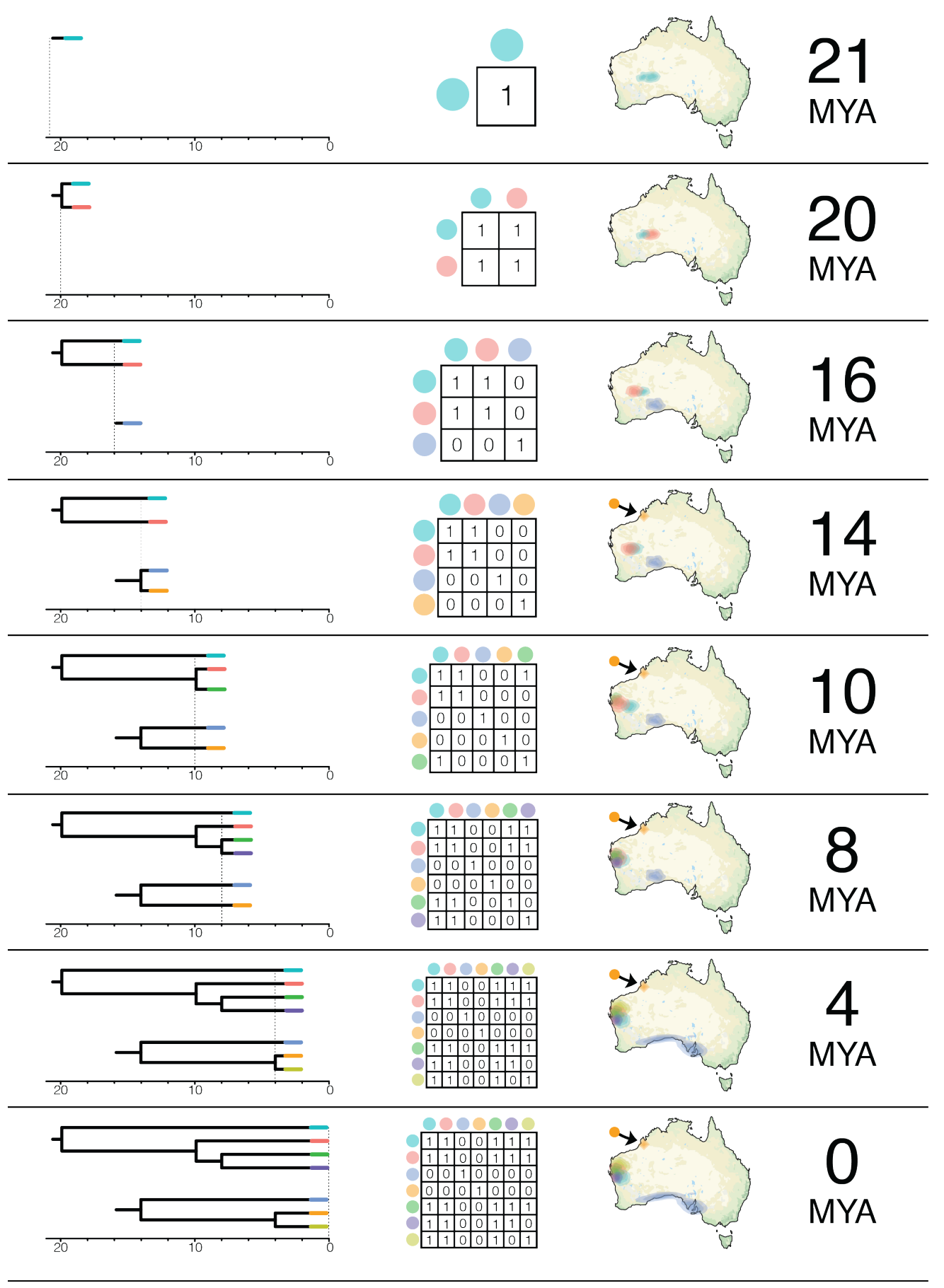

Figure S6: Diagram of the construction of interaction matrices $P$ through time in geographically-informed models, using the $\mathrm{CoEvo}_{\text {all }}$ model as an example. Ancestral ranges were estimated using rase. The process of constructing these matrices is incorporated into the function "CreateCoEvoGeoObject_SP", which takes as input the the trees, and two processed rase objects - one for each clade. 
bioRxiv preprint doi: https://doi.org/10.1101/2020 0202 931188. this version posted February 3,2020 . The copyright holder for this preprint (which was not certified by peer review) is the author/funder, who has granted bioRxiv a license to display the preprint in perpetuity. It is made available under aCC-BY-NC-ND 4.0 International license.

\section{Investigating Data Completeness and Informativeness}

Below we visualize data completeness and informativeness on a per sample and per locus basis, as well as provide some insight into our data cleaning and sample selection.

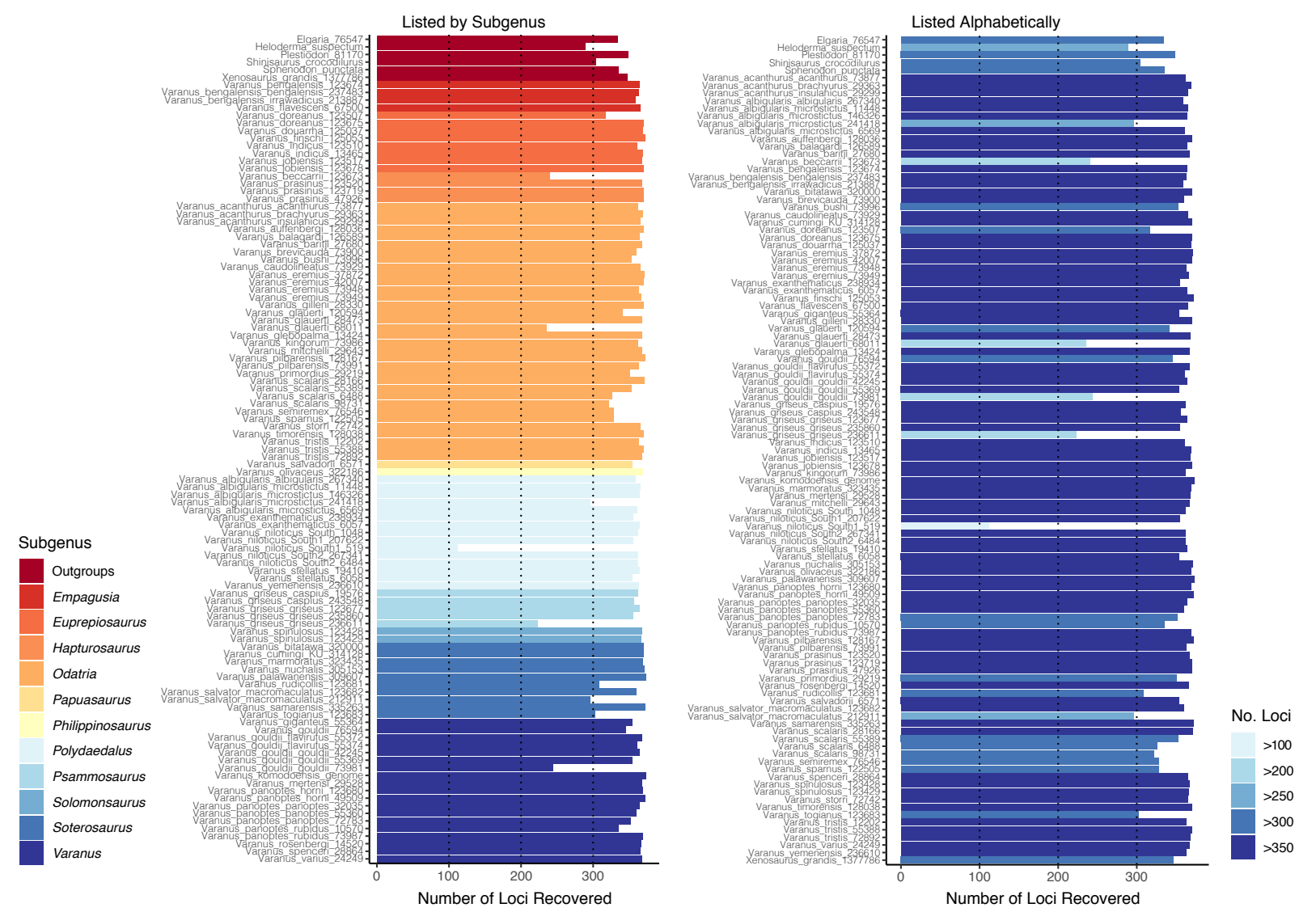

Figure S7: Number of loci recovered per sample for all Varanus and outgroup taxa included in the molecular data. Samples are ordered by subgenus (left) and alphabetically (right). 

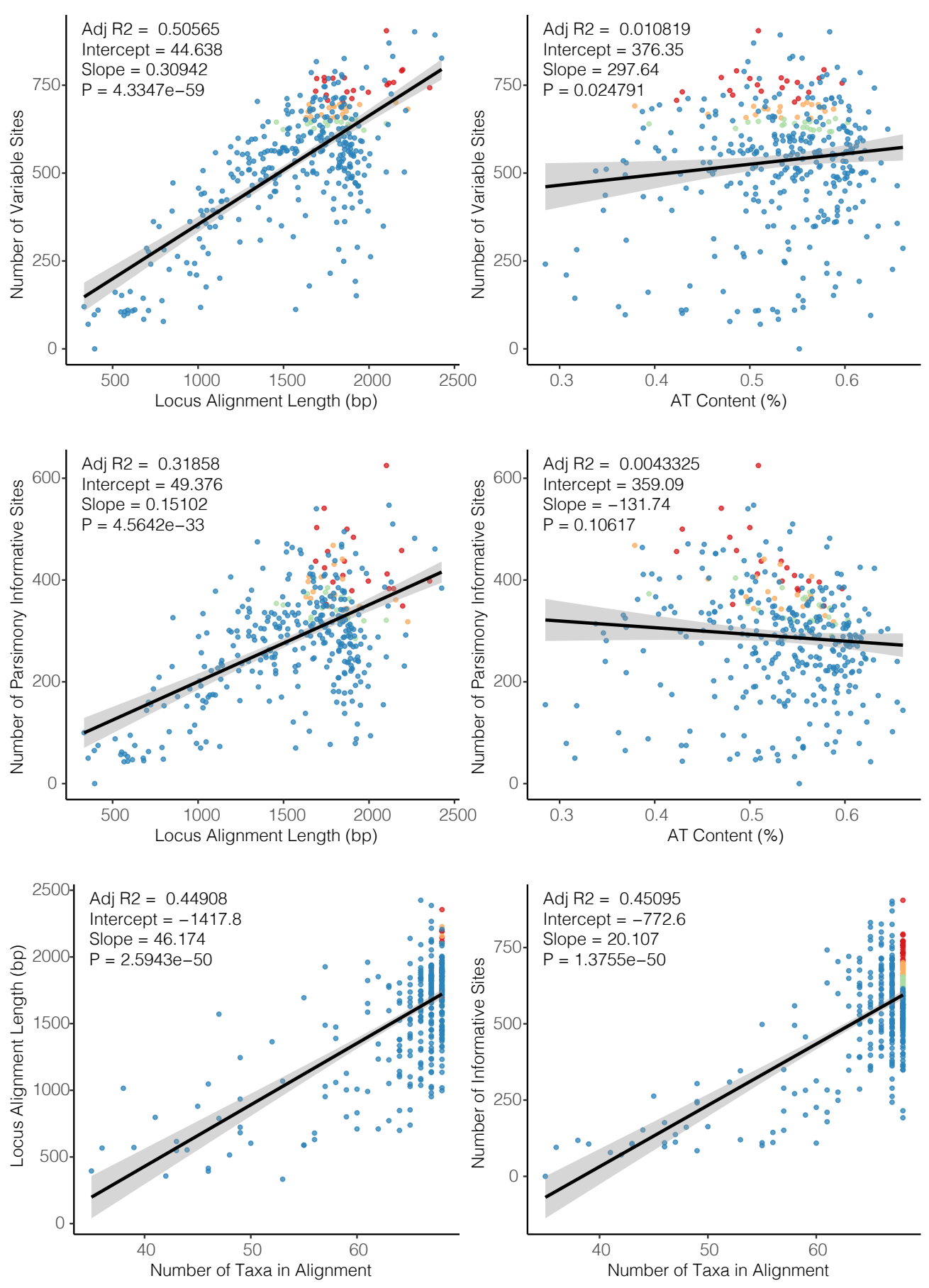

Figure S8: Plots of individual locus completeness and informativeness. For the StarBEAST2 species tree analyses, loci were ordered first by completeness (number of taxa in alignment), then by variable sites. They were then partitioned into 3 sets of twenty loci, and are color coded in these plots: 'top twenty' (1-20: red), 'second twenty' (21-40: orange), 'third twenty' (41-60: green), and all others (blue). Top row shows the number of variable sites in each alignment as a function of alignment length and AT content. The middle row shows the number of parsimony informative sites as a function of alignment length and AT content. The bottom row shows alignment length and number of variable sites as a function of completeness. 

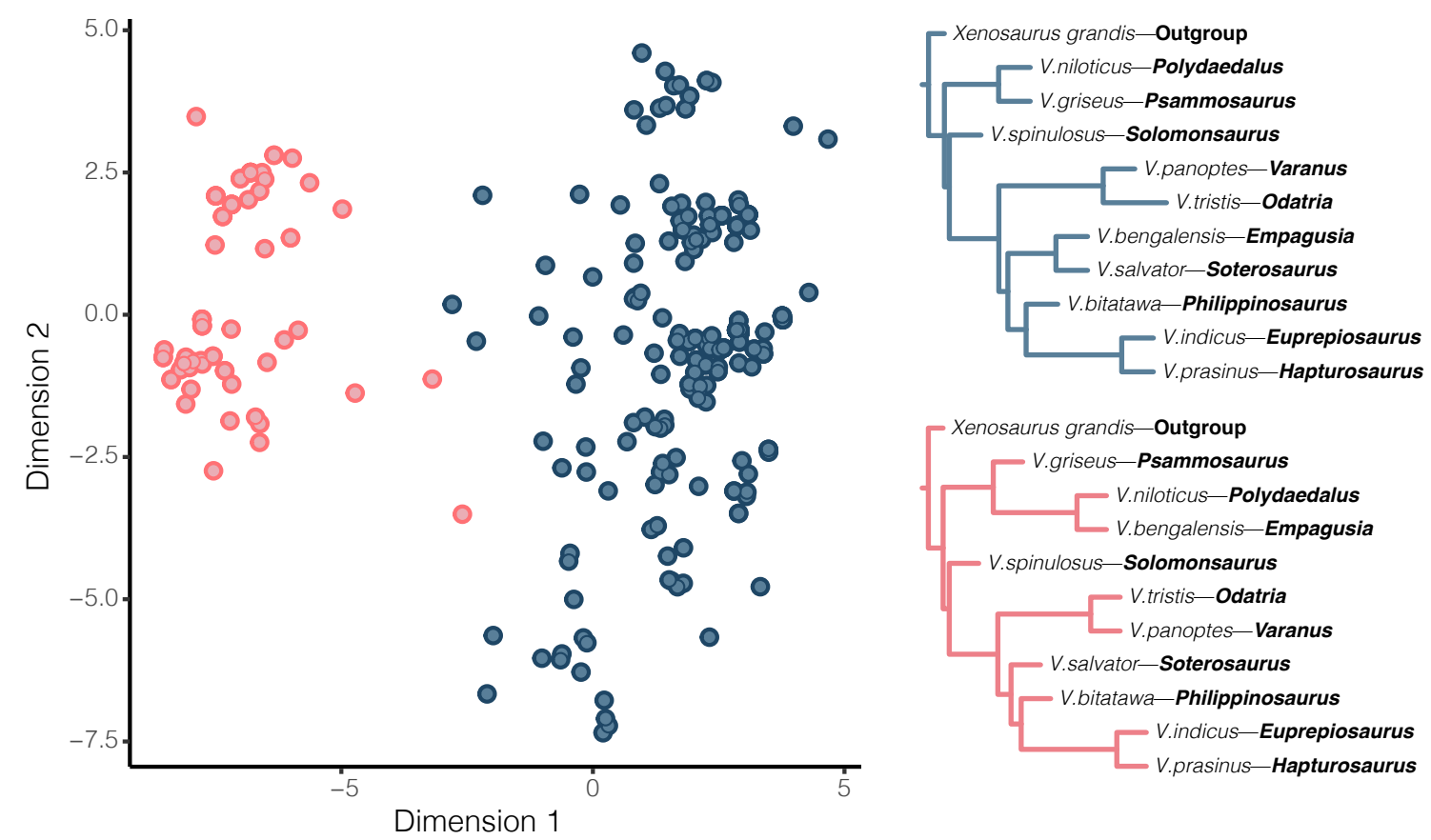

Figure S9: Two dimensional representation of multidimensional scaling (MDS) of gene tree space, colored by optimal clustering scheme $(k=2)$, and their associated topologies inferred using ASTRAL. Analysis in both two and three dimensions supported the same optimum number of clusters, and cluster compositions. Each point represents a single gene tree, colored clusters match colored trees displayed to the right. Bootstrap support of all nodes was 1 . The general topology of the clusters differ only in the placement of $V$. bengalensis - Empagusia as sister to the African group Polydaedalus, or to the Asian group Soterosaurus.

Preliminary analysis of genealogies indicated some strongly conflicting topologies between Varanus subgenera. To address gene-tree incongruence and investigate possible conflicting signals in our data, we used multidimensional scaling (MDS) to approximate the relative distances between gene tree topologies (Hillis et al. 2005), following the methodology of Duchene et al. (2018). To prepare the data, we trimmed down gene trees to a single representative of most subgenera (except Papuasaurus - V. salvadorii) as well as the outgroup Xenosaurus, and discarded loci missing any taxa, leaving us with 340 loci. We then calculated the pairwise distances between all gene trees using the Robinson-Foulds metric, in the R package APE (Paradis et al. 2004). We projected the tree distances into two and three dimensions (representing tree topology space) using MDS, as visualizing and interpreting any more dimensions becomes difficult. To test if gene trees are uniformly distributed throughout tree space, or clustered, we used the partitioning around medoids algorithm as implemented in the R package CLUSTER (Maechler et al. 2018). We chose the optimum number of clusters $(k)$, using the gap statistic, calculated for each $k=1-10$. Clusters of gene trees represent similar topologies, and so we then summarized each cluster using ASTRAL, to identify consistent differences in topology.

Multidimensional scaling (MDS) of gene-trees reveals that nuclear loci constitute two topological clusters. The larger cluster $(n=264$ loci) supports a sister relationship between Empagusia and Soterosaurus, and the smaller cluster ( $n=76$ loci) supports a sister relationship between Empagusia and Polydaedalus (Fig.S9). Looking at fully-sampled gene trees we see that these patterns are driven by a sister relationship between $V$. bengalensis and $V$. flavescens (both Empagusia) in the larger cluster, and a sister relationship between $V$. bengalensis and $V$. albigularis/V. yemenensis in the 
smaller cluster.

This mixed-ancestry sample of $V$. bengalensis is perhaps interesting with regards to the large ranges of some African/Middle Eastern and mainland Asian Varanus. Previous research has highlighted the dispersal abilities of monitor lizards and shown that at least one member of the African varanids Polydaedalus - V. yemenensis has since dispersed back across the Red Sea into the Arabian Peninsula (Portik and Papenfuss 2012). On a similar time frame, V.bengalensis appears to have dispersed west back across Asia, and the subcontinent, into the Middle East. This is relevant because the mixed phylogenetic signature (Fig.S9) between one sample of $V$. bengalensis and members of the $V$. albigularis group, to which $V$. yemenensis belongs, suggests either introgression between these taxa, or a potentially contaminated sample. It remains an exciting concept that secondary contact between distantly related Varanus could result in hybridization, perhaps facilitated by the noted chromosomal conservatism of this genus (King and King 1975). 


\section{Testing for Fossil Taxa as Sampled Ancestors}

Given that we place a prior on the age of each taxon $(\tau)$ and are jointly estimating their position among the phylogeny, including a model $(M)$ of the molecular and morphological evolution, we can sample exclusively from both the prior and posterior of our starBEAST2 analyses. We used a threshold of $\log (\mathrm{BF})>1$ to identify sampled ancestors, $\log (\mathrm{BF})<-1$ to recognize terminal taxa, and $-1<\log (\mathrm{BF})<1$ taxa were categorized as equivocal. To calculate Bayes Factors for fossil taxa as sampled ancestors:

$$
B F=\frac{P\left(H_{1} \mid D, \tau, M\right) P\left(H_{2} \mid \tau, M\right)}{P\left(H_{2} \mid D, \tau, M\right) P\left(H_{1} \mid \tau, M\right)}=\frac{P\left(\text { Posterior }_{\text {ancestor }}\right) P\left(\text { Prior }_{\text {tip }}\right)}{P\left(\text { Posterior }_{\text {tip }}\right) P\left(\text { Prior }_{\text {ancestor }}\right)}
$$

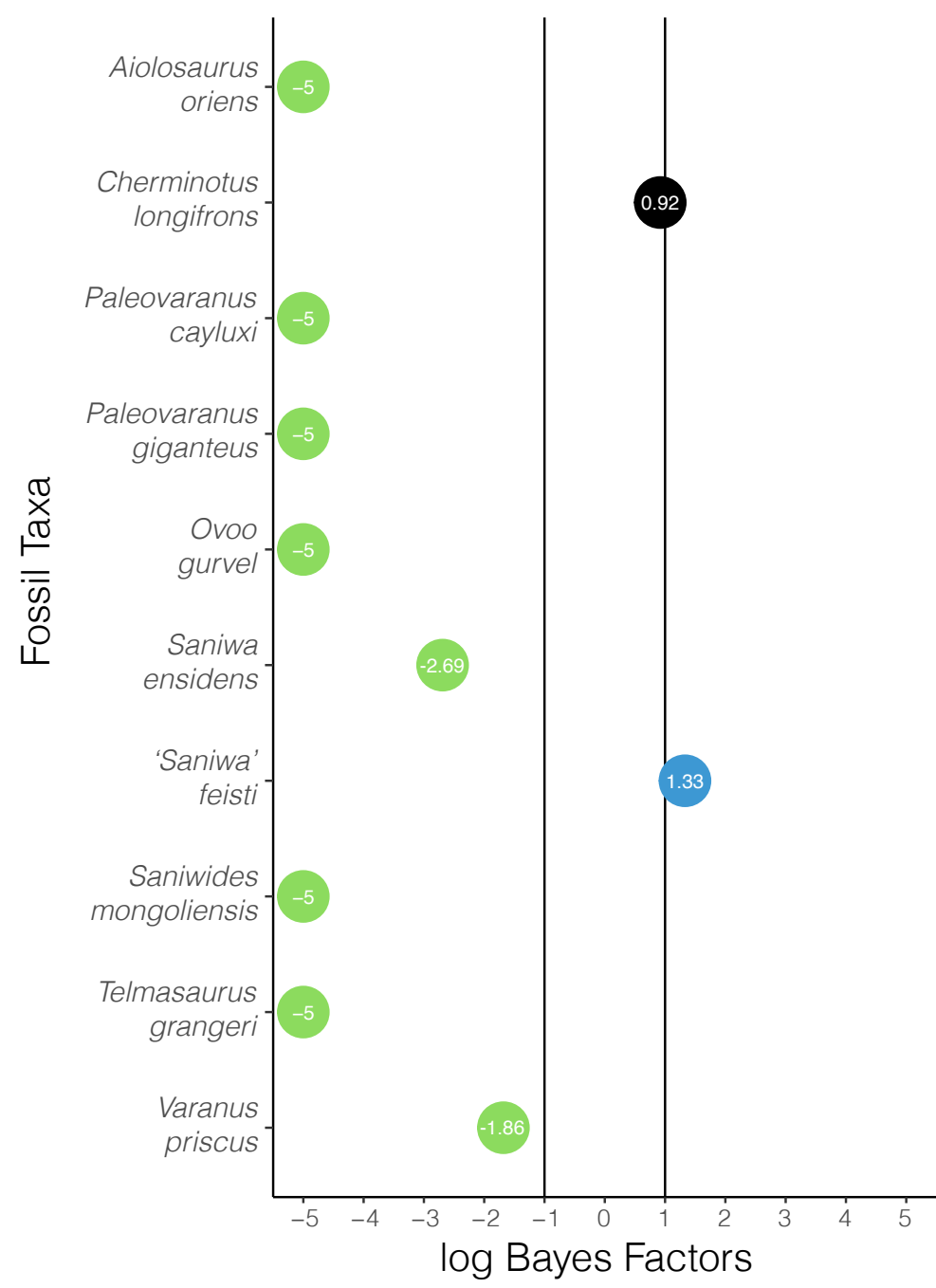

Figure S10: Bayes Factors support the position of nearly all fossil taxa as terminals. Green circles are strongly supported as terminal taxa, and black circles denote equivocal assignment. Very low log BF scores (taxa nearly always sampled as terminals) are reported arbitrarily as -5 to facilitate visualization. 
bioRxiv preprint doi: https://doi.org/10.1101/2020.02.02.931188; this version posted February 3, 2020. The copyright holder for this preprint (which was not certified by peer review) is the author/funder, who has granted bioRxiv a license to display the preprint in perpetuity. It is made available under aCC-BY-NC-ND 4.0 International license.

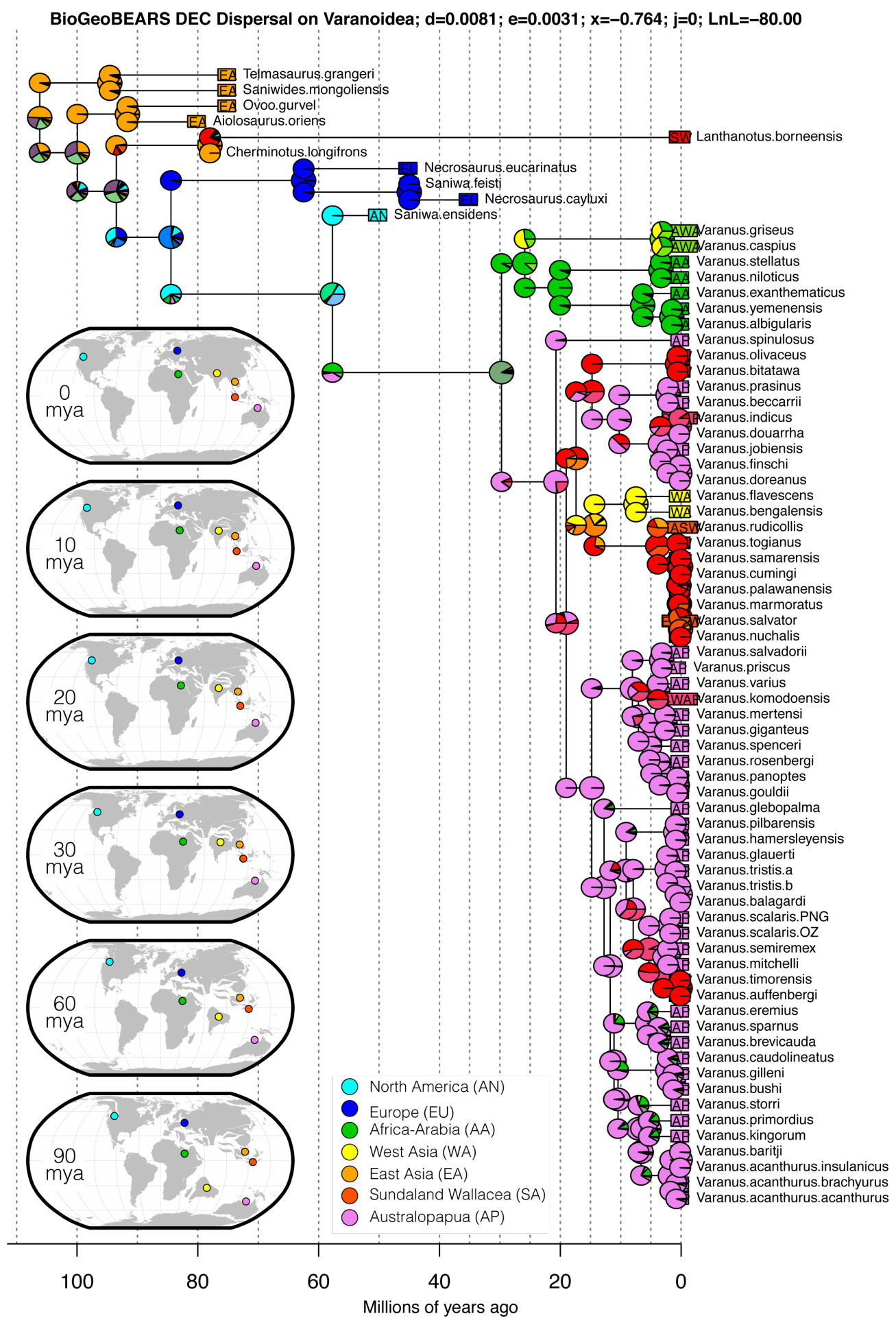

Figure S11: BioGeoBEARS ancestral state reconstruction under the DEC model with dispersal probability modelled as a function of distance among areas. Inset maps show the global position of major continents and land masses at relevant time slices $(0,10,20,30,60,90$ million years ago). The ancestral distribution of varanoids is suggested to be Laurasian (East Asia + Europe), though members of this group are spread across all continents and subregions with the exception of South America and Antarctica. The ancestral distrbution of Varanus is highly ambiguous, and generally returns an estimate composed of all the major regions in which monitor lizards currently live. This is compounded by the enigmatic distribution of Saniwa ensidens in North America. 


\section{Model Fitting Results}

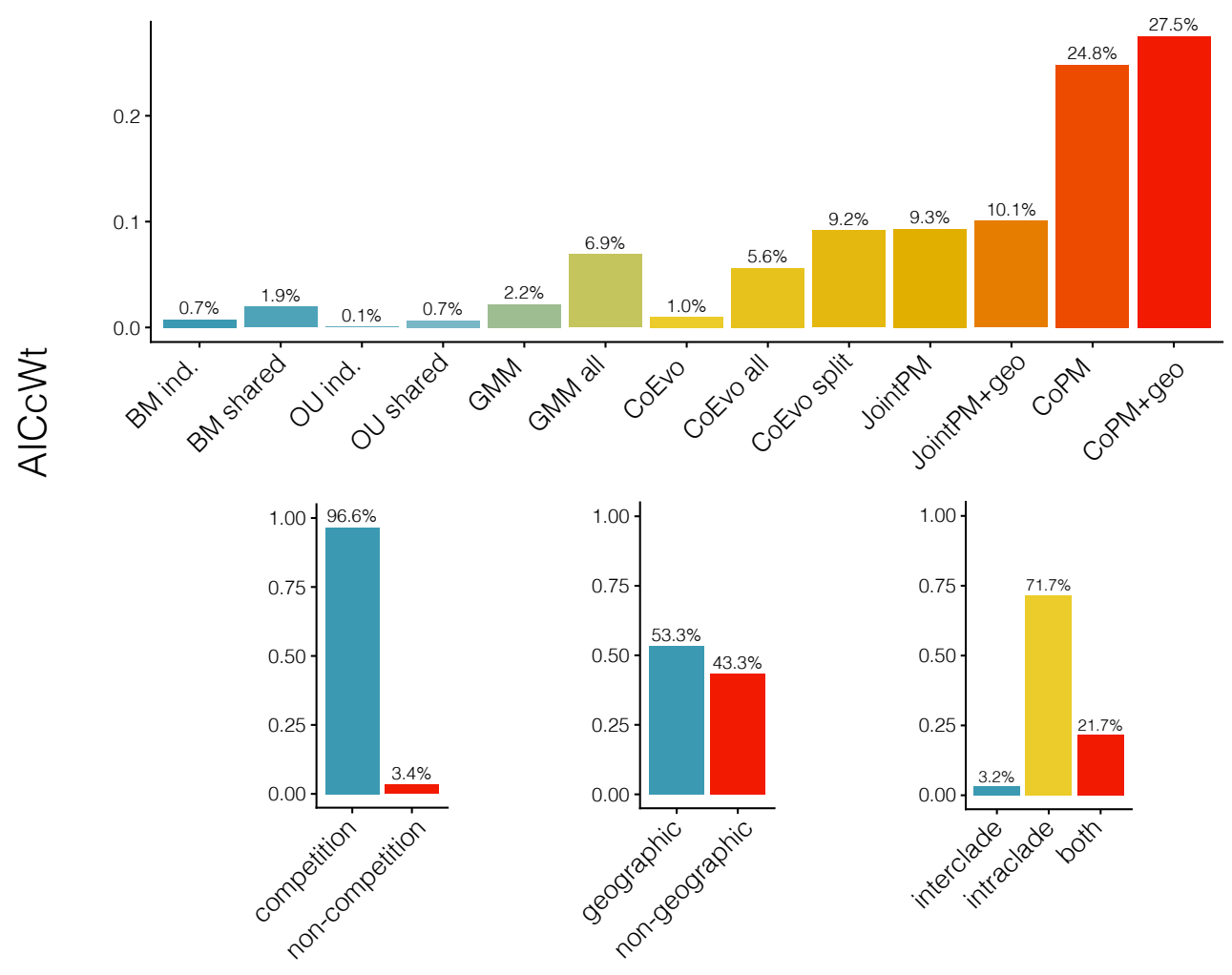

Figure S12: Comparative model fitting highlights the importance of incorporating interactions when modelling body size evolution of monitor lizards and dasyuromorphian marsupials. Modelling competition vastly improves model fit, but size evolution appears largely driven by intraclade evolution and not competition between monitors and mammals. Incorporating historical biogeography only narrowly improves model inference. 


\section{Model Identifiability}
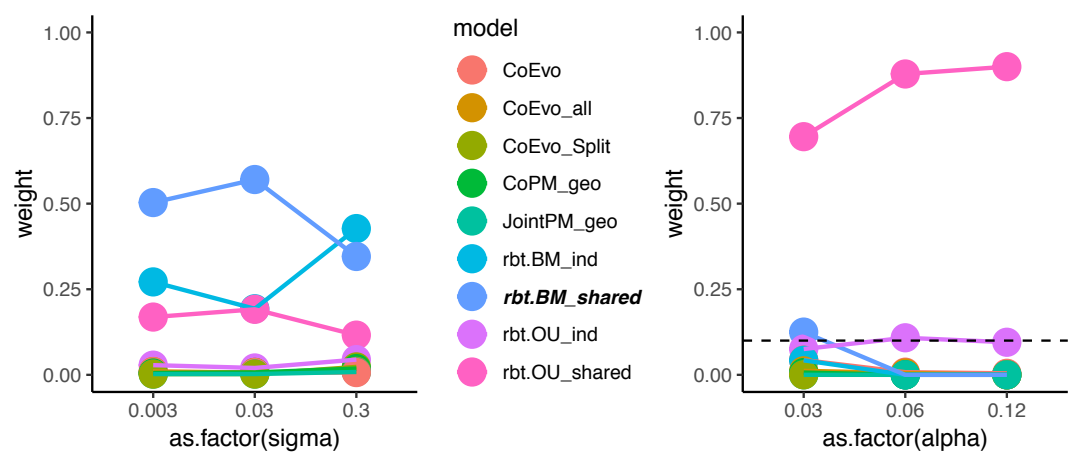

model
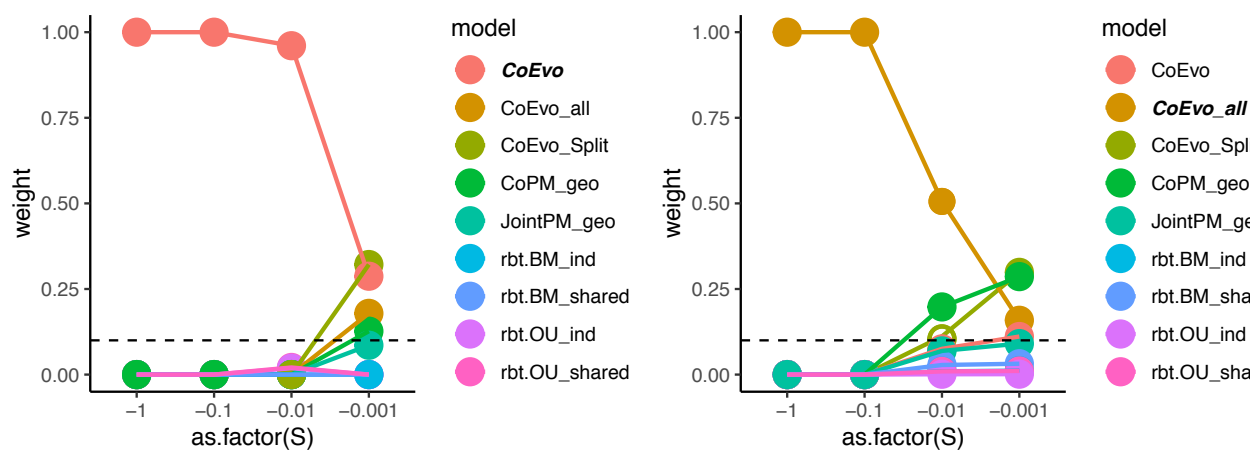

CoEvo_Split

CoPM_geo

- JointPM_geo

rbt.BM_ind

rbt.BM_shared

rbt.OU_ind

rbt.OU_shared
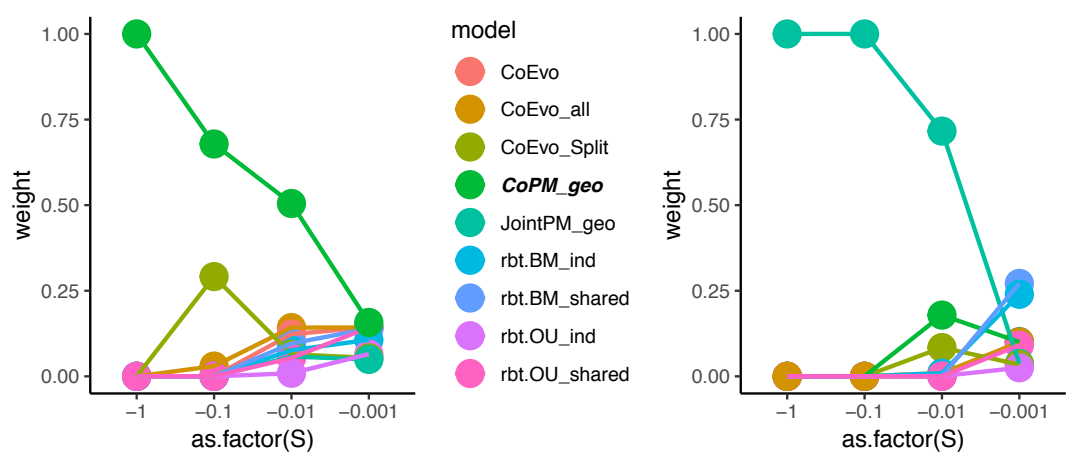

model

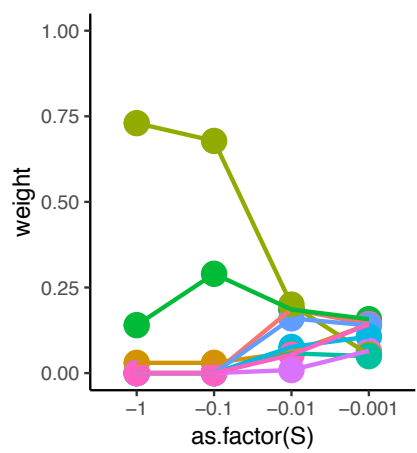

model
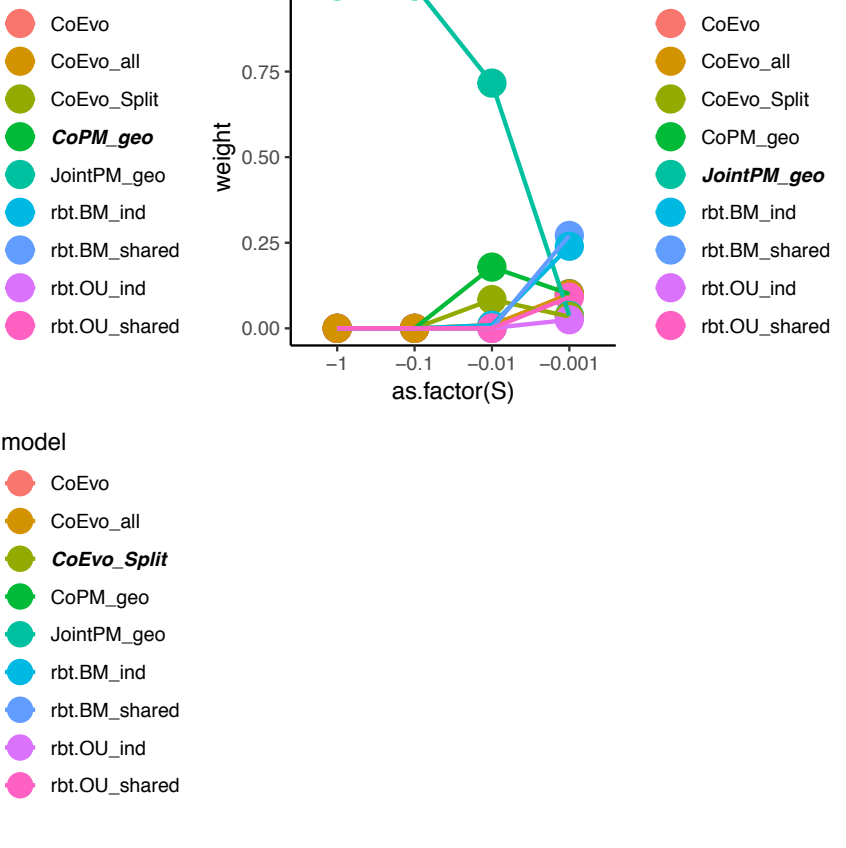

Figure S13: As the strength of competition $S$ increases, model selection becomes more reliable. Results of model identifiability simulations as a function of varying parameter values. Identifiability (presented as AICCweight) of interaction models is uniformly poor for extremely small absolute values of $S$, but increases considerably at values of -0.01 and beyond. Values for simulations are included in Table S4. 


\section{Parameter Estimation Under GMM-type Models}
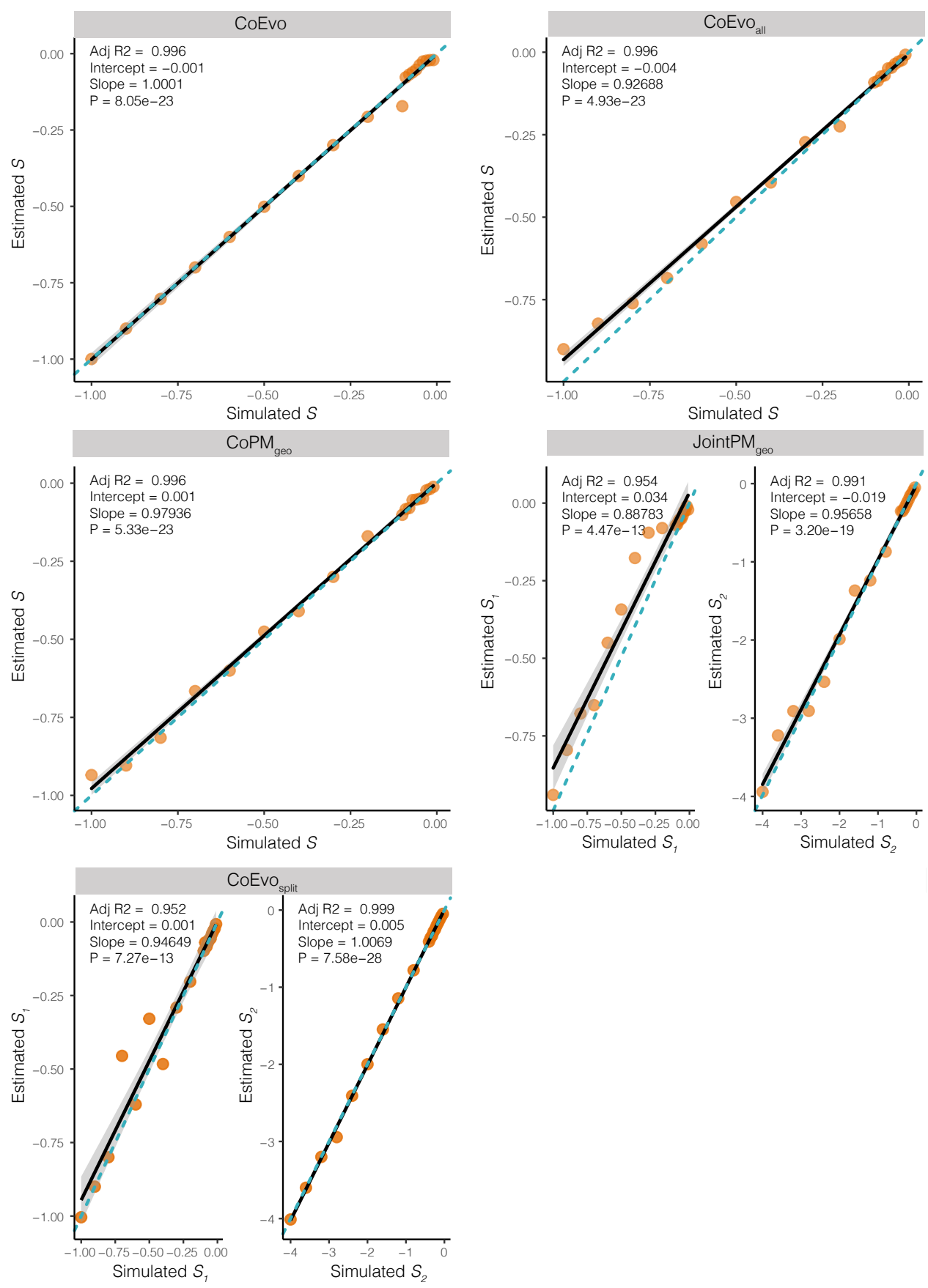

Figure S14: The competition parameter $S$ can be accurately estimated under competitive models. Simulated values were $-0.01,-0.02,-0.03,-0.04,-0.05,-0.06,-0.07,-0.08,-0.09,-0.1,-0.2,-0.3,-0.4,-0.5,-0.6,-0.7,-0.9$, -1 . Estimated values are consistently accurate between these limits. 


\section{Funding}

This work was supported by an International Postgraduate Research Scholarship at the Australian National University to IGB, and by an Australian Research Council grant to JSK and SCD.

\section{Acknowledgments}

We would like to thank the Keogh and Moritz lab groups at ANU for discussion and comments throughout the development of this project. Thanks to Alex Skeels for a crash-course in methods of spatial data and functional diversity, and as always Zoe K.M. Reynolds for troubleshooting scripts. We appreciate the opportunity provided by the Society for Systematic Biology to present this research in the Ernst Mayr symposium at the 2018 Evolution meeting in Montpellier, France. A considerable thank you to the curators and staff of the many Australian and international museums and databases (Atlas of Living Australia, Australian Museum, Museum and Art Gallery of the Northern Territory, South Australian Museum, Australian Biological Tissue Collection, Queensland Museum, Western Australian Museum, Australian National Wildlife Council, University of Michigan Museum of Zoology, Bernice P.Bishop Museum, California Academy of Sciences, Museum of Vertebrate Zoology at Berkeley, Port Elizabeth Museum, Royal Ontario Museum, and University of Kansas Natural History Museum) for access to tissues and locality data that made this work possible. 


\section{References}

Aberer A.J., Krompass D., Stamatakis A. 2012. Pruning rogue taxa improves phylogenetic accuracy: An efficient algorithm and webservice. Systematic Biology. 62:162-166.

Adams D.C., Nason J.D. 2018. A phylogenetic comparative method for evaluating trait coevolution across two phylogenies for sets of interacting species. Evolution. 72:234-243.

Amer S.A.M., Kumazawa Y. 2008. Timing of a mtDNA gene rearrangement and intercontinental dispersal of varanid lizards. Genes \& Genetic Systems. 83:275-280.

Ast J.C. 2001. Mitochondrial DNA evidence and evolution in Varanoidea (Squamata). Cladistics. $17: 211-226$

Barido-Sottani J., Aguirre-Fernandez G., Hopkins M.J., Stadler T., Warnock R. 2019. Ignoring stratigraphic age uncertainty leads to erroneous estimates of species divergence times under the fossilized birth-death process. Proc Biol Sci. 286:20190685.

Baum D.A., Donoghue M.J. 2002. Transference of Function, heterotopy and the evolution of plant development. Systematics Association Special Volume. 65:52-69.

Beaulieu J.M., Jhwueng D.-C., Boettiger C., O'Meara B.C. 2012. Modeling stabilizing selection: Expanding the Ornstein-Uhlenbeck model of adaptive evolution. Evolution. 66:2369-2383.

Beck R.M., Lee M.S. 2014. Ancient dates or accelerated rates? Morphological clocks and the antiquity of placental mammals. Proc Biol Sci. 281.

Benton M.J. 1987. Progress and competition in macroevolution. Biological Reviews. 62:305-338.

Billet G., Bardin J. 2018. Serial Homology and Correlated Characters in Morphological Phylogenetics: Modeling the Evolution of Dental Crests in Placentals. Systematic Biology. 68:267-280.

Borowiec M.L. 2016. AMAS: A fast tool for alignment manipulation and computing of summary statistics. PeerJ. 4:e1660.

Boyden J.A., Müller R.D., Gurnis M., Torsvik T.H., Clark J.A., Turner M., Ivey-Law H., Watson R.J., Cannon J.S. 2011. Next-generation plate-tectonic reconstructions using GPlates..

Brennan I.G., Keogh J.S. 2018. Miocene biome turnover drove conservative body size evolution across Australian vertebrates. Proceedings of the Royal Society B: Biological Sciences. 285.

Brown W.L., Wilson E.O. 1956. Character displacement. Systematic Zoology. 5:49-64.

Bucklitsch Y., Bohme W., Koch A. 2016. Scale morphology and micro-structure of monitor lizards (squamata: Varanidae: Varanus spp.) and their allies: Implications for systematics, ecology, and conservation. Zootaxa. 4153:1-192.

Collar D.C., Schulte Ii J.A., Losos J.B. 2011. Evolution of extreme body size disparity in monitor lizards (Varanus). Evolution. 65:2664-2680. SPIE.

Conrad J.L., Ast J.C., Montanari S., Norell M.A. 2011. A combined evidence phylogenetic analysis of Anguimorpha (Reptilia: Squamata). Cladistics. 27:230-277.

Conrad J.L., Balcarcel A.M., Mehling C.M. 2012. Earliest example of a giant monitor lizard (Varanus, Varanidae, Squamata). PLoS ONE. 7:e41767.

Darwin C. 1859. On the origin of species by means of natural selection, or preservation of favoured races in the struggle for life. London : John Murray, 1859.

Drury J.P., Clavel J., Manceau M., Morlon H. 2016. Estimating the effect of competition on trait evolution using maximum likelihood inference. Systematic Biology. 65:700-710.

Drury J.P., Grether G.F., Garland T. Jr., Morlon H. 2018a. An assessment of phylogenetic tools for analyzing the interplay between interspecific interactions and phenotypic evolution. Systematic Biology. 67:413-427. 
Drury J.P., Tobias J.A., Burns K.J., Mason N.A., Shultz A.J., Morlon H. 2018b. Contrasting impacts of competition on ecological and social trait evolution in songbirds. PLOS Biology. 16:1-23.

Duchene D.A., Bragg J.G., Duchene S., Neaves L.E., Potter S., Moritz C., Johnson R.N., Ho S.Y.W., Eldridge M.D.B. 2018. Analysis of phylogenomic tree space resolves relationships among marsupial families. Syst Biol. 67:400-412.

Esquerre D., Donnellan S., Brennan I.G., Lemmon A.R., Lemmon E.M., Zaher H., Grazziotin F., Keogh J.S. 2019. Phylogenomics, biogeography, and morphometrics reveal rapdi phenotypic evolution in pythons after crossing Wallace's line. in press.

Estes R. 1983. The fossil record and early distribution of lizards. Advances in herpetology and evolutionary biology. 365:398.

Estes R. 1984. Fish, amphibians and reptiles from the Etadunna Formation, Miocene of South Australia. Australian Zoologist. 21:335-343.

Fitch A.J., Goodman A. E., Donnellan S.C. 2006. A molecular phylogeny of the Australian monitor lizards (Squamata:Varanidae) inferrred from mitochondrial DNA sequences. Australian Journal of Zoology. 54:253-269.

Fuller S., Baverstock P., King D. 1998. Biogeographic origins of goannas (Varanidae): A molecular perspective. Molecular Phylogenetics and Evolution. 9:294-307.

Gauthier J.A., Kearney M., Maisano J.A., Rieppel O., Behlke A.D.B. 2012. Assembling the squamate tree of life: Perspectives from the phenotype and the fossil record. Bulletin of the Peabody Museum of Natural History. 53:3-308.

Gavryushkina A., Heath T.A., Ksepka D.T., Stadler T., Welch D., Drummond A.J. 2017. Bayesian Total-Evidence Dating Reveals the Recent Crown Radiation of Penguins. Syst Biol. 66:57-73.

Georgalis G.L. 2017. Necrosaurus or Palaeovaranus? Appropriate nomenclature and taxonomic content of an enigmatic fossil lizard clade (Squamata). Annales de Paléontologie. 103:293-303.

Goloboff P.A., Pittman M., Pol D., Xu X. 2018. Morphological Data Sets Fit a Common Mechanism Much More Poorly than DNA Sequences and Call Into Question the Mkv Model.

Systematic Biology. 68:494-504.

Grant P.R., Grant B.R. 2006. Evolution of character displacement in Darwin's finches. Science. 313:224-226.

Haeseler A. von, Minh B.Q., Nguyen M.A.T. 2013. Ultrafast approximation for phylogenetic bootstrap. Molecular Biology and Evolution. 30:1188-1195.

Hall R. 2002. Cenozoic geological and plate tectonic evolution of SE Asia and the SW Pacific: computer-based reconstructions, model and animations. Journal of Asian Earth Sciences. 20:353431.

Harmon L.J., Andreazzi C.S., Débarre F., Drury J., Goldberg E.E., Martins A.B., Melián C.J., Narwani A., Nuismer S.L., Pennell M.W., Rudman S.M., Seehausen O., Silvestro D., Weber M., Matthews B. 2019. Detecting the macroevolutionary signal of species interactions. Journal of Evolutionary Biology. 32:769-782.

Harvey M.B., Barker D.G. 1998. A New Species of Blue-Tailed Monitor Lizard (Genus Varanus) from Halmahera Island, Indonesia. Herpetologica. 54:34-44.

Heads M. 2010. Old Taxa on Young Islands: A Critique of the Use of Island Age to Date Island-Endemic Clades and Calibrate Phylogenies. Systematic Biology. 60:204-218.

Heath T.A., Huelsenbeck J.P., Stadler T. 2014. The fossilized birth-death process for coherent calibration of divergence-time estimates. Proceedings of the National Academy of Sciences. 111:E2957-E2966.

Hejnol A., Mongiardino Koch N., Gauthier J.A. 2018. Noise and biases in genomic data may underlie radically different hypotheses for the position of Iguania within Squamata. Plos One. 13. 
Hijmans R. 2016. geosphere: spherical trigonometryR package version 1.5-5 https://CRAN. R-project. org $/$ package $=$ geosphere.

Hillis D.M., Heath T.A., John K.S. 2005. Analysis and visualization of tree space. Systematic Biology. 54:471-482.

Ho S.Y.W., Phillips M.J. 2009. Accounting for Calibration Uncertainty in Phylogenetic Estimation of Evolutionary Divergence Times. Systematic Biology. 58:367-380.

Hocknull P.J.A. van den B. Scott A. AND Piper. 2009. Dragon's Paradise Lost: Palaeobiogeography, Evolution and Extinction of the Largest-Ever Terrestrial Lizards (Varanidae). PLOS ONE. $4: 1-15$.

Holmes R.B., Murray A.M., Attia Y.S., Simons E.L., Chatrath P. 2010. Oldest known Varanus (Squamata: Varanidae) from the Upper Eocene and Lower Oligocene of Egypt: Support for an African origin of the genus. Palaeontology. 53:1099-1110.

Ivanov M., Ruta M., Klembara J., Böhme M. 2017. A new species of Varanus (Anguimorpha: Varanidae) from the early Miocene of the Czech Republic, and its relationships and palaeoecology. Journal of Systematic Palaeontology. 16:767-797.

James C.D., Losos J.B., King D.R. 1992. Reproductive Biology and Diets of Goannas (Reptilia: Varanidae) from Australia. Journal of Herpetology. 26:128-136.

Jennings W., Pianka E. 2004. Tempo and timing of the Australian Varanus radiation. Varanoid Lizards of the World. Indiana University Press, Bloomington, Indiana.:77-87.

Jones K.E., Bielby J., Cardillo M., Fritz S.A., O’Dell J., Orme C.D.L., Safi K., Sechrest W., Boakes E.H., Carbone C., Connolly C., Cutts M.J., Foster J.K., Grenyer R., Habib M., Plaster C.A., Price S.A., Rigby E.A., Rist J., Teacher A., Bininda-Emonds O.R.P., Gittleman J.L., Mace G.M., Purvis A. 2009. PanTHERIA: A species-level database of life history, ecology, and geography of extant and recently extinct mammals. Ecology. 90:2648-2648.

Keast A. 1971. Continental drift and the evolution of the biota on southern continents. The Quarterly Review of Biology. 46:335-378.

Keogh J.S. 1998. Molecular phylogeny of elapid snakes and a consideration of their biogeographic history. Biological Journal of the Linnean Society. 63:177-203.

King M., King D. 1975. Chromosomal Evolution in the Lizard Genus Varanus (Reptilia). Australian Journal of Biological Sciences. 28:89-108.

Kubatko L.S., Degnan J.H. 2007. Inconsistency of Phylogenetic Estimates from Concatenated Data under Coalescence. Systematic Biology. 56:17-24.

Laliberté E., Legendre P., Shipley B., Laliberté M.E. 2014. Package "fd". Measuring functional diversity from multiple traits, and other tools for functional ecology.

Lee M.S.Y., Oliver P.M., Hutchinson M.N. 2009. Phylogenetic uncertainty and molecular clock calibrations: A case study of legless lizards (Pygopodidae, Gekkota). Molecular Phylogenetics and Evolution. 50:661-666.

Lemmon A.R., Emme S.A., Lemmon E.M. 2012. Anchored hybrid enrichment for massively high-throughput phylogenomics. Syst Biol. 61:727-44.

Lewis P.O. 2001. A Likelihood Approach to Estimating Phylogeny from Discrete Morphological Character Data. Systematic Biology. 50:913-925.

Lin L.-H., Wiens J.J. 2017. Comparing macroecological patterns across continents: Evolution of climatic niche breadth in varanid lizards. Ecography. 40:960-970.

Losos J.B. 1990. A phylogenetic analysis of character displacement in Caribbean Anolis lizards. Evolution. 44:558-569.

Luo A., Duchêne D.A., Zhang C., Zhu C.-D., Ho S.Y. 2018. A Simulation-Based Evaluation of Total-Evidence Dating Under the Fossilized Birth-Death Process. bioRxiv. 
Maechler M., Rousseeuw P., Struyf A., Hubert M., Hornik K. 2018. Cluster: Cluster analysis basics and extensions..

Manceau M., Lambert A., Morlon H. 2017. A unifying comparative phylogenetic framework including traits coevolving across interacting lineages. Systematic Biology. 66:551-568.

Matzke N.J. 2014. Model selection in historical biogeography reveals that founder-event speciation is a crucial process in island clades. Systematic Biology. 63:951-970.

Molnar R. 2004. The long and honorable history of monitors and their kin. Varanoid lizards of the world.:10-67.

Morlon H., Lewitus E., Condamine F.L., Manceau M., Clavel J., Drury J. 2016. RPANDA: An r package for macroevolutionary analyses on phylogenetic trees. Methods in Ecology and Evolution. 7:589-597.

Nuismer S.L., Harmon L.J. 2015. Predicting rates of interspecific interaction from phylogenetic trees. Ecology Letters. 18:17-27.

Ogilvie H.A., Heled J., Xie D., Drummond A.J. 2016. Computational performance and statistical accuracy of *BEAST and comparisons with other methods. Systematic Biology.

Ogilvie H.A., Vaughan T.G., Matzke N.J., Slater G.J., Stadler T., Welch D., Drummond A.J. 2018. Inferring species trees using integrative models of species evolution. bioRxiv.

Oliver P.M., Brown R.M., Kraus F., Rittmeyer E., Travers S.L., Siler C.D. 2018. Lizards of the lost arcs: mid-Cenozoic diversification, persistence and ecological marginalization in the West Pacific. Proceedings of the Royal Society B: Biological Sciences. 285.

Oliver P.M., Travers S.L., Richmond J.Q., Pikacha P., Fisher R.N. 2017. At the end of the line: independent overwater colonizations of the Solomon Islands by a hyperdiverse trans-Wallacean lizard lineage (Cyrtodactylus: Gekkota: Squamata). Zoological Journal of the Linnean Society. 182:681-694.

O'Reilly J.E., Donoghue P.C. 2016. Tips and nodes are complementary not competing approaches to the calibration of molecular clocks. Biol Lett. 12.

Paradis E., Claude J., Strimmer K. 2004. APE: Analyses of phylogenetics and evolution in R language. Bioinformatics. 20:289-290.

Pennell M.W., Slater G.J., Eastman J.M., Uyeda J.C., Brown J.W., Harmon L.J., Alfaro M.E., FitzJohn R.G. 2014. geiger v2.0: an expanded suite of methods for fitting macroevolutionary models to phylogenetic trees. Bioinformatics. 30:2216-2218.

Peters R.H., Peters R.H. 1986. The ecological implications of body size. Cambridge University Press.

Pianka E.R. 1995. Evolution of body size: Varanid lizards as a model system. The American Naturalist. 146:398-414.

Plummer M., Best N., Cowles K., Vines K. 2006. CODA: Convergence diagnosis and output analysis for MCMC. R news. 6:7-11.

Portik D.M., Papenfuss T.J. 2012. Monitors cross the Red Sea: the biogeographic history of Varanus yemenensis. Mol Phylogenet Evol. 62:561-5.

Pulvers J.N., Colgan D.J. 2007. Molecular phylogeography of the fruit bat genus melonycteris in northern melanesia. Journal of Biogeography. 34:713-723.

Puttick M.N., O’Reilly J.E., Tanner A.R., Fleming J.F., Clark J., Holloway L., Lozano-Fernandez J., Parry L.A., Tarver J.E., Pisani D., Donoghue P.C. 2017. Uncertain-tree: discriminating among competing approaches to the phylogenetic analysis of phenotype data. Proc Biol Sci. 284.

Pyron R.A. 2011. Divergence Time Estimation Using Fossils as Terminal Taxa and the Origins of Lissamphibia. Systematic Biology. 60:466-481.

Pyron R.A. 2017. Novel approaches for phylogenetic inference from morphological data and total-evidence dating in squamate reptiles (lizards, snakes, and amphisbaenians). Systematic Biology. 
66:38-56.

Quintero I., Keil P., Jetz W., Crawford F.W. 2015. Historical biogeography using species geographical ranges. Syst Biol. 64:1059-73.

Quintero I., Landis M.J. 2019. Interdependent Phenotypic and Biogeographic Evolution Driven by Biotic Interactions. bioRxiv.

Rambaut A., Drummond A.J., Xie D., Baele G., Suchard M.A. 2018. Posterior Summarization in Bayesian Phylogenetics Using Tracer 1.7. Systematic Biology. 67:901-904.

Ree R.H., Sanmartín I. 2018. Conceptual and statistical problems with the DEC+J model of founder-event speciation and its comparison with DEC via model selection. Journal of Biogeography. 45:741-749.

Reynolds G.R., Niemiller M.L., Revell L.J. 2014. Toward a Tree-of-Life for the boas and pythons: multilocus species-level phylogeny with unprecedented taxon sampling. Mol Phylogenet Evol. 71:201-13.

Ronquist F., Klopfstein S., Vilhelmsen L., Schulmeister S., Murray D.L., Rasnitsyn A.P. 2012. A Total-Evidence Approach to Dating with Fossils, Applied to the Early Radiation of the Hymenoptera. Systematic Biology. 61:973-999.

Scanlon J.D. 2014. Giant terrestrial reptilian carnivores of Cenozoic Australia. Carnivores of Australia: Past, Present and Future.:27.

Schluter D., Price T.D., Grant P.R. 1985. Ecological character displacement in Darwin's finches. Science. 227:1056-1059.

Schmidt H.A., Minh B.Q., Haeseler A. von, Nguyen L.-T. 2014. IQ-tree: A fast and effective stochastic algorithm for estimating maximum-likelihood phylogenies. Molecular Biology and Evolution. 32:268-274.

Schulte 2. J. A., Melville J., Larson A. 2003. Molecular phylogenetic evidence for ancient divergence of lizard taxa on either side of Wallace's Line. Proc Biol Sci. 270:597-603.

Sepkoski Jr J.J. 1996. Competition in macroevolution: The double wedge revisited. Evolutionary paleobiology::211-255.

Smith K.T., Bhullar B.-A.S., Holroyd P.A. 2008. Earliest African record of the Varanus stemclade (Squamata: Varanidae) from the Early Oligocene of Egypt. Journal of Vertebrate Paleontology. 28:909-913.

Sweet S.S., Pianka E.R. 2007. Monitors, mammals and Wallace's Line. Mertensiella. 16:79-99. Uetz P., Hošek J. 2019. The Reptile Database. 2019.

Vaurie C. 1951. Adaptive differences between two sympatric species of nuthatches (Sitta). Proc. Xth int. Ornith. Congress, uppsala.:163-166.

Vidal N., Marin J., Sassi J., Battistuzzi F.U., Donnellan S., Fitch A.J., Fry B.G., Vonk F.J., Rodriguez de la Vega R.C., Couloux A., Hedges S.B. 2012. Molecular evidence for an Asian origin of monitor lizards followed by tertiary dispersals to Africa and Australasia. Biology Letters. 8:853-855.

Wilson D.S. 1975. The adequacy of body size as a niche difference. The American Naturalist. 109:769-784.

Wilson S., Swan G. 2013. A complete guide to reptiles of Australia. Chatswood, New South Wales: New Holland Publishers.

Woodhead J., Hand S.J., Archer M., Graham I., Sniderman K., Arena D.A., Black K.H., Godthelp H., Creaser P., Price E. 2016. Developing a radiometrically-dated chronologic sequence for Neogene biotic change in Australia, from the Riversleigh World Heritage Area of Queensland. Gondwana Research. 29:153-167.

Wroe S. 2002. A review of terrestrial mammalian and reptilian carnivore ecology in Australian fossil faunas, and factors influencing their diversity: The myth of reptilian domination and its broader ramifications. Australian Journal of Zoology. 50:1-24. 
1170 contracting low support branches.:53-75.

Ziegler T., Böhme W., Schmitz A. 2007a. A new species of theVaranus indicus group (squamata, varanidae) from halmahera island, moluccas: Morphological and molecular evidence. Mitteilungen aus dem Museum für Naturkunde in Berlin - Zoologische Reihe. 83:109-119.

Ziegler T., Schmitz A., Koch A., Böhme W. 2007b. A review of the subgenus Euprepiosaurus 1175 of Varanus (Squamata: Varanidae): morphological and molecular phylogeny, distribution and zoogeography, with an identification key for the members of the $\mathrm{V}$. indicus and $\mathrm{V}$. prasinus groups. Zootaxa. 1472:1-28. 